Supporting Information

Thermodynamics and Electronic Properties of Heterometallic Multinuclear An-MOFs with "Structural Memory"

Otega A. Ejegbavwo, ${ }^{\dagger}$ Corey R. Martin,${ }^{\dagger}$ Oyindamola A. Olorunfemi, ${ }^{\dagger}$ Gabrielle A. Leith, ${ }^{\dagger}$ Richard T. Ly, ${ }^{\dagger}$ Allison M. Rice,$^{\dagger}$ Ekaterina A. Dolgopolova, ${ }^{\dagger}$ Mark D. Smith, ${ }^{\dagger}$ Stavros G. Karakalos, ${ }^{\ddagger}$ Nancy Birkner, $₫ \|$ Brian A. Powell, $\|$ Shubham Pandey, ${ }^{\Uparrow}$ Robert J. Koch, ${ }^{\#}$ Scott T. Misture, ${ }^{+}$Hans-Conrad zur Loye, ${ }^{\dagger}$ Simon R. Phillpot, ${ }^{\circledR}$ Kyle S. Brinkman, $§ \|$ and Natalia B. Shustova ${ }^{\dagger *}$

'Department of Chemistry and Biochemistry, University of South Carolina, Columbia, South Carolina 29208, United States

College of Engineering and Computing, University of South Carolina, Columbia, South Carolina 29208, United States

$\S$ Department of Materials Science and Engineering, Clemson University, Clemson, South Carolina 29634, United States

-Department of Environmental Engineering and Earth Science, Clemson University, Clemson, South Carolina 29634, United States

$\|_{\text {Center for Nuclear Environmental Engineering Sciences and Radioactive Waste Management }}$ (NEESRWM), Clemson University, Clemson, South Carolina 29634, United States

"Department of Materials Science and Engineering, University of Florida, Gainesville, Florida 32611, United States

${ }^{+}$Kazuo Inamori School of Ceramic Engineering, Alfred University, Alfred, New York 14802, United States

\#Brookhaven National Laboratory, Upton, New York 11973, United States 
1. Synthesis and characterization of $\mathrm{U}_{6}-\mathrm{Me}_{2} \mathrm{BPDC}-\mathrm{TFA}-10 \quad \mathbf{S 5}$

2. Thermodynamic studies $\quad$ S5

3. Table S1. Thermochemical cycle used to compute the enthalpies of formation of Th-MOF

4. Table S2. Experimental thermodynamics data applied to the thermodynamic cycle to compute enthalpies of formation of Th-MOF S6

5. Theoretical studies

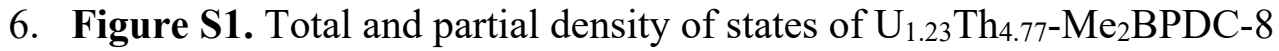
with U@position 1 and 3

7. Figure S2. Truncated cluster models of M-8, M-10, and M-12 MOFs

8. X-ray crystal structure determination of $\mathrm{Th}_{6}-\mathrm{Me}_{2} \mathrm{BPDC}-\mathrm{NO}_{3}-10$

9. X-ray crystal structure determination of $\mathrm{Th}_{6}-\mathrm{Me}_{2} \mathrm{BPDC}-8 \mathrm{~b}$

10. X-ray crystal structure determination of $\mathrm{U}_{6}-\mathrm{Me}_{2} \mathrm{BPDC}-\mathrm{TFA}-10$

11. X-ray crystal structure determination of $\mathrm{U}_{6}-\mathrm{Me}_{2} \mathrm{BPDC}-8-\mathrm{H}_{2} \mathrm{O}-1 \mathrm{~d}$

12. X-ray crystal structure determination of $\mathrm{U}_{6}-\mathrm{Me}_{2} \mathrm{BPDC}-8-\mathrm{H}_{2} \mathrm{O}-4 \mathrm{~d}$

13. X-ray crystal structure determination of $\mathrm{Th}_{6}-\mathrm{Me}_{2} \mathrm{BPDC}-10-\mathrm{MeOH}$

14. X-ray crystal structure determination of $\mathrm{Th}_{6}-\mathrm{Me}_{2} \mathrm{BPDC}\left(\mathrm{Me}_{2} \mathrm{TPDC}\right)-12$

15. X-ray crystal structure determination of $\mathrm{Th}_{6}-\mathrm{Me}_{2} \mathrm{BPDC}-8$-intermediate

S12

16. X-ray crystal structure determination of Th6-Me $\mathrm{T}_{2} \mathrm{BPDC}$ (“QPDC")-10

S13

17. X-ray crystal structure determination of $\mathrm{Th}_{6}-\mathrm{Me}_{2} \mathrm{BPDC}$ (" $\mathrm{Me}_{2} \mathrm{BPDC}$ ")- 10

S14

18. X-ray crystal structure determination of $\mathrm{Th}_{6}$-BPDC-10

S15

19. X-ray crystal structure determination of $\mathrm{Th}_{6}$-BPDC-12

S16

20. Table S3. X-ray structure refinement data for $\mathrm{Th}_{6}-\mathrm{Me}_{2} \mathrm{BPDC}-\mathrm{NO}_{3}-10$, $\mathrm{Th}_{6}-\mathrm{Me}_{2} \mathrm{BPDC}-8 \mathrm{~b}$, and $\mathrm{U}_{6}-\mathrm{Me}_{2} \mathrm{BPDC}-\mathrm{TFA}-10$

21. Table S4. X-ray structure refinement data for $\mathrm{U}_{6}-\mathrm{Me}_{2} \mathrm{BPDC}-8-\mathrm{H}_{2} \mathrm{O}-1 \mathrm{~d}$ and $\mathrm{U}_{6}-\mathrm{Me}_{2} \mathrm{BPDC}-8-\mathrm{H}_{2} \mathrm{O}-4 \mathrm{~d}$

22. Table S5. X-ray structure refinement data for $\mathrm{Th}_{6}-\mathrm{Me}_{2} \mathrm{BPDC}-10-\mathrm{MeOH}$

23. Table S6. X-ray structure refinement data for $\mathrm{Th}_{6}-\mathrm{Me}_{2} \mathrm{BPDC}\left(\mathrm{Me}_{2} \mathrm{TPDC}\right)-12$ and $\mathrm{Th}_{6}-\mathrm{Me}_{2} \mathrm{BPDC}-8$-intermediate

24. Table S7. X-ray structure refinement data for $\mathrm{Th}_{6}-\mathrm{Me}_{2} \mathrm{BPDC}$ ("Me $2 \mathrm{BPDC}$ ")-10 and $\mathrm{Th}_{6}-\mathrm{Me}_{2} \mathrm{BPDC}$ ("QPDC")-10

25. Table S8. X-ray structure refinement data for $\mathrm{Th}_{6}$-BPDC-10 and $\mathrm{Th}_{6}$-BPDC-12

26. Figure S3. Single crystal photograph of $\mathrm{U}_{6}-\mathrm{Me}_{2} \mathrm{BPDC}-8$

27. Figure S4. Single crystal structures and secondary building units of $\mathrm{U}_{6}-\mathrm{Me}_{2} \mathrm{BPDC}-\mathrm{TFA}-10$ and $\mathrm{Th}_{6}-\mathrm{Me}_{2} \mathrm{BPDC}-\mathrm{NO}_{3}-10$

28. Figure S5. Reversible phase transition from $\mathrm{Th}_{6}-\mathrm{Me}_{2} \mathrm{BPDC}-8 \mathrm{a}$ to $\mathrm{Th}_{6}-\mathrm{Me}_{2} \mathrm{BPDC}-8 \mathrm{~b}$

29. Figure S6. PXRD patterns and FTIR spectrum of $\mathrm{Th}_{6}-\mathrm{Me}_{2} \mathrm{BPDC}-\mathrm{NO}_{3}-10$

30. Figure S7. PXRD patterns and FTIR spectrum of $\mathrm{Th}_{6}-\mathrm{Me}_{2} \mathrm{BPDC}-8$

31. Figure S8. PXRD patterns and FTIR spectrum of $\mathrm{U}_{6}-\mathrm{Me}_{2} \mathrm{BPDC}-\mathrm{TFA}-10$

32. Figure S9. FTIR spectra of $\mathrm{U}_{6}-\mathrm{Me}_{2} \mathrm{BPDC}-8$ in water

33. Figure S10. FTIR spectra of $\mathrm{Th}_{6}-\mathrm{Me}_{2} \mathrm{BPDC}-8$ and $\mathrm{Th}_{6}-\mathrm{Me}_{2} \mathrm{BPDC}-\mathrm{NO}_{3}-10$ in $\mathrm{H}_{2} \mathrm{O}$

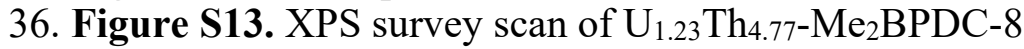


and $\mathrm{U}_{1.23} \mathrm{Th}_{4.77} \mathrm{Co}_{3}-\mathrm{Me}_{2} \mathrm{BPDC}-8$.

37. Figure S14. Single crystal photographs, PXRD patterns, and Tauc plots of $\mathrm{U}_{6}-\mathrm{Me}_{2} \mathrm{BPDC}-8, \mathrm{U}_{1.23} \mathrm{Th}_{4.77}-\mathrm{Me}_{2} \mathrm{BPDC}-8$, and $\mathrm{U}_{1.23} \mathrm{Th}_{4.77} \mathrm{Co}_{3}-\mathrm{Me}_{2} \mathrm{BPDC}-8$.

38. Figure S15. XPS analysis of $\mathrm{U}_{1.23} \mathrm{Th}_{4.77} \mathrm{Co}_{3}-\mathrm{Me}_{2} \mathrm{BPDC}-8$ and cobalt oxides in the $\mathrm{Co}(2 \mathrm{p})$ region

39. Figure S16. XPS analysis of $\mathrm{U}_{1.23} \mathrm{Th}_{4.77} \mathrm{Co}_{3}-\mathrm{Me}_{2} \mathrm{BPDC}-8$ and cobalt oxides in the $\mathrm{O}(1 \mathrm{~s})$ region

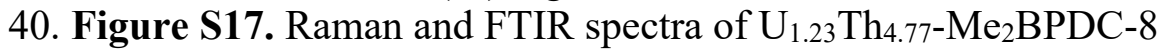
and $\mathrm{U}_{1.23} \mathrm{Th}_{4.77} \mathrm{Co}_{3}-\mathrm{Me}_{2} \mathrm{BPDC}-8$

41. Figure S18. PXRD patterns of $\mathrm{Th}_{6}-\mathrm{Me}_{2} \mathrm{BPDC}-8$ and $\mathrm{Th}_{6}-\mathrm{Me}_{2} \mathrm{BPDC}-\mathrm{NO}_{3}-10$ in water

42. Figure S19. Photograph of the crystal and the X-ray crystal structure of $\mathrm{Th}_{6}-\mathrm{Me}_{2} \mathrm{BPDC}-10-\mathrm{MeOH}$

S33

43. Figure S20. PXRD patterns of $\mathrm{Th}_{6}-\mathrm{Me}_{2} \mathrm{BPDC}-8$ after exposure to methanol and re-immersion in DMF during five structural cycles

44. Figure S21. PXRD patterns of $\mathrm{Th}_{6}-\mathrm{Me}_{2} \mathrm{BPDC}-8$ after one week in dimethylacetamide and diethylformamide

45. Figure S22. PXRD patterns of $\mathrm{Th}_{6}-\mathrm{Me}_{2} \mathrm{BPDC}-8$ and $\mathrm{Th}_{6}-\mathrm{Me}_{2} \mathrm{BPDC}-\mathrm{NO}_{3}-10$ after exposure to dichloromethane, chloroform, and hexanes and re-immersion in DMF

S35

46. Figure S23. PXRD patterns of $\mathrm{Th}_{6}-\mathrm{Me}_{2} \mathrm{BPDC}-8$ and $\mathrm{Th}_{6}-\mathrm{Me}_{2} \mathrm{BPDC}-\mathrm{NO}_{3}-10$ after exposure to acetonitrile, tetrahydrofuran, ethanol, methanol and re-immersion in DMF

47. Figure S24. PXRD patterns of $\mathrm{Th}_{6}-\mathrm{Me}_{2} \mathrm{BPDC}-8$ and $\mathrm{Th}_{6}-\mathrm{Me}_{2} \mathrm{BPDC}-\mathrm{NO}_{3}-10$ after exposure to acetone and re-immersion in $\mathrm{DMF}$

48. Figure S25. PXRD patterns of $\mathrm{Th}_{6}-\mathrm{Me}_{2} \mathrm{BPDC}-8$ and $\mathrm{Th}_{6}-\mathrm{Me}_{2} \mathrm{BPDC}-\mathrm{NO}_{3}-10$ after exposure to ethyl acetate and re-immersion in $\mathrm{DMF}$

49. Figure S26. PXRD patterns of $\mathrm{Zr}_{6}-\mathrm{Me}_{2} \mathrm{BPDC}-8$ and $\mathrm{Th}_{6}-\mathrm{Me}_{2} \mathrm{BPDC}-8$ after exposure to different solvents

50. Figure S27. Single-crystal structures and secondary building units of $\mathrm{Th}_{6}$-BPDC-12

51. Figure S28. PXRD patterns and FTIR spectrum of Th6-BPDC-12

S39

S39

52. Figure S29. PXRD patterns of $\mathrm{Zr}_{6}$-BPDC-12 and $\mathrm{Th}_{6}-\mathrm{BPDC}-12$ after exposure different solvents

53. Figure S30. PXRD patterns of $\mathrm{Th}_{6}-\mathrm{Me}_{2} \mathrm{BPDC}\left(\mathrm{Me}_{2} \mathrm{BPDC}\right)-10$, $\mathrm{Th}_{6}-\mathrm{Me}_{2} \mathrm{BPDC}\left(\mathrm{Me}_{2} \mathrm{TPDC}\right)-10, \mathrm{Th}_{6}-\mathrm{Me}_{2} \mathrm{BPDC}$ ("QPDC")-8, and $\mathrm{Th}_{6}-\mathrm{Me}_{2} \mathrm{BPDC}$ (“Me $2 \mathrm{BPDC}$ ')-10, $\mathrm{Th}_{6}-\mathrm{Me}_{2} \mathrm{BPDC}\left(\mathrm{Me}_{2} \mathrm{TPDC}\right)-12$, and $\mathrm{Th}_{6}-\mathrm{Me}_{2} \mathrm{BPDC}$ ("QPDC")-10

54. Figure S31. PXRD patterns of $\mathrm{Th}_{6}-\mathrm{Me}_{2} \mathrm{BPDC}(\mathrm{BDC})-10$ and $\mathrm{Th}_{6}-\mathrm{Me}_{2} \mathrm{BPDC}\left(\mathrm{Me}_{2} \mathrm{TPDC}\right)-12$

55. Figure S32. PXRD patterns of $\mathrm{Th}_{6}-\mathrm{BPDC}-10$

56. Figure S33. Schematic representation of the linker installation

$\mathrm{S42}$

57. Figure S34. ${ }^{1} \mathrm{H}$ NMR spectrum of digested $\mathrm{Th}_{6}-\mathrm{Me}_{2} \mathrm{BPDC}\left(\mathrm{Me}_{2} \mathrm{TPDC}\right)-12 \quad \mathbf{S 4 3}$

58. Figure S35. ${ }^{1} \mathrm{H}$ NMR spectrum of digested $\mathrm{Th}_{6}-\mathrm{Me}_{2} \mathrm{BPDC}(\mathrm{BDC})-10 \quad \mathbf{S 4 3}$

59. Figure S36. ${ }^{1} \mathrm{H}$ NMR spectrum of digested $\mathrm{Th}_{6}$-BPDC-10 $\quad$ S44

60. Figure S37. ${ }^{1} \mathrm{H}$ NMR spectrum of digested $\mathrm{Th}_{6}-\mathrm{Me}_{2} \mathrm{BPDC}\left(\mathrm{Me}_{2} \mathrm{TPDC}\right)-10 \quad \mathbf{S 4 4}$

61. Figure S38. ${ }^{1} \mathrm{H}$ NMR spectrum of digested $\mathrm{Th}_{6}-\mathrm{Me}_{2} \mathrm{BPDC}(\mathrm{BDC})-10 \quad \mathbf{S 4 5}$

62. Table S9. Percentage of linker installations calculated from ${ }^{1} \mathrm{H}$ NMR studies $\quad \mathbf{S 4 5}$ 
63. References

S46 
Synthesis and Characterization of $\mathbf{U}_{6}-\mathbf{M e}_{2}$ BPDC-TFA-10. A mixture of $\mathrm{UCl}_{4}(12 \mathrm{mg}, 32 \mu \mathrm{mol})$, $\mathrm{H}_{2} \mathrm{Me}_{2} \mathrm{BPDC}(4.3 \mathrm{mg}, 16 \mu \mathrm{mol})$, trifluoroacetic acid $(25 \mu \mathrm{L})$, and DMF $(0.56 \mathrm{~mL})$ was put in a $1 / 2$-dram vial and heated in an isothermal oven at $120{ }^{\circ} \mathrm{C}$ for $72 \mathrm{~h}$. After cooling to room temperature, the green crystals of $\mathrm{U}_{6}-\mathrm{Me}_{2} \mathrm{BPDC}-\mathrm{TFA}-10$ ( $7.2 \mathrm{mg}, 2.3 \mu \mathrm{mol}$, yield $72 \%$ ) were retained in the mother liquor and stored under inert environment to prevent the oxidation of uranium to the +6 state. IR (neat, $\mathrm{cm}^{-1}$ ): 2932, 1639, 1583, 1532, 1410, 1374, 1251, 1194, 1140, 1116, 1062, 1007, 923, 842, 805, 777, 721, and 670 (Figure S8). The obtained crystals were suitable for single-crystal XRD studies; detailed description of the data collection and refinement details are given below. Table S3 contains the crystallographic refinement data. As shown in Figure $\mathrm{S} 8$, the PXRD pattern of the as-synthesized $\mathrm{U}_{6}-\mathrm{Me}_{2} \mathrm{BPDC}-\mathrm{TFA}-10$ matches the simulated pattern from the single-crystal X-ray data. PXRD studies were also used to confirm the crystallinity of bulk material (Figure S8).

\section{Thermodynamic Studies.}

In the experimental data presented in Table $\mathrm{S} 1$ below, the standard reaction enthalpy for the dissolution of one mole of $\mathrm{ThO}_{2(\mathrm{~s})}$ for $\Delta H_{2}$ was computed based on already reported data ${ }^{1}$ and using the standard formation enthalpy values of the dense components in their standard state for the general relationship:

$\Delta H_{\text {soln }}(\mathrm{rxn})=\sum \mathrm{a} \Delta H_{f}^{\circ}$ (products) $-\sum \mathrm{b} \Delta H_{f}^{\circ}$ (reactants) [where $a$ and $b$ are the stoichiometric reaction coefficients]. ${ }^{2}$ More specifically, this reaction is given as:

$\Delta H_{\text {soln }}\left(\mathrm{ThO}_{2}\right)=\Delta H_{f}^{\circ}\left(\mathrm{Th}^{4+}{ }_{(\mathrm{aq})}\right)+\left[2 \times \Delta H_{f}^{\circ}\left(\mathrm{H}_{2} \mathrm{O}_{(\mathrm{l})}\right)\right]-\Delta H_{f}^{\circ}\left(\mathrm{ThO}_{2(\mathrm{~s})}\right)$. [under strongly acidic conditions, the oxides of thorium dissolve into the tetravalent ion]. $]^{3,4}$

The enthalpy of formation reaction from solution components:

$\Delta H_{\mathrm{f}, \mathrm{soln}}=\Delta H_{1}+\Delta H_{2}+\Delta H_{3}+\Delta H_{4}+\Delta H_{5}$, is computed using the relationship:

$6 \mathrm{ThO}_{2(\mathrm{~s})}+4 \mathrm{H}_{2} \mathrm{Me}_{2} \mathrm{BPDC}_{(\mathrm{cr})}+\mathrm{XDMF}_{(\mathrm{l})} \longrightarrow\left[\mathrm{Th}_{6} \mathrm{O}_{4}(\mathrm{OH})_{8}\left(\mathrm{Me}_{2} \mathrm{BPDC}_{4}\right] \cdot \mathrm{XDMF}_{(\mathrm{cr})}\right.$

(where $\mathrm{X}=25.6$ and 5.5 for $\mathrm{Th}_{6}-\mathrm{Me}_{2} \mathrm{BPDC}-8$ and $\mathrm{Th}_{6}-\mathrm{Me}_{2} \mathrm{BPDC}-8$ evacuated, respectively).

Enthalpy measurement values $\left(\Delta \mathrm{H}_{\mathrm{s}}\right)$ can be found in Table $\mathrm{S} 2$.

Table S1. Thermochemical cycle used to compute the enthalpies of formation of Th-MOF with respect to its components $\left(\mathrm{ThO}_{2}, \mathrm{H}_{2} \mathrm{Me}_{2} \mathrm{BPDC}, \mathrm{DMF}\right)$ as measured in $2: 1(\mathrm{v} / \mathrm{v}) 5 \mathrm{M} \mathrm{HCl}$ and DMF.

\begin{tabular}{|c|c|}
\hline Thermochemical Scheme & Enthalpy Measurement \\
\hline $\begin{array}{l}6 \mathrm{Th}^{4+}{ }_{(\mathrm{aq})}+4 \mathrm{Me}_{2} \mathrm{BPDC}^{2-}{ }_{(\mathrm{aq})}+25.6 \mathrm{DMF}_{(\mathrm{aq})}+12 \mathrm{H}_{2} \mathrm{O}_{(\mathrm{aq})} \longrightarrow \\
{\left[\mathrm{Th}_{6} \mathrm{O}_{4}(\mathrm{OH})_{8}\left(\mathrm{Me}_{2} \mathrm{BPDC}_{4}\right] \cdot 25.6 \mathrm{DMF}_{(\mathrm{cr})}+16 \mathrm{H}^{+}{ }_{(\mathrm{aq})}\right.}\end{array}$ & $\Delta H_{1}=-\Delta H_{\mathrm{s}}(\mathrm{Th}-\mathrm{MOF})$ \\
\hline $6 \times\left[\mathrm{ThO}_{2(\mathrm{~s})}+4 \mathrm{H}^{+}(\mathrm{aq}) \longrightarrow \mathrm{Th}^{4+}(\mathrm{aq})+2 \mathrm{H}_{2} \mathrm{O}_{(\mathrm{aq})}\right]$ & $\Delta H_{2}=6 \times \Delta H_{\mathrm{s}}\left(\mathrm{ThO}_{2}\right)$ \\
\hline $4 \times\left[\mathrm{H}_{2} \mathrm{Me}_{2} \mathrm{BPDC}_{(\mathrm{cr})} \longrightarrow\left(\mathrm{Me}_{2} \mathrm{BPDC}^{2-}{ }_{(\mathrm{aq})}+2 \mathrm{H}^{+}{ }_{(\mathrm{aq})}\right]\right.$ & $\Delta H_{3}=4 \times \Delta H_{\mathrm{s}}\left(\mathrm{H}_{2} \mathrm{Me}_{2} \mathrm{BPDC}\right)$ \\
\hline $25.6 \times\left[\mathrm{DMF}_{(\mathrm{l})} \longrightarrow \mathrm{DMF}_{(\mathrm{aq})}\right]$ & $\Delta H_{4}=25.6 \times \Delta H_{\mathrm{s}}(\mathrm{DMF})$ \\
\hline $12 \times\left[\mathrm{H}_{2} \mathrm{O}_{(\mathrm{aq})} \longrightarrow \mathrm{H}_{2} \mathrm{O}_{(\mathrm{l})}\right]$ & $\Delta H_{5}=12 \times \Delta H_{\mathrm{dil}}\left(\mathrm{H}_{2} \mathrm{O}\right)$ \\
\hline $\begin{array}{l}6 \mathrm{ThO}_{2(\mathrm{~s})}+4 \mathrm{H}_{2} \mathrm{Me}_{2} \mathrm{BPDC}_{(\mathrm{cr})}+25.6 \mathrm{DMF}_{(\mathrm{l})} \longrightarrow \\
{\left[\mathrm{Th}_{6} \mathrm{O}_{4}(\mathrm{OH})_{8}\left(\mathrm{Me}_{2} \mathrm{BPDC}\right)_{4}\right] 25.6 \mathrm{DMF}_{(\mathrm{cr})}}\end{array}$ & $\begin{array}{l}\Delta H_{\mathrm{f}}=\Delta H_{1}+\Delta H_{2}+\Delta H_{3}+ \\
\Delta H_{4}+\Delta H_{5}\end{array}$ \\
\hline
\end{tabular}


$\Delta H_{\mathrm{s}}=$ enthalpy of solution; $\Delta H_{\mathrm{f}}=$ enthalpy of formation from reaction solution components; and $\Delta H_{(\mathrm{f}, 298 \mathrm{~K})}=$ standard enthalpy of formation from the components in their standard state. The standard enthalpy of formation from the elements of one mole of Th-MOF is computed using the standard formation enthalpy of reaction components in their standard states and includes the enthalpy of formation from solution components for that formation reaction.

This is computed using the relationship:

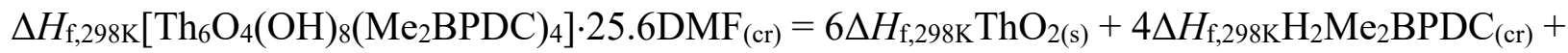
$\left.25.6 \Delta H_{\mathrm{f}, 298 \mathrm{~K}} \mathrm{DMF}(\mathrm{l})+\Delta H_{\mathrm{f}, \text { soln }} \mathrm{Th}_{6} \mathrm{O}_{4}(\mathrm{OH})_{8}\left(\mathrm{Me}_{2} \mathrm{BPDC}\right)_{4}\right] 25.6 \mathrm{DMF}_{(\mathrm{cr})}$.

For $\mathrm{Th}_{6}-\mathrm{Me}_{2} \mathrm{BPDC}-8$ evacuated:

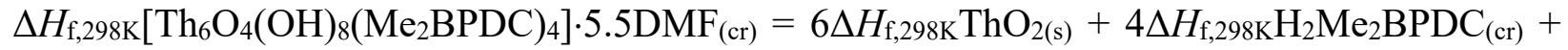
$\left.5.5 \Delta H_{\mathrm{f}, 298 \mathrm{~K}} \mathrm{DMF}_{(\mathrm{l})}+\Delta H_{\mathrm{f}, \mathrm{soln}} \mathrm{Th}_{6} \mathrm{O}_{4}(\mathrm{OH})_{8}\left(\mathrm{Me}_{2} \mathrm{BPDC}\right)_{4}\right] \cdot 5.5 \mathrm{DMF}_{(\mathrm{cr})}$.

Table S2. Experimental thermodynamics data applied to the thermodynamic cycle to compute enthalpies of formation of Th-MOF.

\begin{tabular}{|c|c|c|c|c|}
\hline Compound & $\begin{array}{l}\Delta \mathrm{H}_{\mathrm{s}} \mathrm{kJ} / \mathrm{mol} \\
\text { formula }\end{array}$ & $\begin{array}{l}\Delta \mathrm{H}_{\mathrm{f}, \text { soln } \mathrm{kJ} / \mathrm{mol}} \\
\text { Formula }\end{array}$ & $\begin{array}{l}\Delta \mathbf{H}_{\mathrm{f}, \mathrm{soln}} \mathrm{kJ} / \mathrm{mol} \\
\text { Thorium }\end{array}$ & $\begin{array}{l}\Delta H_{(f, 298 K)} \mathrm{kJ} / \mathrm{mol} \\
\text { of formula }\end{array}$ \\
\hline $\mathrm{Th}_{6}-\mathrm{Me}_{2} \mathrm{BPDC}-8$ & $\begin{array}{l}-383.73^{\mathrm{a}} \pm \\
7.75^{\mathrm{b}}(2)^{\mathrm{c}}\end{array}$ & $\begin{array}{l}2,030.47 \pm \\
7.96^{\mathrm{d}}\end{array}$ & $338.32 \pm 1.33^{\mathrm{d}}$ & $-14317.45 \pm 8.6^{\mathrm{d}}$ \\
\hline $\begin{array}{l}\mathrm{Th}_{6}-\mathrm{Me}_{2} \mathrm{BPDC}-8 \\
\text { evacuated }\end{array}$ & $\begin{array}{l}-312.21^{\mathrm{a}} \pm \\
6.53^{\mathrm{b}}(2)^{\mathrm{c}}\end{array}$ & $\begin{array}{l}2,148.90 \pm \\
7.96^{\mathrm{d}}\end{array}$ & $360.10 \pm 1.13$ & $-9387.08 \pm 7.72^{d}$ \\
\hline $\mathrm{ThO}_{2}$, Thorianite & $311.65 \pm 1.8^{\mathrm{e}, 1}$ & N/A & $\mathrm{N} / \mathrm{A}$ & $-1226.4 \pm 3.5^{5}$ \\
\hline $\mathrm{H}_{2} \mathrm{Me}_{2} \mathrm{BPDC}$ & $4.48 \pm 0.06$ & N/A & $\mathrm{N} / \mathrm{A}$ & $-715.22^{6}$ \\
\hline $\mathrm{H}_{2} \mathrm{BPDC}$ & $13.25 \pm 0.08$ & N/A & N/A & $-651.00^{6}$ \\
\hline DMF & $-9.45 \pm 0.01$ & N/A & N/A & $-239.4 \pm 1.2^{7}$ \\
\hline $\mathrm{H}_{2} \mathrm{O}$ & $0.07^{8}$ & $\mathrm{~N} / \mathrm{A}$ & N/A & $-285.8 \pm 0.1^{5}$ \\
\hline
\end{tabular}

$a_{\text {average of the measurements }}$

${ }^{b}$ the standard error of the average value

${ }^{c}$ number of measurements

${ }^{d}$ computed as the square root of the sum of the squares of reported errors

${ }^{e}$ computed for the solvent $(2: 1 \mathrm{v} / \mathrm{v} 5 \mathrm{M} \mathrm{HCl}: \mathrm{DMF})$ dissolution at $\mathrm{pH}=3.33$ 


\section{Theoretical Studies.}

Density of states (DOS) calculations were further carried out to explore the change in electronic

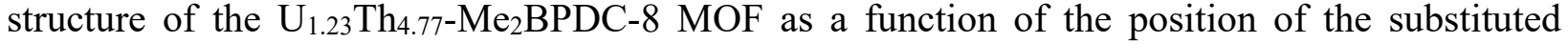
uranium atom in the MOF structure. The orbital-projected DOS suggest that with U substituted at the position 3 the calculated band gap was found to be $3.0 \mathrm{eV}$, while the U-substitution at the position 1 resulted in a band gap of $3.2 \mathrm{eV}$ (Figure S1).

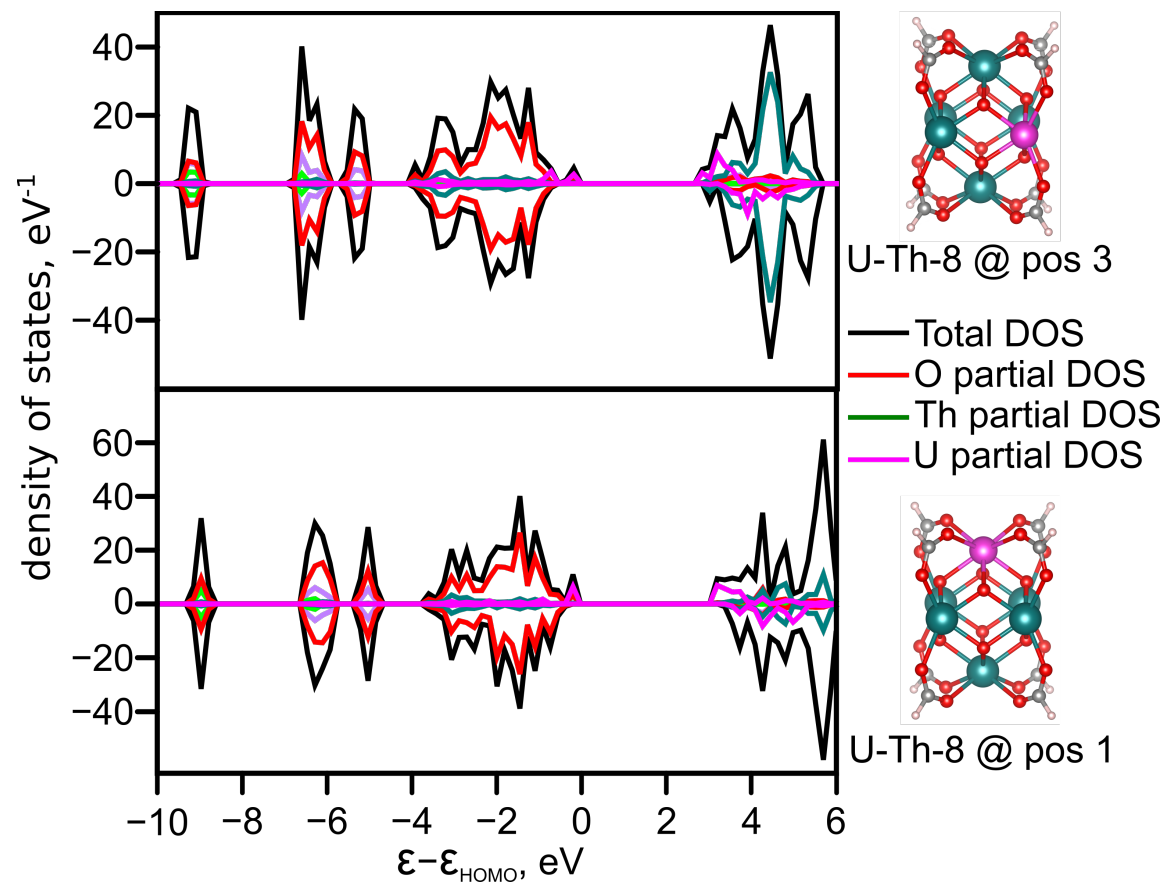

Figure S1. Total and partial DOS computed using the GGA-PBE level of theory and DFT $+U$

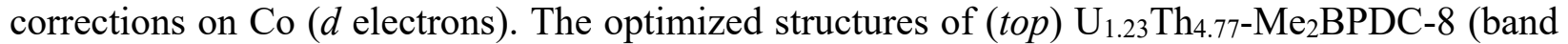

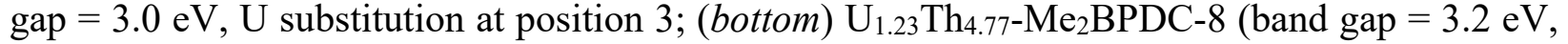
U substitution at position 1). The teal, lilac, red, grey, and light pink spheres represent Th, U, O, $\mathrm{C}$, and $\mathrm{H}$ atoms, respectively.
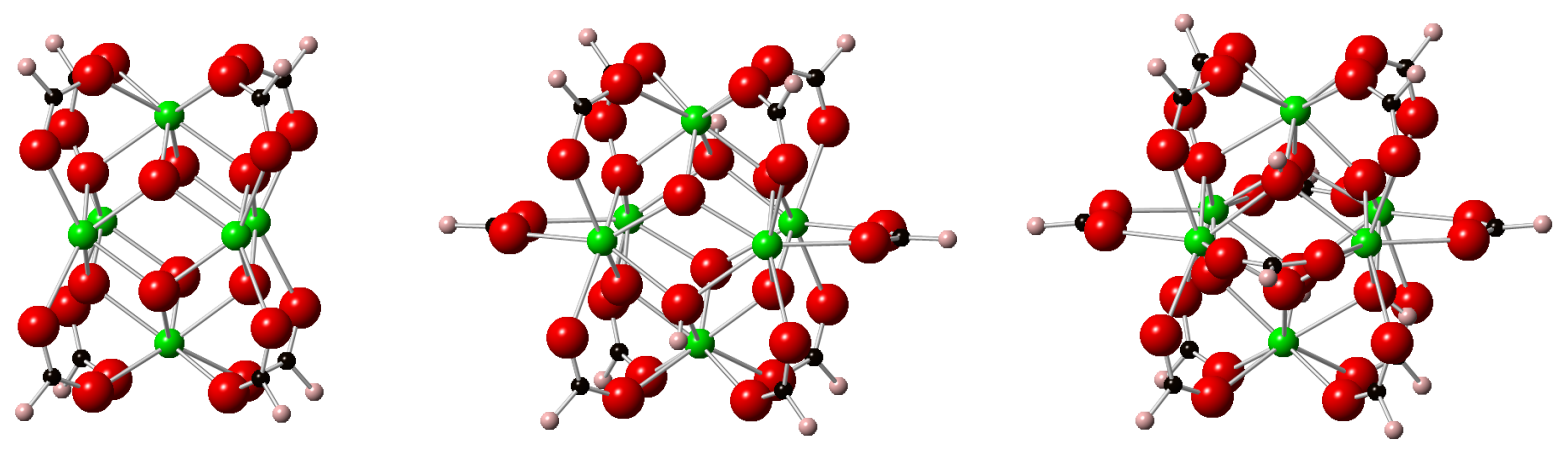

Figure S2. Truncated cluster models with formic acid linkers: (left) 8-coordinated metal node, (middle) 10-coordinated metal node, and (right) 12-coordinated metal node. The green, red, black, and pink spheres represent $\mathrm{M}(\mathrm{M}=\mathrm{Th}, \mathrm{U}), \mathrm{O}, \mathrm{C}$, and $\mathrm{H}$ atoms, respectively. 


\section{$\mathrm{X}$-ray crystal structure determination.}

Th$_{6}-\mathrm{Me}_{2}$ BPDC-NO $\mathrm{O}_{3}-10\left(\mathrm{C}_{80} \mathrm{H}_{60} \mathrm{~N}_{2} \mathrm{O}_{40} \mathrm{Th}_{6}\right)$. X-ray intensity data from a colorless rod-like crystal were collected at 100(2) K using a Bruker D8 QUEST diffractometer equipped with a PHOTON100 CMOS area detector and an Incoatec microfocus source (Mo $\mathrm{K}_{\alpha}$ radiation, $\lambda=0.71073 \AA$ ). The raw area detector data frames were reduced and corrected for absorption effects using the Bruker APEX3, SAINT+ and SADABS programs. ${ }^{9,10}$ Final unit cell parameters were determined by least-squares refinement of 9966 reflections taken from the data set. The structure was solved with SHELXT. ${ }^{3}$ Subsequent difference Fourier calculations and full-matrix least-squares refinement against $F^{2}$ were performed with SHELXL-2018 11,12 using OLEX2. ${ }^{13}$

The compound crystallizes in the tetragonal system. The pattern of systematic absences in the intensity data was consistent with the space groups $P 4_{2} / m m c, P-42 c$, and $P 4_{2} m c$. The centrosymmetric group $P 4_{2} / m m c$ (No. 131) was confirmed by structure solution. The asymmetric unit consists of two crystallographically unique thorium atoms, two unique $\mu_{3}$-bridging oxygen atoms $(\mathrm{O} 1$ and $\mathrm{O} 2)$, two unique terminal oxygen atoms $(\mathrm{O} 6$ and $\mathrm{O} 7 \mathrm{~A} / \mathrm{B})$, a bridging nitrate anion (N1 and O8A-C), two unique $\mathrm{C}_{16} \mathrm{H}_{12} \mathrm{O}_{4}{ }^{2-}$ ligands and a large region of interstitial disordered solvent species. The entire $\mathrm{Th}_{6}$ cluster has $\mathrm{mmm}\left(D_{2 \mathrm{~h}}\right)$ point symmetry. Most individual species lie on positions of special crystallographic symmetry. The Th1, O1, O2, and $\mathrm{O} 7$ atoms are located on a mirror plane. The Th2 and O6 atoms lie on two mirror planes and a two-fold axis $(\mathrm{m} 2 \mathrm{~m}$. site symmetry). The nitrate anion is simultaneously disordered across two mirror planes and a twofold axis $(\mathrm{m} 2 \mathrm{~m} / \mathrm{C} 2 \mathrm{v}$ symmetry) and is represented in the asymmetric unit by three half-occupied oxygen atoms (O8A-C) and one half-occupied nitrogen (N1). Oxygen $\mathrm{O} 7$ atom is disordered equally over two sites A/B. Ligand $\mathrm{O} 3 / \mathrm{O} 4 / \mathrm{C} 1-\mathrm{C} 8$ is located on a two-fold axis and only half is present per asymmetric unit. This ligand is full ordered. Ligand $\mathrm{O} 5 / \mathrm{C} 9-\mathrm{C} 14$ is extensively disordered about a site of high symmetry $\left(\mathrm{mmm} / \mathrm{D}_{2 \mathrm{~h}}\right)$. Only $1 / 4$ of this ligand is independent by symmetry. The six-membered rings $(\mathrm{C} 10-\mathrm{C} 13)$ are disordered across mirror planes. The methyl group of this ligand (atom C14) has four equally likely positions of attachment to the sixmembered ring (C12 and its three symmetry-equivalents) and is apparently disordered over these four sites. The $\mathrm{C} 14$ atom was therefore refined with $1 / 4-$ occupancy. The thorium atoms, all oxygen atoms and atoms of the ordered ligand $\mathrm{O} 3 / \mathrm{O} 4 / \mathrm{C} 1-\mathrm{C} 8$ were refined with anisotropic displacement parameters. Most disordered atoms were refined isotropically. Separate common displacement parameters were used for atoms $\mathrm{C} 9-\mathrm{C} 13$ and $\mathrm{N} 1 / \mathrm{O} 8 \mathrm{~A}-\mathrm{C}$. The anisotropic displacement parameters of ligand $\mathrm{O} 3 / \mathrm{O} 4 / \mathrm{C} 1-\mathrm{C} 8$ and of oxygen $\mathrm{O} 8$ were restrained to adopt a spherical shape with an ISOR instruction. The $\mathrm{C}-\mathrm{C}$ distance restraints and a FLAT instruction were applied to atoms of ligand $\mathrm{C} 9-\mathrm{C} 14$. The $\mathrm{N}-\mathrm{O}$ and $\mathrm{O}-\mathrm{O}$ distance restraints were applied to the nitrate atoms. Hydrogen atoms bonded to carbon were placed in geometrically idealized positions and included as riding atoms with appropriate occupancies. No hydrogen atoms could be located, and none were calculated for the $\mu_{3}$-bridging or terminal oxygen atoms. These are presumably a mixture of oxo, hydroxyl, aquo or hydronium ligands appropriate to satisfy crystal electroneutrality. Efforts to model the interstitial solvent disorder were unsuccessful. The Squeeze program in PLATON was used to account for these species. ${ }^{14,15}$ The solvent-accessible volume was calculated to be $7403 \AA^{3}$ per unit cell ( $66 \%$ of the total cell volume), containing the equivalent of 1359 electrons per unit cell. The scattering contribution of this electron density was added to the structure factors computed from the modeled part of the structure during refinement. For comparison, the residual factors were $R_{1} / w R_{2}=0.055 / 0.176$ for the best disorder model, and $R_{1} / w R_{2}=0.044 / 0.113$ after applying Squeeze. The reported crystal density and $F . W$. were calculated from the known part of the structure only. The largest residual electron density peak and hole in the final difference map are +2.08 and $-2.60 \mathrm{e} / \AA^{3}$, located 0.57 and $0.97 \AA$ from Th1, respectively. 
Th $_{6}$ - $\mathbf{M e}_{2}$ BPDC-8b $\left(\mathrm{C}_{64} \mathrm{H}_{48} \mathrm{O}_{34} \mathrm{Th}_{6}\right)$. Single crystals of $\mathrm{Th}_{6}-\mathrm{Me}_{2} \mathrm{BPDC}-8 \mathrm{~b}$ formed as colorless tablets. A suitable crystal was selected and mounted on a Bruker D8 Quest diffractometer equipped with a PHOTON-100 CMOS area detector and an Incoatec microfocus source (Mo $\mathrm{K}_{\alpha}$ radiation, $\lambda$ $=0.71073 \AA$ ). The crystal was kept at $100(2) \mathrm{K}$ during data collection. The raw area detector data frames were reduced and corrected for absorption effects using the Bruker APEX3, SAINT+ and SADABS programs. ${ }^{9,10}$ Final unit cell parameters were determined by least-squares refinement of 9677 reflections taken from the data set. Using OLEX2, ${ }^{12}$ the structure was solved with the SHELXT structure solution program using Intrinsic Phasing and refined with the XL refinement package using least-squares minimization. ${ }^{11,16}$

The compound crystallizes in the space group $\mathrm{P}_{2} / \mathrm{mmc}$ of the tetragonal system. The asymmetric unit consists of formally $1 / 8$ of one $\mathrm{Th}_{6} \mathrm{O}_{4}(\mathrm{OH})_{8}\left(\mathrm{C}_{16} \mathrm{H}_{12} \mathrm{O}_{4}\right)_{4}$ cluster which is located at the intersection of three mutually perpendicular mirror planes (site symmetry of the cluster centroid is $\mathrm{mmm}$.). All located atoms except for those of the ligand reside on at least one mirror plane. There are two unique thorium atoms, two unique $\mu 3$-bridging oxygen atoms $(\mathrm{O} 1$ and $\mathrm{O} 2)$, and three unique terminal oxygen atoms (O5-O7). The ligand is located on a two-fold axis of rotation and only half is crystallographically unique. It was refined with the aid of 11 restraints: a rigid six-membered ring (C2-C7, AFIX 66), FLAT, DFIX for $\mathrm{C}-\mathrm{C}$ single bonds). Ligand hydrogen atoms were placed in idealized positions and included as standard riding atoms. No hydrogen atoms were located or calculated for the bridging and terminal oxygen atoms of the cluster. Their identity as water, hydroxo, or oxo ligands is unknown. All non-hydrogen atoms were refined with anisotropic displacement parameters; those of the carbon and oxygen atoms were restrained from becoming abnormally elongated using a spherical approximation restraint (SHELX ISOR). The structure contains a large volume of disordered and unidentifiable solvent species, likely water and DMF, which were accounted for with Squeeze technique $\left(6670 \AA^{3}\right.$ solvent-accessible volume, 1480 electrons per unit cell). ${ }^{14,15}$ The largest peak in the final residual difference electron density map is $2.26 \mathrm{e} / \AA^{3}$, located $1.32 \AA$ from Th1.

$\mathbf{U}_{6}-\mathrm{Me}_{2}$ BPDC-TFA-10 $\left(\mathrm{C}_{84} \mathrm{H}_{60} \mathrm{~F}_{6} \mathrm{O}_{34} \mathrm{U}_{6}\right)$. X-ray intensity data from a green rod-like crystal were collected at 100(2) K using a Bruker D8 QUEST diffractometer equipped with a PHOTON-100 CMOS area detector and an Incoatec microfocus source (Mo K $\alpha$ radiation, $\lambda=0.71073 \AA$ ). The raw area detector data frames were reduced and corrected for absorption effects using the Bruker APEX3, SAINT+ and SADABS programs. ${ }^{9}, 10$ Final unit cell parameters were determined by leastsquares refinement of 9438 reflections taken from the data set. The structure was solved with SHELXT. ${ }^{3}$ Subsequent difference Fourier calculations and full-matrix least-squares refinement against $F^{2}$ were performed with SHELXL-2018 $8^{11,12}$ using OLEX2. ${ }^{13}$

The compound crystallizes in the tetragonal system. The pattern of systematic absences in the intensity data was consistent with the space groups $P 4_{2} / m m c, P-42 c$ and $P 4_{2} m c$. The centrosymmetric group $P 4_{2} / m m c$ (No. 131) was confirmed by structure solution. The asymmetric unit consists of two crystallographically unique uranium atoms, two unique $\mu_{3}$-bridging oxygen atoms (O1 and $\mathrm{O} 2)$, one unique terminal oxygen atom (O6), a bridging trifluoroacetate (TFA) anion, two unique $\mathrm{C}_{16} \mathrm{H}_{12} \mathrm{O}_{4}{ }^{2-}$ ligands and a large region of disordered solvent species. The entire $\mathrm{U}_{6}$ cluster has $\mathrm{mmm}\left(D_{2 \mathrm{~h}}\right)$ point symmetry. Most individual species lie on positions of special crystallographic symmetry. Th1, O1 and $\mathrm{O} 2$ are located on a mirror plane. Th2 and $\mathrm{O} 6$ lie on two mirror planes and a two-fold axis ( $\mathrm{m} 2 \mathrm{~m}$. site symmetry). The TFA anion is simultaneously disordered across two mirror planes and a two-fold axis $(\mathrm{m} 2 \mathrm{~m} / \mathrm{C} 2 v$ symmetry) and is represented in the asymmetric unit by one oxygen atom $(\mathrm{O} 8)$, two carbon atoms and three $1 / 4$-occupied fluorine atoms. Crystal symmetry generates 12 fluorine positions, for a total of $3 \mathrm{~F}$ per ligand taking into account the $1 / 4$-occupancy. Ligand $\mathrm{O} 3 / \mathrm{O} 4 / \mathrm{C} 1-\mathrm{C} 8$ is located on a two-fold axis and only half is present per asymmetric unit. This ligand is full ordered. Ligand O5/C9-C14 is extensively 
disordered about a site of high symmetry $\left(m m m / D_{2 h}\right)$. Only $1 / 4$ of this ligand is independent by symmetry. The six-membered rings $(\mathrm{C} 10-\mathrm{C} 13)$ are disordered across mirror planes. The methyl group of this ligand (atom C14) has four equally likely positions of attachment to the sixmembered ring (C12 and its three symmetry-equivalents) and is apparently disordered over these four sites. The $\mathrm{C} 14$ atom was therefore refined with $1 / 4$-occupancy. The uranium atoms, all oxygen atoms and atoms of the ordered ligand $\mathrm{O} 3 / \mathrm{O} 4 / \mathrm{C} 1-\mathrm{C} 8$ were refined with anisotropic displacement parameters. Disordered atoms were refined isotropically, some (F16A/B/C and C15) with arbitrarily fixed displacement parameters to prevent abnormally large values. Atomic coordinates of the $\mathrm{F}$ atoms were also fixed once reasonable positions had been obtained. The anisotropic displacement parameters of ligand $\mathrm{O} 3 / \mathrm{O} 4 / \mathrm{C} 1-\mathrm{C} 8$ and of oxygen $\mathrm{O} 8$ were restrained to adopt a spherical shape with an ISOR instruction. The $\mathrm{C}-\mathrm{C}$ distance restraints and a FLAT instruction were applied to atoms of ligand $\mathrm{C} 9-\mathrm{C} 14$. Hydrogen atoms bonded to carbon were placed in geometrically idealized positions and included as riding atoms with appropriate occupancies. No hydrogen atoms could be located, and none were calculated for the $\mu_{3}$-bridging or terminal oxygen atoms. These are presumably a mixture of oxo, hydroxy, or aquo ligands appropriate to satisfy crystal electroneutrality. Efforts to model the solvent disorder were unsuccessful. The Squeeze program in PLATON was used to account for these species. ${ }^{14,15}$ The solvent-accessible volume was calculated to be $7127 \AA^{3}$ per unit cell $(65.9 \%$ of the total cell volume), containing the equivalent of 1826 electrons per unit cell. The scattering contribution of this electron density was added to the structure factors computed from the modeled part of the structure during refinement. The reported crystal density and F.W. are calculated from the known part of the structure only. The largest residual electron density peak and hole in the final difference map are +1.55 and -1.80 $\mathrm{e} / \AA,{ }^{3}$ located $0.85 \AA$ from $\mathrm{O} 8$ and $0.02 \AA$ from $\mathrm{C} 16$, respectively.

$\mathrm{U}_{6}-\mathrm{Me}_{2}$ BPDC-8- $\mathrm{H}_{2} \mathrm{O}-1 \mathbf{1 d}\left(\mathrm{C}_{64} \mathrm{H}_{48} \mathrm{O}_{34} \mathrm{U}_{6}\right)$. Single crystals of $\mathrm{C}_{64} \mathrm{H}_{48} \mathrm{O}_{34} \mathrm{U}_{6}$ formed as pale green polyhedra. Diffraction quality of the available crystals was low, with broad diffraction profiles and weak intensities. Data were truncated at $2 \theta(\max )=35.1^{\circ}$, above this value no significant diffraction intensities were observed. The crystal was selected and mounted on a Bruker D8 Quest diffractometer. The crystal was kept at $100(2) \mathrm{K}$ during data collection. Using OLEX2 ${ }^{13}$, the structure was solved with the SHELXT ${ }^{11}$ structure solution program using Intrinsic Phasing and refined with the $\mathrm{XL}^{12}$ refinement package using least-squares minimization. The space group $\mathrm{P}_{2} / \mathrm{mmc}$ was found by XT and was confirmed by structure solution and refinement. The asymmetric unit consists of formally $1 / 8$ of one $\mathrm{U}_{6} \mathrm{O}_{4}(\mathrm{OH})_{8}\left(\mathrm{C}_{14} \mathrm{H}_{12} \mathrm{O}_{4}\right)_{4}$ cluster which is located at the intersection of three mutually perpendicular mirror planes (the site symmetry of the cluster centroid is $\mathrm{mmm}$.). All located atoms except for those of the ligand reside on at least one mirror plane. The ligand is located on a two-fold axis of rotation and only half is crystallographically unique. It was refined with the aid of 11 restraints: a rigid six-membered ring (C2-C7, AFIX 66), FLAT, DFIX and SADI for $\mathrm{C}-\mathrm{C}$ and $\mathrm{C}-\mathrm{O}$ single bonds, and all ligand atoms refined with a common isotropic displacement parameter. Ligand hydrogen atoms were idealized. No hydrogen atoms were located or calculated for the bridging and terminal oxygen atoms of the cluster. Their identity as water, hydroxo, or oxo ligands is unknown. Only the two unique uranium atoms were refined anisotropically; all other atoms were refined with isotropic displacement parameters. The structure contains a large volume of disordered and unidentifiable solvent species which were accounted for with Squeeze (6734 $\AA^{3}$ solvent-accessible volume, 1133 electrons per unit cell). The best disorder model, involving several randomly distributed and partially occupied oxygen atoms, converged at $R_{1}=0.154$. Because of the low crystal quality, the structure data should be considered of limited reliability except for general connectivity features. 
$\mathbf{U}_{6}-\mathbf{M e}_{2} \mathbf{B P D C}-\mathbf{8}-\mathrm{H}_{2} \mathrm{O}-\mathbf{4} \mathbf{d}\left(\mathrm{C}_{64} \mathrm{H}_{48} \mathrm{O}_{34} \mathrm{U}_{6}\right)$. Single crystals of $\mathrm{C}_{64} \mathrm{H}_{48} \mathrm{O}_{34} \mathrm{U}_{6}$ formed as pale green tablets. A suitable crystal was selected and mounted on a Bruker D8 Quest diffractometer. The crystal was kept at 100(2) K during data collection. Using OLEX2 ${ }^{13}$, the structure was solved with the SHELXT ${ }^{11}$ structure solution program using intrinsic phasing and refined with the XL ${ }^{12}$ refinement package using least-squares minimization. The asymmetric unit consists of formally $1 / 8$ of one $\mathrm{U}_{6} \mathrm{O}_{4}(\mathrm{OH})_{8}\left(\mathrm{C}_{16} \mathrm{H}_{12} \mathrm{O}_{4}\right)_{4}$ cluster which is located at the intersection of three mutually perpendicular mirror planes (site symmetry of the cluster centroid is $\mathrm{mmm}$ ). All located atoms except for those of the ligand reside on at least one mirror plane. The ligand is located on a twofold axis of rotation and only half is crystallographically unique. It was refined with the aid of 12 restraints: a rigid six-membered ring (C2-C7, AFIX 66), FLAT and DFIX for $\mathrm{C}-\mathrm{C}$ single bonds, and all carbon atoms were given a common isotropic displacement parameter. Ligand hydrogen atoms were idealized. No hydrogen atoms were located or calculated for the bridging and terminal oxygen atoms of the cluster. Their identity as water, hydroxo, or oxo ligands is unknown. The unique terminal oxygen $\mathrm{O} 7$ is disordered across a mirror plane and was refined with halfoccupancy. The structure contains a large volume of disordered and unidentifiable solvent species, likely water, which were accounted for with Squeeze $\left(6643 \AA^{3}\right.$ solvent-accessible volume, 1119 electrons per unit cell). The best disorder model, involving several randomly distributed and partially occupied oxygen atoms, converged at $R_{1}=0.080$.

Th$_{6}-\mathrm{Me}_{2} \mathrm{BPDC}-10-\mathrm{MeOH}\left(\mathrm{C}_{80} \mathrm{H}_{60} \mathrm{O}_{37} \mathrm{Th}_{6}\right)$. Crystals of the compound decompose to a white powder essentially instantaneously after removing from the crystallization solvent, even when rapidly immersed in paratone-N oil. A crystal could not be extracted from the mother liquor and transferred to the diffractometer cold stream before decomposition. For data collection, a colorless rod crystal was mounted inside a glass capillary tube in the presence of the mother liquor. The capillary was then flame-sealed at both ends. X-ray intensity data were collected at 301(2) K using a Bruker D8 QUEST diffractometer equipped with a PHOTON-100 CMOS area detector and an Incoatec microfocus source (Mo $\mathrm{K}_{\alpha}$ radiation, $\lambda=0.71073 \AA$ ). The raw area detector data frames were reduced and corrected for absorption effects using the Bruker APEX3, SAINT+, and SADABS programs. ${ }^{9,10}$ Final unit cell parameters were determined by least-squares refinement of 9900 reflections taken from the data set. The structure was solved with SHELXT. ${ }^{11,12}$ Subsequent difference Fourier calculations and full-matrix least-squares refinement against $F^{2}$ were performed with SHELXL-2018 $8^{11,12}$ using OLEX2. ${ }^{13}$

The compound crystallizes in the space group $P 4_{2} / m m c$ of the tetragonal system. The asymmetric unit consists of two crystallographically unique thorium atoms, two unique $\mu_{3}$ bridging oxygen atoms $(\mathrm{O} 1$ and $\mathrm{O} 2)$, one unique terminal oxygen atom $(\mathrm{O} 6)$, another disordered terminal oxygen atom $(\mathrm{O} 7 \mathrm{~A}-\mathrm{C})$, part of two unique $\mathrm{C}_{16} \mathrm{H}_{12} \mathrm{O}_{4}{ }^{2-}$ ligands and a large region of disordered solvent species. The entire $\mathrm{Th}_{6}$ cluster has $\mathrm{mmm}\left(\mathrm{D}_{2 \mathrm{~h}}\right)$ point symmetry. Most individual species lie on positions of special crystallographic symmetry. Th1, O1, O2 and O7A-C are located on mirror planes. The Th2 and $\mathrm{O} 6$ atoms lie on two mirror planes and a two-fold axis $(\mathrm{m} 2 \mathrm{~m}$. site symmetry). Ligand $\mathrm{O} 3 / \mathrm{O} 4 / \mathrm{Cl}-\mathrm{C} 8$ is located on a two-fold axis and only half is present per asymmetric unit. The methyl group (C8) is disordered over two sites and was refined with halfoccupancy. Ligand O5/C9-C14 is extensively disordered about a site of high symmetry $\left(\mathrm{mmm} / \mathrm{D}_{2 \mathrm{~h}}\right)$. Only $1 / 4$ of this ligand is independent by symmetry. The six-membered rings $(\mathrm{C} 10$ C13) are disordered across mirror planes. The methyl group of this ligand (atom C14) has four equally likely positions of attachment to the six-membered ring (C12 and its three symmetryequivalents) and is apparently disordered over these four sites. The C14 atom was therefore refined with $1 / 4$-occupancy. The oxygen $\mathrm{O} 7$ atom is disordered over three sites (A-C) bonded to Th1 in the asymmetric unit. Interpretation of the electron density map in this region was difficult because of the presence of many small peaks clustered together, none of which refined to full occupancy. 
They do not correspond to the carboxylic group of another ligand. The final disorder model used three oxygen atoms whose occupancies were fixed at values giving sensible displacement parameters. The model implies Th1 atoms have either two $(\mathrm{O} 7 \mathrm{~A} / \mathrm{B})$ or one $(\mathrm{O} 7 \mathrm{C}) \mathrm{O} 7$ ligands at this site. The thorium atoms, oxygen atoms O1-O7B and atoms of the ordered ligand $\mathrm{O} 3 / \mathrm{O} 4 / \mathrm{C} 1-$ $\mathrm{C} 8$ were refined with anisotropic displacement parameters. Carbon atoms of disordered ligand O5/C9-C14 were refined isotropically. The anisotropic displacement parameters of atoms C1-C8 and of oxygens $\mathrm{O} 1$ and $\mathrm{O} 2$ were restrained to adopt a spherical shape with ISOR instructions. The $\mathrm{C}-\mathrm{C}$ distance restraints and a FLAT instruction were applied to atoms of ligand C9-C14. Hydrogen atoms bonded to carbon were placed in geometrically idealized positions and included as riding atoms with appropriate occupancies. No hydrogen atoms could be located, and none were calculated for the $\mu_{3}$-bridging or terminal oxygen atoms. These are presumably a mixture of oxo, hydroxy, or aquo ligands appropriate to satisfy crystal electroneutrality. Efforts to model the solvent disorder were unsuccessful. The Squeeze program in PLATON was used to account for these species. ${ }^{14,15}$ The solvent-accessible volume was calculated to be $7475 \AA^{3}$ per unit cell $(65.6 \%$ of the total cell volume), containing the equivalent of 1088 electrons per unit cell. The scattering contribution of this electron density was added to the structure factors computed from the modeled part of the structure during refinement. For comparison, the residual factors were $R_{1} / w R_{2}=$ $0.0386 / 0.106$ for the best disorder model, and $R_{1} / w R_{2}=0.0316 / 0.0860$ after applying Squeeze. The reported crystal density and $F . W$. are calculated from the known part of the structure only. The largest residual electron density peak and hole in the final difference map are +1.31 and -1.27 $\mathrm{e} / \AA^{3}$, located $0.63 \AA$ from $\mathrm{O} 2$ and $0.74 \AA$ from $\mathrm{C} 10$, respectively.

Th $_{6}-\mathrm{Me}_{2}$ BPDC(Me $\left.\mathbf{T P D C}\right)-12\left(\mathrm{C}_{102} \mathrm{H}_{76} \mathrm{O}_{38} \mathrm{Th}_{6}\right)$. X-ray intensity data from a colorless rod-like crystal were collected at 100(2) K using a Bruker D8 QUEST diffractometer equipped with a PHOTON-100 CMOS area detector and an Incoatec microfocus source (Mo $\mathrm{K}_{\alpha}$ radiation, $\lambda=$ $0.71073 \AA$ ). The raw area detector data frames were reduced and corrected for absorption effects using the Bruker APEX3, SAINT+ and SADABS programs. ${ }^{9,10}$ Final unit cell parameters were determined by least-squares refinement of 9860 reflections taken from the data set. The structure was solved with SHELXT. ${ }^{11,12}$ Subsequent difference Fourier calculations and full-matrix leastsquares refinement against $F^{2}$ were performed with SHELXL-2018 ${ }^{11,12}$ using OLEX2. ${ }^{13}$

The compound crystallizes in the tetragonal system. The pattern of systematic absences in the intensity data was consistent with the space groups $P 4_{2} / m m c, P-42 c$ and $P 4_{2} m c$. The centrosymmetric group $P 4_{2} / m m c$ (No. 131) was confirmed by structure solution. The asymmetric unit consists of two crystallographically unique thorium atoms, two unique $\mu_{3}$-bridging oxygen atoms (O1 and $\mathrm{O} 2)$, two unique terminal oxygen atoms (O6 and $\mathrm{O} 7)$, two unique $\mathrm{C}_{16} \mathrm{H}_{12} \mathrm{O}_{4}{ }^{2-}$ ( $\mathrm{Me}_{2} \mathrm{BPDC}$ ) ligands, one unique $\mathrm{C}_{22} \mathrm{H}_{16} \mathrm{O}_{4}{ }^{2-}$ ( $\mathrm{Me}_{2}$ TPDC) ligand and a large region of interstitial disordered solvent species. The entire $\mathrm{Th}_{6}$ cluster has $\mathrm{mmm}\left(\mathrm{D}_{2 \mathrm{~h}}\right)$ point symmetry. Most individual species lie on positions of special crystallographic symmetry. The Th1, O1, O2, and $\mathrm{O} 7$ atoms are located on a mirror plane. The Th2 and $\mathrm{O} 6$ atoms lie on two mirror planes and a two-fold axis ( $m 2 m$. site symmetry). $\mathrm{Me}_{2} \mathrm{BPDC}$ ligand $\mathrm{O} 3 / \mathrm{O} 4 / \mathrm{C} 1-\mathrm{C} 8$ is located on a two-fold axis and only half is present per asymmetric unit. This ligand is not disordered. The $\mathrm{Me}_{2} \mathrm{BPDC}$ ligand O5/C9-C14 and the $\mathrm{Me}_{2} \mathrm{TPDC}$ ligand $(\mathrm{O} / \mathrm{C} 15-\mathrm{C} 22)$ are both disordered about sites of high symmetry $\left(\mathrm{mmm} / \mathrm{D}_{2 \mathrm{~h}}\right)$. Only $1 / 4$ of each of these ligands is independent by symmetry. The methyl-substituted six-membered rings of the $\mathrm{Me}_{2} \mathrm{BPDC}$ ligand $(\mathrm{C} 10-\mathrm{C} 14)$ are disordered across mirror planes. The methyl group (atom $\mathrm{C} 14$ ) has four equally probable positions of attachment to the six-membered ring (C12 and its three symmetry-equivalents) and is disordered over these four sites. The C14 atom was therefore refined with $1 / 4$-occupancy. The two methyl-substituted six-membered rings of the $\mathrm{Me}_{2}$ TPDC ligand $(\mathrm{C} 16-\mathrm{C} 19, \mathrm{C} 22)$ were modeled as lying in the mirror plane. The methyl carbon $(\mathrm{C} 22)$ therefore has two possible equally probable positions of attachment per ring (C18 
and symmetry-equivalent) and was therefore refined as half-occupied. The central phenyl ring is generated from two atoms $\mathrm{C} 20 / \mathrm{C} 21$. The $\mathrm{C} 21$ atom is disordered over two positions across a mirror plane and was refined as half-occupied. The thorium atoms, all oxygen atoms and atoms of the ordered ligand $\mathrm{O} 3 / \mathrm{O} 4 / \mathrm{C} 1-\mathrm{C} 8$ were refined with anisotropic displacement parameters. Most disordered atoms were refined isotropically. Carbon atom $U_{\text {iso }}$ parameters of the $\mathrm{Me}_{2} \mathrm{BPDC}$ ligand were refined freely. Those of atoms $\mathrm{C} 17-\mathrm{C} 22$ of the $\mathrm{Me}_{2}$ TPDC ligand were assigned a fixed $U_{\text {iso }}$ value of $0.175 \AA^{2}$. The anisotropic displacement parameters of ligand O3/O4/C1-C8 were restrained to adopt a spherical shape with an ISOR instruction. Appropriate $\mathrm{C}-\mathrm{C}$ distance restraints were applied to atoms of ligands O5/C9-C14 and O8/C15-C22. A FLAT instruction was applied to atoms C9-C14. Distances to methyl carbons were restrained to 1.54(1) $\AA$. Hydrogen atoms bonded to carbon were placed in geometrically idealized positions and included as riding atoms with appropriate occupancies. No hydrogen atoms could be located, and none were calculated for the $\mu_{3}$-bridging or terminal oxygen atoms. These are presumably a mixture of oxo, hydroxyl, aquo or hydronium ligands appropriate to satisfy crystal electroneutrality. Efforts to model the interstitial solvent disorder were unsuccessful. The Squeeze program in PLATON was used to account for these species. ${ }^{15}$ The solvent-accessible volume was calculated to be $6990 \AA^{3}$ per unit cell ( $62 \%$ of the total cell volume), containing the equivalent of 1457 electrons per unit cell. The scattering contribution of this electron density was added to the structure factors computed from the modeled part of the structure during refinement. For comparison, the residual factors were $R_{1} / w R_{2}=0.039 / 0.128$ for the best disorder model, and $R_{1} / w R_{2}=0.029 / 0.081$ after applying Squeeze. The reported crystal density and $F . W$. are calculated from the known part of the structure only. The largest residual electron density peak and hole in the final difference map are +1.05 and $-1.41 \mathrm{e} / \AA^{3}$, located $0.48 \AA$ and $0.28 \AA$ from O2 and C20, respectively.

Th6-Me 2 BPDC-8-intermediate $\left(\mathrm{C}_{64} \mathrm{H}_{48} \mathrm{O}_{38} \mathrm{Th}_{6}\right)$. X-ray intensity data from a colorless rod-like crystal were collected at 100(2) K using a Bruker D8 QUEST diffractometer equipped with a PHOTON-100 CMOS area detector and an Incoatec microfocus source (Mo K $\mathrm{K}_{\alpha}$ radiation, $\lambda=$ $0.71073 \AA$ ). The raw area detector data frames were reduced and corrected for absorption effects using the Bruker APEX3, SAINT+ and SADABS programs. ${ }^{9,10}$ The structures were solved with SHELXT. ${ }^{11,12}$ Subsequent difference Fourier calculations and full-matrix least-squares refinement against $F^{2}$ were performed with SHELXL-2018 11,12 using OLEX2. ${ }^{13}$

The compound crystallizes in the tetragonal system. The pattern of systematic absences in the intensity data was consistent with the space groups $P 4_{2} / m m c, P-42 c$ and $P 4_{2} m c$. The centrosymmetric group $P 4_{2} / m m c$ (No. 131) was confirmed by structure solution. The asymmetric unit consists of two crystallographically unique thorium atoms, half of one unique $\mathrm{C}_{16} \mathrm{H}_{12} \mathrm{O}_{4}{ }^{2-}$ ( $\mathrm{Me}_{2} \mathrm{BPDC}$ ) ligand, two unique $\mu_{3}$-bridging oxygen atoms (O1 and $\mathrm{O} 2$ ), two unique terminal oxygen atoms (O6 and $\mathrm{O} 7$ ), a constellation of disordered and unidentified species bridging the equator of the $\mathrm{Th}_{6}$ cluster (Th1 and its three symmetry-equivalents), and a large region of interstitial disordered solvent species. The entire $\mathrm{Th}_{6}$ cluster has $m m m\left(D_{2 \mathrm{~h}}\right)$ point symmetry. Most individual species lie on positions of special crystallographic symmetry. Th1, O1, O2 and $\mathrm{O} 7$ are located on a mirror plane. Th2 lies on two mirror planes and a two-fold axis ( $\mathrm{m} 2 \mathrm{~m}$. site symmetry). O6 is disordered over four symmetry-equivalent sites and was refined with 1/4-occupancy. Ligand O3/O4/C1-C8 is located on a two-fold axis and only half is present per asymmetric unit. O5 and $\mathrm{O} 8$ are located in the mirror plane containing Th1 and its equivalents. Except for atoms directly bonded to Th1 (O5, O7, and O8) the observed electron density around the Th1/Th1* equator of the cluster is uninterpretable but could be modeled sensibly. The observed density near these atoms is not consistent with another $\mathrm{Me}_{2} \mathrm{BPDC}$ ligand, even a partial, disordered one. Several trial models were unsuccessful. O5 and O8 both generate symmetry equivalent atoms separated by ca. $2.2 \AA$ across mirror planes, suggesting a carboxylato or nitrate species. Further away, the next closest 
peaks are found at long distances $(>1.7 \AA)$ and are not arranged in a chemically sensible pattern. Occupancies of the other peaks in this region refine to low values and could not be modeled reasonably. These species remain unknown because of the disorder. There may be a mixture of ligands scrambled over these sites. All atoms except $\mathrm{O} 6$ and $\mathrm{O} 7$ were refined with anisotropic displacement parameters; O6 was given a fixed $U_{\text {iso }}$ value of $0.125 \AA^{2}$. O7 is disordered over two closely separated sites with fixed occupancies of $\mathrm{O} 7 \mathrm{~A} / \mathrm{O} 7 \mathrm{~B}=0.3 / 0.7$. The anisotropic displacement parameters of the $\mathrm{Me}_{2} \mathrm{BPDC}$ ligand were restrained to adopt a spherical shape with ISOR instructions. C-C distance restraints and a DELU displacement parameter restraint were applied to atoms $\mathrm{C} 4$ and $\mathrm{C} 8$. Hydrogen atoms bonded to carbon were placed in geometrically idealized positions and included as riding atoms. No hydrogen atoms could be located, and none were calculated for the $\mu_{3}$-bridging or terminal oxygen atoms. These are presumably a mixture of oxo, hydroxyl, aquo or hydronium ligands appropriate to satisfy crystal electroneutrality. The disordered interstitial solvent could not be modeled successfully and was accounted for using the Squeeze program in PLATON. ${ }^{14,15}$ The solvent-accessible volume was calculated to be $8203 \AA^{3}$ per unit cell $(73.6 \%$ of the total cell volume). The scattering contribution of the disordered electron density was added to the structure factors computed from the modeled part of the structure during refinement. The reported crystal density and $F . W$. are calculated from the known part of the structure only. The largest residual electron density peak and hole in the final difference map are +2.06 and $-4.14 \mathrm{e} / \AA^{3}$, located $1.16 \AA$ from $\mathrm{O} 1$ and $1.02 \AA$ from Th1, respectively.

Th6-Me 2 BPDC(“QPDC")-10 $\left(\mathrm{C}_{80} \mathrm{H}_{60} \mathrm{O}_{38} \mathrm{Th}_{6}\right)$. X-ray intensity data from a colorless rod-like crystal were collected at 100(2) K using a Bruker D8 QUEST diffractometer equipped with a PHOTON-100 CMOS area detector and an Incoatec microfocus source (Mo $\mathrm{K}_{\alpha}$ radiation, $\lambda=$ $0.71073 \AA$ ). The raw area detector data frames were reduced and corrected for absorption effects using the Bruker APEX3, SAINT+ and SADABS programs. ${ }^{9,10}$ The structures were solved with SHELXT. ${ }^{11,12}$ Subsequent difference Fourier calculations and full-matrix least-squares refinement against $F^{2}$ were performed with SHELXL-2018 $8^{11,12}$ using OLEX2. ${ }^{13}$

The compound crystallizes in the tetragonal system. The pattern of systematic absences in the intensity data was consistent with the space groups $P 4_{2} / m m c, P-42 c$ and $P 4_{2} m c$. The centrosymmetric group $P 4_{2} / m m c$ (No. 131) was confirmed by structure solution. The asymmetric unit consists of two crystallographically unique thorium atoms, two unique $\mu_{3}$-bridging oxygen atoms (O1 and $\mathrm{O} 2)$, two unique terminal oxygen atoms (O6 and $\mathrm{O} 7 \mathrm{~A} / \mathrm{B})$, a disordered and unidentified species bridging two symmetry-equivalent Th atoms (Th1/Th1*) at coordination sites 11 and 12, two unique $\mathrm{C}_{16} \mathrm{H}_{12} \mathrm{O}_{4}{ }^{2-}\left(\mathrm{Me}_{2} \mathrm{BPDC}\right)$ ligands and a large region of interstitial disordered solvent species. The entire $\mathrm{Th}_{6}$ cluster has $\mathrm{mmm}\left(D_{2 \mathrm{~h}}\right)$ point symmetry. Most individual species lie on positions of special crystallographic symmetry. Th1, O1, O2 and $\mathrm{O} 7$ are located on a mirror plane. Th2 and O6 lie on two mirror planes and a two-fold axis ( $m 2 m$. site symmetry). The unknown bridging species is simultaneously disordered across two mirror planes and a two-fold axis ( $m 2 m / C 2 v$ symmetry) and is represented in the asymmetric unit by one oxygen atom (O8). Within the constraints that no trifluoroacetate or formate anions are present in the crystals, the observed electron density bridging Th1/Th1* at potential coordination sites 11 and 12 is uninterpretable and cannot be modeled sensibly. The observed density near these atoms is certainly not consistent with another $\mathrm{Me}_{2} \mathrm{BPDC}$ ligand, even a partial, disordered one. There are two oxygen atoms $08 / \mathrm{O}^{*}$, separated by $c a .2 .3 \AA$ across a mirror plane. A central atom, where a carboxylate carbon would be, is also observed at $c a .1 .3 \AA$ from the $\mathrm{O} 8$ atoms (i.e. resembling a formate group). These observations suggest a short carboxylato species (e.g. formate, acetate, or trifluoroacetate), which are unlikely to be present in the crystal based on the synthesis route. Further away, the next closest peaks are found at distances $>1.6 \AA$ and are not arranged in a chemically sensible pattern. Occupancies of the other peaks in this region refine to very low values $(e . g .<25 \%$ of a carbon) 
and could not be modeled reasonably. This species remains unknown because of the disorder. There may be a mixture of ligands scrambled over these sites. Oxygen $\mathrm{O} 7$ is disordered equally over two sites A/B. Ligand $\mathrm{O} 3 / \mathrm{O} 4 / \mathrm{C} 1-\mathrm{C} 8$ is located on a two-fold axis and only half is present per asymmetric unit. 1,2- and 1,4-C-C "same-distance" restraints were necessary to maintain a regular geometry for this ligand. Ligand $\mathrm{O} 5 / \mathrm{C} 9-\mathrm{C} 14$ is extensively disordered about a site of high symmetry $\left(\mathrm{mmm} / \mathrm{D}_{2 \mathrm{~h}}\right)$. Only $1 / 4$ of this ligand is independent by symmetry. The six-membered rings (C10-C13) are disordered across mirror planes. The methyl group of this ligand (atom C14) has four equally likely positions of attachment to the six-membered ring (C12 and its three symmetryequivalents) and is apparently disordered over these four sites. C14 was therefore refined with $1 / 4-$ occupancy. The thorium atoms, all oxygen atoms and atoms of the ordered ligand O3/O4/C1-C8 were refined with anisotropic displacement parameters. Most disordered atoms were refined isotropically. The anisotropic displacement parameters of ligand atoms $\mathrm{O} 3 / \mathrm{O} 4 / \mathrm{C} 1-\mathrm{C} 8$ were restrained to adopt a spherical shape with an ISOR instruction. The $\mathrm{C}-\mathrm{C}$ distance restraints and a FLAT instruction were applied to atoms of ligand C9-C14. Hydrogen atoms bonded to carbon were placed in geometrically idealized positions and included as riding atoms with appropriate occupancies. No hydrogen atoms could be located, and none were calculated for the $\mu_{3}$-bridging or terminal oxygen atoms. These are presumably a mixture of oxo, hydroxyl, aquo or hydronium ligands appropriate to satisfy crystal electroneutrality. Efforts to model the interstitial solvent disorder were unsuccessful. The Squeeze program in PLATON was used to account for these species. ${ }^{14,15}$ The solvent-accessible volume was calculated to be, typically, $7512 \AA^{3}$ per unit cell ( $68 \%$ of the total cell volume). The scattering contribution of the disordered electron density was added to the structure factors computed from the modeled part of the structure during refinement. The reported crystal density and $F . W$. are calculated from the known part of the structure only. The largest residual electron density peak and hole in the final difference map are +2.11 and $-1.74 \mathrm{e} / \AA^{3}$, located 0.62 and $1.22 \AA$ from $\mathrm{Th} 1$ and $\mathrm{O} 2$, respectively.

Th $_{6}-\mathrm{Me}_{2}$ BPDC(“"Me $\mathbf{M P D C}_{2}$ ')-10 $\left(\mathrm{C}_{80} \mathrm{H}_{60} \mathrm{O}_{38} \mathrm{Th}_{6}\right)$. X-ray intensity data from a colorless rod-like crystal were collected at 100(2) K using a Bruker D8 QUEST diffractometer equipped with a PHOTON-100 CMOS area detector and an Incoatec microfocus source (Mo $\mathrm{K}_{\alpha}$ radiation, $\lambda=$ $0.71073 \AA$ ). The raw area detector data frames were reduced and corrected for absorption effects using the Bruker APEX3, SAINT+ and SADABS programs. ${ }^{9,10}$ The structures were solved with SHELXT. ${ }^{11,12}$ Subsequent difference Fourier calculations and full-matrix least-squares refinement against $F^{2}$ were performed with SHELXL-2018 ${ }^{11,12}$ using OLEX2. ${ }^{13}$

The compound crystallizes in the tetragonal system. The pattern of systematic absences in the intensity data was consistent with the space groups $P 4_{2} / m m c, P-42 c$ and $P 4_{2} m c$. The centrosymmetric group $P 4_{2} / m m c$ (No. 131) was confirmed by structure solution. The asymmetric unit consists of two crystallographically unique thorium atoms, two unique $\mu_{3}$-bridging oxygen atoms (O1 and O2), two unique terminal oxygen atoms (O6 and O7A/B), a disordered and unidentified species bridging two symmetry-equivalent Th atoms (Th1/Th1*) at coordination sites 11 and 12, two unique $\mathrm{C}_{16} \mathrm{H}_{12} \mathrm{O}_{4}{ }^{2-}\left(\mathrm{Me}_{2} \mathrm{BPDC}\right)$ ligands and a large region of interstitial disordered solvent species. The entire $\mathrm{Th}_{6}$ cluster has $\mathrm{mmm}\left(D_{2 \mathrm{~h}}\right)$ point symmetry. Most individual species lie on positions of special crystallographic symmetry. Th1, O1, O2 and $\mathrm{O} 7$ are located on a mirror plane. Th2 and O6 lie on two mirror planes and a two-fold axis ( $m 2 m$. site symmetry). The unknown bridging species is simultaneously disordered across two mirror planes and a two-fold axis ( $m 2 m / C 2 v$ symmetry) and is represented in the asymmetric unit by one oxygen atom (O8). Within the constraints that no trifluoroacetate or formate anions are present in the crystals, the observed electron density bridging Th1/Th1* at potential coordination sites 11 and 12 is uninterpretable and cannot be modeled sensibly. The observed density near these atoms is certainly not consistent with another $\mathrm{Me}_{2} \mathrm{BPDC}$ ligand, even a partial, disordered one. There are two oxygen 
atoms $08 / \mathrm{O}^{*}$, separated by ca. $2.2 \AA$ across a mirror plane. A central atom, where a carboxylate carbon would be, is also observed at ca. $1.3 \AA$ (i.e., a formate group). These observations suggest a short carboxylato species (e.g. formate, acetate, or trifluoroacetate), which are unlikely to be present in the crystal based on the synthesis route. Further away, the next closest peaks are found at distances $>1.7 \AA$ and are not arranged in a chemically sensible pattern. Occupancies of the other peaks in this region refine to very low values (e.g. $<25 \%$ of a carbon) and could not be modeled reasonably. This species remains unknown because of the disorder. There may be a mixture of ligands scrambled over these sites. The $\mathrm{O} 7$ atom is disordered equally over two sites $\mathrm{A} / \mathrm{B}$. Ligand $\mathrm{O} 3 / \mathrm{O} 4 / \mathrm{C} 1-\mathrm{C} 8$ is located on a two-fold axis and only half is present per asymmetric unit. This ligand is full ordered. Ligand $\mathrm{O} 5 / \mathrm{C} 9-\mathrm{C} 14$ is extensively disordered about a site of high symmetry $\left(\mathrm{mmm} / \mathrm{D}_{2 \mathrm{~h}}\right)$. Only $1 / 4$ of this ligand is independent by symmetry. The six-membered rings $(\mathrm{C} 10-$ C13) are disordered across mirror planes. The methyl group of this ligand (atom C14) has four equally likely positions of attachment to the six-membered ring ( $\mathrm{C} 12$ and its three symmetryequivalents) and is apparently disordered over these four sites. C14 was therefore refined with $1 / 4-$ occupancy. The thorium atoms, all oxygen atoms and atoms of the ordered ligand $\mathrm{O} 3 / \mathrm{O} 4 / \mathrm{C} 1-\mathrm{C} 8$ were refined with anisotropic displacement parameters. Most disordered atoms were refined isotropically. The anisotropic displacement parameters of ligand $\mathrm{O} 3 / \mathrm{O} 4 / \mathrm{C} 1-\mathrm{C} 8$ and of oxygen $\mathrm{O} 8$ were restrained to adopt a spherical shape with an ISOR instruction. The O6 atom was given a fixed $U_{\text {iso }}$ value of $0.10 \AA^{2}$. The $\mathrm{C}-\mathrm{C}$ distance restraints and a FLAT instruction were applied to atoms of ligand C9-C14. Hydrogen atoms bonded to carbon were placed in geometrically idealized positions and included as riding atoms with appropriate occupancies. No hydrogen atoms could be located, and none were calculated for the $\mu_{3}$-bridging or terminal oxygen atoms. These are presumably a mixture of oxo, hydroxyl, aquo or hydronium ligands appropriate to satisfy crystal electroneutrality. Efforts to model the interstitial solvent disorder were unsuccessful. The Squeeze program in PLATON was used to account for these species. ${ }^{14,15}$ The solvent-accessible volume was calculated to be typically, $7608 \AA^{3}$ per unit cell ( $68 \%$ of the total cell volume). The scattering contribution of the disordered electron density was added to the structure factors computed from the modeled part of the structure during refinement. The reported crystal density and $F . W$. are calculated from the known part of the structure only. The largest residual electron density peak and hole in the final difference map are +1.29 and $-1.74 \mathrm{e} / \AA^{3}$, located 0.72 and 0.12 $\AA$ from Th1 and O6, respectively.

Th6-BPDC-10 $\left(\mathrm{C}_{70} \mathrm{H}_{40} \mathrm{O}_{38} \mathrm{Th}_{6}\right)$. X-ray intensity data from a colorless rod-like crystal were collected at 100(2) K using a Bruker D8 QUEST diffractometer equipped with a PHOTON-100 CMOS area detector and an Incoatec microfocus source (Mo $\mathrm{K}_{\alpha}$ radiation, $\lambda=0.71073 \AA$ ). The raw area detector data frames were reduced and corrected for absorption effects using the Bruker APEX3, SAINT+ and SADABS programs. ${ }^{9,10}$ The structures were solved with SHELXT. ${ }^{11,12}$ Subsequent difference Fourier calculations and full-matrix least-squares refinement against $F^{2}$ were performed with SHELXL-2018 ${ }^{11,12}$ using OLEX2. ${ }^{13}$

The compound crystallizes in the tetragonal system. The pattern of systematic absences in the intensity data was consistent with the space groups $P 4_{2} / m m c, P-42 c$ and $P 4_{2} m c$. The centrosymmetric group $P 4_{2} / m m c$ (No. 131) was confirmed by structure solution. The asymmetric unit consists of two crystallographically unique thorium atoms, two unique $\mu_{3}$-bridging oxygen atoms (O1 and $\mathrm{O} 2)$, two unique terminal oxygen atoms (O6 and $\mathrm{O} 7)$, a disordered and unidentified species bridging two symmetry-equivalent thorium atoms (Th1/Th1*), two unique $\mathrm{C}_{14} \mathrm{H}_{8} \mathrm{O}_{4}{ }^{2-}$ (BPDC) ligands and a large region of interstitial disordered solvent species. The entire $\mathrm{Th}_{6} \mathrm{cluster}$ has $m m m\left(D_{2 h}\right)$ point symmetry. Most individual species lie on positions of special crystallographic symmetry. The Th1, O1, O2, and $\mathrm{O} 7$ atoms are located on a mirror plane. The Th2 atom lies on two mirror planes and a two-fold axis ( $m 2 m$. site symmetry). O6 is disordered over four symmetry- 
equivalent sites and was refined with 1/4-occupancy. The unknown bridging species is simultaneously disordered across two mirror planes and a two-fold axis ( $\mathrm{m} 2 \mathrm{~m} / \mathrm{C} 2 \mathrm{v}$ symmetry) and is represented in the asymmetric unit by one oxygen atom (O8). The observed electron density bridging Th1/Th1* is uninterpretable and cannot be modeled sensibly. The observed density near these atoms is certainly not consistent with another BPDC ligand, even a partial, disordered one. There are two oxygen atoms O8/O8*, separated by ca. $2.26 \AA$ across a mirror plane. A central atom, where a carboxylate carbon would be, is also observed at ca. $1.3 \AA$ (i.e. like a formate group). These observations suggest a short carboxylato species (e.g. formate, acetate, or trifluoroacetate), which are unlikely to be present in the crystal based on the synthesis route. Further away, the next closest peaks are found at distances $>1.7 \AA$ and are not arranged in a chemically sensible pattern. Occupancies of the other peaks in this region refine to very low values (e.g. $<25 \%$ of a carbon) and could not be modeled reasonably. This species remains unknown because of the disorder. There may be a mixture of ligands scrambled over these sites. Ligand $\mathrm{O} 3 / \mathrm{O} 4 / \mathrm{C} 1-\mathrm{C} 7$ is located on a two-fold axis and only half is present per asymmetric unit. The phenyl rings of ligand O5/C9$\mathrm{C} 13$ are disordered across mirror planes; the affected atoms $\mathrm{C} 11$ and $\mathrm{C} 12$ were refined with halfoccupancy. All atoms except O6 were refined with anisotropic displacement parameters; O6 was given a fixed $U_{\text {iso }}$ value of $0.125 \AA^{2}$. The anisotropic displacement parameters of both BPDC ligands were restrained to adopt a spherical shape with ISOR instructions. C-C distance restraints and a FLAT instruction were applied to atoms of ligand O5/C9-C13. Hydrogen atoms bonded to carbon were placed in geometrically idealized positions and included as riding atoms with appropriate occupancies. No hydrogen atoms could be located, and none were calculated for the $\mu_{3}$-bridging or terminal oxygen atoms. These are presumably a mixture of oxo, hydroxyl, aquo or hydronium ligands appropriate to satisfy crystal electroneutrality. The disordered interstitial solvent could not be modeled successfully and was accounted for using the Squeeze program in PLATON. ${ }^{14,15}$ The solvent-accessible volume was calculated to be $8206 \AA^{3}$ per unit cell $(73 \%$ of the total cell volume). The scattering contribution of the disordered electron density was added to the structure factors computed from the modeled part of the structure during refinement. The reported crystal density and $F . W$. are calculated from the known part of the structure only. The largest residual electron density peak and hole in the final difference map are +0.97 and $-1.01 \mathrm{e} / \AA^{3}$, located 0.84 and $1.14 \AA$ from Th1 and O1, respectively. 
Th6-BPDC-12 $\left(\mathrm{C}_{102} \mathrm{H}_{90} \mathrm{~N}_{6} \mathrm{O}_{38} \mathrm{Th}_{6}\right)$. X-ray intensity data from a colorless octahedron crystal were collected at 100(2) K using a Bruker D8 QUEST diffractometer equipped with a PHOTON-100 CMOS area detector and an Incoatec microfocus source (Mo K $\alpha$ radiation, $\lambda=0.71073 \AA$ ). While stable indefinitely at low temperature, the crystals were observed to decompose over a period of hours at room temperature despite being immersed in oil. The raw area detector data frames were reduced and corrected for absorption effects using the Bruker APEX3, SAINT+ and SADABS programs. ${ }^{9}, 10$ The structure was solved with SHELXT. ${ }^{11,12}$ Subsequent difference Fourier calculations and full-matrix least-squares refinement against $F^{2}$ were performed with SHELXL$2018^{11,12}$ using OLEX2. ${ }^{13}$

The compound crystallizes in the space group $F m-3 m$ of the cubic system. The asymmetric unit consists of one crystallographically unique thorium atom, one unique $\mu_{3}$-bridging oxygen atom $(\mathrm{O} 2 \mathrm{~A} / \mathrm{B}), 1 / 4$ of one $\mathrm{C}_{14} \mathrm{H}_{8} \mathrm{O}_{4}{ }^{2-}$ (BPDC) ligand, one unique terminal DMF ligand and a large volume of disordered solvent species. Each $\mathrm{Th}_{6}$ cluster node is centered on a position of $O_{\mathrm{h}}(\mathrm{m}$ $3 m$ ) point symmetry. Most individual species lie on positions of special crystallographic symmetry. The BPDC ligand lies on two perpendicular mirror planes and one two-fold axis. The phenyl rings are disordered across one mirror plane and the affected atoms ( $\mathrm{C} 3$ and $\mathrm{C} 4)$ were refined with half-occupancy. The $\mu_{3}$-bridging oxygen atom is disordered over two sites $(\mathrm{O} 2 \mathrm{~A} / \mathrm{O} 2 \mathrm{~B})$ with occupancies fixed at 0.5 . The two sites likely represent oxo $(\mathrm{O} 2 \mathrm{~A}, d(\mathrm{Th}-\mathrm{O})=$ $2.319(1) \AA)$ and hydroxo $(\mathrm{O} 2 \mathrm{~B}, d(\mathrm{Th}-\mathrm{O})=2.490(3) \AA)$ species. The terminally coordinated DMF is disordered over four symmetry-equivalent sites across two mirror planes. DMF atoms were refined with $1 / 4-$ occupancies. Strict geometric restraints were necessary to maintain a reasonable DMF molecular geometry. All non-hydrogen atoms were refined with anisotropic displacement parameters except for the disordered DMF carbon and nitrogen atoms, which were given a fixed isotropic displacement parameter of $0.10 \AA^{2}$. The DMF oxygen atom was refined isotropically. The anisotropic displacement parameters of the BPDC ligand atoms were restrained to conform to a spherical shape with ISOR instructions. FLAT instructions and 1,2- and $1,3-\mathrm{C}-\mathrm{C}, \mathrm{C}-\mathrm{N}$, and $\mathrm{C}-$ $\mathrm{O}$ distance restraints were applied to atoms of the BPDC ligand and the DMF ligand. Hydrogen atoms bonded to carbon were placed in geometrically idealized positions and included as riding atoms with $d(\mathrm{C}-\mathrm{H})=0.95 \AA$ and $U_{\mathrm{iso}}(\mathrm{H})=1.2 U \mathrm{eq}(\mathrm{C})$ for aromatic hydrogen atoms and $d(\mathrm{C}-\mathrm{H})=$ $0.98 \AA$ and $U_{\text {iso }}(\mathrm{H})=1.5 U$ eq $(\mathrm{C})$ for methyl hydrogen. No hydrogen atoms could be located, and none were calculated for the disordered $\mu_{3}$-bridging oxygen atoms. The disordered interstitial solvent could not be modeled successfully and was accounted for using the Squeeze program in PLATON. ${ }^{14,15}$ The solvent-accessible volume was calculated to be $11109 \AA^{3}$ per unit cell $(51.3 \%$ of the total cell volume). The scattering contribution of the disordered electron density was added to the structure factors computed from the modeled part of the structure during refinement. The reported crystal density and $F . W$. were calculated from the known part of the structure only. The largest residual electron density peak and hole in the final difference map are +0.53 and -0.78 $\mathrm{e} / \AA^{3}$, located 1.26 and $0.82 \AA$ from $\mathrm{O} 2 \mathrm{~A}$ and $\mathrm{C} 7$, respectively. 
Table S3. X-ray structure refinement data for $\mathrm{Th}_{6}-\mathrm{Me}_{2} \mathrm{BPDC}-\mathrm{NO}_{3}-10,{ }^{a} \mathrm{Th}_{6}-\mathrm{Me}_{2} \mathrm{BPDC}-8 \mathrm{~b},{ }^{a}$ and $\mathrm{U}_{6}-\mathrm{Me}_{2} \mathrm{BPDC}$-TFA- $10 .^{a}$

\begin{tabular}{|c|c|c|c|}
\hline compound & $\mathrm{Th}_{6}-\mathrm{Me}_{2} \mathrm{BPDC}-\mathrm{NO}_{3}-10$ & $\mathrm{Th}_{6}-\mathrm{Me}_{2} \mathrm{BPDC}-8 \mathrm{~b}$ & $\mathrm{U}_{6}-\mathrm{Me}_{2} \mathrm{BPDC}-\mathrm{TFA}-10$ \\
\hline formula & $\mathrm{C}_{80} \mathrm{H}_{60} \mathrm{~N}_{2} \mathrm{O}_{40} \mathrm{Th}_{6}$ & $\mathrm{C}_{64} \mathrm{H}_{48} \mathrm{O}_{34} \mathrm{Th}_{6}$ & $\mathrm{C}_{84} \mathrm{H}_{60} \mathrm{~F}_{6} \mathrm{O}_{34} \mathrm{U}_{6}$ \\
\hline FW & 3081.54 & 2753.26 & 3155.50 \\
\hline$T, \mathrm{~K}$ & $100(2)$ & $100(2)$ & $100(2)$ \\
\hline crystal system & tetragonal & tetragonal & tetragonal \\
\hline space group & $\mathrm{P} 4_{2} / m m c$ & $\mathrm{P} 4_{2} / m m c$ & $\mathrm{P} 4_{2} / m m c$ \\
\hline $\mathrm{Z}$ & 2 & 2 & 2 \\
\hline$a, \AA$ & $23.7918(8)$ & $25.5223(17)$ & $23.6374(10)$ \\
\hline$b, \AA$ & $23.7918(8)$ & $25.5223(17)$ & $23.6374(10)$ \\
\hline$c, \AA$ & $19.6923(7)$ & $14.6275(11)$ & $19.3363(9)$ \\
\hline$\alpha,^{\circ}$ & 90 & 90 & 90 \\
\hline$\beta, \circ$ & 90 & 90 & 90 \\
\hline$\gamma,^{\circ}$ & 90 & 90 & 90 \\
\hline$V, \AA^{3}$ & $11146.8(8)$ & $9528.2(15)$ & $10803.7(10)$ \\
\hline$\rho_{\text {calc }} \mathrm{g} / \mathrm{cm}^{3}$ & 0.918 & 0.960 & 0.970 \\
\hline$\mu, \mathrm{mm}^{-1}$ & 4.024 & 4.699 & 4.521 \\
\hline $\mathrm{F}(000)$ & 2828.0 & 2488.0 & 2884.0 \\
\hline crystal size, $\mathrm{mm}^{3}$ & $0.2 \times 0.06 \times 0.06$ & $0.14 \times 0.08 \times 0.06$ & $0.18 \times 0.1 \times 0.08$ \\
\hline theta range & 4.352 to 55.18 & 4.236 to 50.334 & 4.392 to 44.986 \\
\hline index ranges & $\begin{array}{r}-29 \leq \mathrm{h} \leq 30 \\
-30 \leq \mathrm{k} \leq 31 \\
-25 \leq 1 \leq 25\end{array}$ & $\begin{array}{r}-30 \leq \mathrm{h} \leq 28 \\
-28 \leq \mathrm{k} \leq 30 \\
-17 \leq 1 \leq 17\end{array}$ & $\begin{array}{l}-25 \leq \mathrm{h} \leq 25 \\
-25 \leq \mathrm{k} \leq 25 \\
-20 \leq 1 \leq 20\end{array}$ \\
\hline refl. collected & 486156 & 182288 & 71450 \\
\hline $\begin{array}{l}\text { data/restraints/ } \\
\text { parameters }\end{array}$ & $6950 / 73 / 154$ & $4669 / 101 / 63$ & $3860 / 124 / 143$ \\
\hline GOF on $\mathrm{F}^{2}$ & 1.042 & 1.049 & 1.035 \\
\hline $\begin{array}{c}\text { Largest diff. } \\
\text { peak/hole / e } \AA^{-3}\end{array}$ & $2.08 /-2.96$ & $2.26 /-2.62$ & $1.55 /-1.80$ \\
\hline $\begin{array}{c}R_{1} / w R_{2} \\
{[\mathrm{I} \geq 2 \sigma(\mathrm{I})]^{b}}\end{array}$ & $0.0438 / 0.1131$ & $0.0895 / 0.2378$ & $0.0480 / 0.1233$ \\
\hline
\end{tabular}

${ }^{a} \mathrm{Mo}-\mathrm{K}_{\alpha}(\lambda=0.71073 \AA)$ radiation

${ }^{b} R_{1}=\Sigma|| F_{o}|-| \mathrm{F}_{\mathrm{c}}|| / \Sigma\left|F_{o}\right|, w R_{2}=\left\{\Sigma\left[w\left(F_{o}^{2}-F_{c}^{2}\right)^{2}\right] / \Sigma\left[w\left(F_{o 2}\right)_{2}\right]\right\}^{1 / 2}$ 
Table S4. X-ray structure refinement data for $\mathrm{U}_{6}-\mathrm{Me}_{2} \mathrm{BPDC}-8-\mathrm{H}_{2} \mathrm{O}-1 \mathrm{~d}^{a}$ and $\mathrm{U}_{6}-\mathrm{Me}_{2} \mathrm{BPDC}-8-\mathrm{H}_{2} \mathrm{O}-4 \mathrm{~d} .^{a}$

\begin{tabular}{|c|c|c|}
\hline compound & $\mathrm{U}_{6}-\mathrm{Me}_{2} \mathrm{BPDC}-8-\mathrm{H}_{2} \mathrm{O}-1 \mathrm{~d}$ & $\mathrm{U}_{6}-\mathrm{Me}_{2} \mathrm{BPDC}-8-\mathrm{H}_{2} \mathrm{O}-4 \mathrm{~d}$ \\
\hline formula & $\mathrm{C}_{64} \mathrm{H}_{48} \mathrm{O}_{34} \mathrm{U}_{6}$ & $\mathrm{C}_{64} \mathrm{H}_{48} \mathrm{O}_{34} \mathrm{U}_{6}$ \\
\hline FW & 2789.20 & 2789.20 \\
\hline$T, \mathrm{~K}$ & $100(2)$ & $100(2)$ \\
\hline crystal system & Tetragonal & Tetragonal \\
\hline space group & $\mathrm{P}_{2} / m m c$ & $\mathrm{P} 4_{2} / m m c$ \\
\hline $\mathrm{Z}$ & 2 & 2 \\
\hline$a, \AA$ & $25.114(3)$ & $25.1420(15)$ \\
\hline$b, \AA$ & $25.114(3)$ & $25.1420(15)$ \\
\hline$c, \AA$ & $15.2262(16)$ & $15.1163(9)$ \\
\hline$\alpha,^{\circ}$ & 90 & 90 \\
\hline$\beta, \circ$ & 90 & 90 \\
\hline$\gamma,^{\circ}$ & 90 & 90 \\
\hline$V, \AA^{3}$ & $9603(2)$ & $9555.3(13)$ \\
\hline$\rho_{\text {calc }} \mathrm{g} / \mathrm{cm}^{3}$ & 0.965 & 0.969 \\
\hline$\mu, \mathrm{mm}^{-1}$ & 5.075 & 5.100 \\
\hline $\mathrm{F}(000)$ & 2512.02 & 2512.0 \\
\hline crystal size, $\mathrm{mm}^{3}$ & $0.12 \times 0.1 \times 0.08$ & $0.14 \times 0.08 \times 0.06$ \\
\hline theta range & 4.506 to 35.05 & 4.214 to 44.424 \\
\hline index ranges & $\begin{array}{l}-19 \leq \mathrm{h} \leq 21 \\
-21 \leq \mathrm{k} \leq 21 \\
-12 \leq 1 \leq 12\end{array}$ & $\begin{array}{c}-32 \leq \mathrm{h} \leq 26 \\
-29 \leq \mathrm{k} \leq 32 \\
-31 \leq 1 \leq 32\end{array}$ \\
\hline refl. collected & 37244 & 145182 \\
\hline $\begin{array}{l}\text { data/restraints/ } \\
\text { parameters }\end{array}$ & $1732 / 11 / 44$ & $3325 / 12 / 72$ \\
\hline GOF on $\mathrm{F}^{2}$ & 1.304 & 1.035 \\
\hline $\begin{array}{c}\text { Largest diff. peak/hole / } \\
\text { e } \AA^{-3}\end{array}$ & $3.26 /-1.60$ & $0.77 /-0.82$ \\
\hline $\begin{array}{c}R_{1} / w R_{2} \\
{[\mathrm{I} \geq 2 \sigma(\mathrm{I})]^{b}}\end{array}$ & $0.1030 / 0.2896$ & $0.0559 / 0.1479$ \\
\hline
\end{tabular}

${ }^{a} \mathrm{Mo}-\mathrm{K}_{\alpha}(\lambda=0.71073 \AA)$ radiation

${ }^{b} R_{1}=\Sigma|| F_{o}|-| \mathrm{F}_{\mathrm{c}}|| / \Sigma\left|F_{o}\right|, w R_{2}=\left\{\Sigma\left[w\left(F_{o}{ }^{2}-F_{c}{ }^{2}\right)^{2}\right] / \Sigma\left[w\left(F_{o 2}\right)_{2}\right]\right\}^{1 / 2}$ 
Table S5. X-ray structure refinement data for $\mathrm{Th}_{6}-\mathrm{Me}_{2} \mathrm{BPDC}-10(\mathrm{MeOH}){ }^{a}$

\begin{tabular}{|c|c|}
\hline compound & $\mathrm{Th}_{6}-\mathrm{Me}_{2} \mathrm{BPDC}-10(\mathrm{MeOH})$ \\
\hline formula & $\mathrm{C}_{80} \mathrm{H}_{60} \mathrm{O}_{37} \mathrm{Th}_{6}$ \\
\hline $\mathrm{FW}$ & 3005.52 \\
\hline$T, \mathrm{~K}$ & $301(2)$ \\
\hline crystal system & Tetragonal \\
\hline space group & $\mathrm{P} 4_{2} / m m c$ \\
\hline $\mathrm{Z}$ & 2 \\
\hline$a, \AA$ & $24.0205(8)$ \\
\hline$b, \AA$ & $24.0205(8)$ \\
\hline$c, \AA$ & $19.7574(6)$ \\
\hline$\alpha,{ }^{\circ}$ & 90 \\
\hline$\beta,^{\circ}$ & 90 \\
\hline$\gamma^{\circ}$ & 90 \\
\hline$V, \AA^{3}$ & $11399 .(8)$ \\
\hline$\rho_{\text {calc }} \mathrm{g} / \mathrm{cm}^{3}$ & 0.876 \\
\hline$\mu, \mathrm{mm}^{-1}$ & 3.933 \\
\hline $\mathrm{F}(000)$ & 2752.0 \\
\hline crystal size, $\mathrm{mm}^{3}$ & $0.16 \times 0.04 \times 0.04$ \\
\hline theta range & 4.316 to 52.82 \\
\hline index ranges & $\begin{array}{l}-29 \leq \mathrm{h} \leq 27 \\
-30 \leq \mathrm{k} \leq 30 \\
-21 \leq 1 \leq 24\end{array}$ \\
\hline refl. collected & 116021 \\
\hline $\begin{array}{l}\text { data/restraints/ } \\
\text { parameters }\end{array}$ & $6309 / 109 / 160$ \\
\hline GOF on $\mathrm{F}^{2}$ & 1.082 \\
\hline $\begin{array}{c}\text { Largest peak/ } \\
\text { hole, e } / \AA^{3}\end{array}$ & $1.31 /-1.27$ \\
\hline $\begin{array}{c}R_{1} / w R_{2} \\
{[\mathrm{I} \geq 2 \sigma(\mathrm{I})]^{b}}\end{array}$ & $0.0316 / 0.0802$ \\
\hline
\end{tabular}

${ }^{a} \mathrm{Mo}-\mathrm{K}_{\alpha}(\lambda=0.71073 \AA)$ radiation

${ }^{b} R_{1}=\Sigma|| F_{o}|-| \mathrm{F}_{\mathrm{c}}|/ \Sigma| F_{o} \mid, w R_{2}=\left\{\Sigma\left[w\left(F_{o}^{2}-F_{c}^{2}\right)^{2}\right] / \Sigma\left[w\left(F_{o 2}\right)_{2}\right]\right\}^{1 / 2}$ 
Table S6. X-ray structure refinement data for $\mathrm{Th}_{6}-\mathrm{Me}_{2} \mathrm{BPDC}\left(\mathrm{Me}_{2} \mathrm{TPDC}\right)-12^{a}$ and $\mathrm{Th}_{6}-\mathrm{Me}_{2} \mathrm{BPDC}-$ 8 (an intermediate). ${ }^{a}$

\begin{tabular}{|c|c|c|}
\hline compound & $\mathrm{Th}_{6}-\mathrm{Me}_{2} \mathrm{BPDC}\left(\mathrm{Me}_{2} \mathrm{TPDC}\right)-12$ & $\begin{array}{c}\mathrm{Th}_{6}-\mathrm{Me}_{2} \mathrm{BPDC}-8 \\
\text { (intermediate) }\end{array}$ \\
\hline formula & $\mathrm{C}_{102} \mathrm{H}_{76} \mathrm{O}_{38} \mathrm{Th}_{6}$ & $\mathrm{C}_{64} \mathrm{H}_{48} \mathrm{O}_{38} \mathrm{Th}_{6}$ \\
\hline FW & 3301.86 & 2817.26 \\
\hline$T, \mathrm{~K}$ & $100(2)$ & $100(2)$ \\
\hline crystal system & tetragonal & tetragonal \\
\hline space group & $\mathrm{P} 4_{2} / m m c$ & $\mathrm{P} 4_{2} / m m c$ \\
\hline $\mathrm{Z}$ & 2 & 2 \\
\hline$a, \AA$ & $23.8841(16)$ & $23.9422(10)$ \\
\hline$b, \AA$ & $23.8841(16)$ & $23.9422(10)$ \\
\hline$c, \AA$ & $19.6378(14)$ & $19.4231(10)$ \\
\hline$\alpha,^{\circ}$ & 90 & 90 \\
\hline$\beta,{ }^{\circ}$ & 90 & 90 \\
\hline$\gamma,{ }^{\circ}$ & 90 & 90 \\
\hline$V, \AA^{3}$ & $11202.4(17)$ & $11133.9(11)$ \\
\hline$d_{\text {calc }}, \mathrm{g} / \mathrm{cm}^{3}$ & 0.979 & 0.840 \\
\hline$\mu, \mathrm{mm}^{-1}$ & 4.007 & 4.024 \\
\hline $\mathrm{F}(000)$ & 3064.0 & 2552.0 \\
\hline $\begin{array}{l}\text { crystal size, } \\
\mathrm{mm}^{3}\end{array}$ & $0.24 \times 0.08 \times 0.07$ & $0.14 \times 0.08 \times 0.06$ \\
\hline theta range & 3.992 to 55.3 & 1.7 to 52.864 \\
\hline index ranges & $\begin{array}{l}-31 \leq \mathrm{h} \leq 31 \\
-31 \leq \mathrm{k} \leq 31 \\
-25 \leq 1 \leq 25\end{array}$ & $\begin{array}{l}-29 \leq \mathrm{h} \leq 29 \\
-29 \leq \mathrm{k} \leq 29 \\
-24 \leq 1 \leq 23\end{array}$ \\
\hline refl. collected & 376298 & 243676 \\
\hline $\begin{array}{l}\text { data/restraints/ } \\
\text { parameters }\end{array}$ & $7010 / 85 / 172$ & $6193 / 56 / 136$ \\
\hline GOF on $\mathrm{F}^{2}$ & 1.058 & 1.047 \\
\hline $\begin{array}{c}\text { Largest peak/ } \\
\text { hole, } \mathrm{e} / \AA^{3}\end{array}$ & $1.05 /-1.41$ & $2.06 /-4.14$ \\
\hline $\begin{array}{c}\mathrm{R}_{1} / w \mathrm{R}_{2} \\
{[\mathrm{I} \geq 2 \sigma(\mathrm{I})]^{b}}\end{array}$ & $0.0290 / 0.0764$ & $0.0581 / 0.1469$ \\
\hline
\end{tabular}

${ }^{a} \mathrm{Mo}_{\mathrm{\alpha}} \mathrm{K}_{\alpha}(\lambda=0.71073 \AA)$ radiation

${ }^{b} R_{1}=\Sigma|| F_{\mathrm{O}}|-| F_{\mathrm{c}}|| / \Sigma\left|F_{\mathrm{O}}\right|, w \mathrm{R}_{2}=\left\{\Sigma\left[w\left(\mathrm{~F}_{0}-\mathrm{F}_{\mathrm{c}}^{2}\right)^{2}\right] / \Sigma\left[\mathrm{w}\left(\mathrm{F}_{0}^{2}\right)^{2}\right]\right\}^{1 / 2}$ 
Table S7. X-ray structure refinement data for $\mathrm{Th}_{6}-\mathrm{Me}_{2} \mathrm{BPDC}\left(\right.$ (" $\mathrm{Me}_{2} \mathrm{BPDC}$ ")- $10^{a}$ and $\mathrm{Th}_{6}$ $\mathrm{Me}_{2} \mathrm{BPDC}$ (“QQPDC”)-10 .

\begin{tabular}{|c|c|c|}
\hline compound & $\mathrm{Th}_{6}-\mathrm{Me}_{2} \mathrm{BPDC}\left({ }^{\prime} \mathrm{Me}_{2} \mathrm{BPDC} "\right)-10$ & $\mathrm{Th}_{6}-\mathrm{Me}_{2} \mathrm{BPDC}$ (“QPDC")-10 \\
\hline formula & $\mathrm{C}_{80} \mathrm{H}_{60} \mathrm{O}_{38} \mathrm{Th}_{6}$ & $\mathrm{C}_{80} \mathrm{H}_{60} \mathrm{O}_{38} \mathrm{Th}_{6}$ \\
\hline FW & 3021.52 & 3021 \\
\hline$T, \mathrm{~K}$ & $100(2)$ & $100(2)$ \\
\hline crystal system & Tetragonal & Tetragonal \\
\hline space group & $\mathrm{P} 4_{2} / m m c$ & $\mathrm{P} 4_{2} / m m c$ \\
\hline $\mathrm{Z}$ & 2 & 2 \\
\hline$a, \AA$ & $23.8374(9)$ & $23.668(2)$ \\
\hline$b, \AA$ & $23.8374(9)$ & $23.668(2)$ \\
\hline$c, \AA$ & $19.6890(9)$ & $19.6202(19)$ \\
\hline$\alpha,{ }^{\circ}$ & 90 & 90 \\
\hline$\beta,{ }^{\circ}$ & 90 & 90 \\
\hline$\gamma,^{\circ}$ & 90 & 90 \\
\hline$V, \AA^{3}$ & $11187.7(10)$ & $10991.0(2)$ \\
\hline$\rho_{\text {calc }} \mathrm{g} / \mathrm{cm}^{3}$ & 0.897 & 0.913 \\
\hline$\mu, \mathrm{mm}^{-1}$ & 4.008 & 4.080 \\
\hline $\mathrm{F}(000)$ & 2768.0 & 2768.0 \\
\hline crystal size, $\mathrm{mm}^{3}$ & $0.16 \times 0.06 \times 0.05$ & $0.18 \times 0.06 \times 0.04$ \\
\hline theta range & 1.708 to 54.038 & 1.72 to 53.13 \\
\hline index ranges & $\begin{array}{l}-30 \leq \mathrm{h} \leq 30 \\
-30 \leq \mathrm{k} \leq 30 \\
-24 \leq 1 \leq 25\end{array}$ & $\begin{array}{l}-29 \leq \mathrm{h} \leq 29 \\
-29 \leq \mathrm{k} \leq 29 \\
-24 \leq 1 \leq 23\end{array}$ \\
\hline refl. collected & 269756 & 171972 \\
\hline $\begin{array}{c}\text { data/restraints/ } \\
\text { parameters }\end{array}$ & $6596 / 66 / 152$ & $6149 / 103 / 149$ \\
\hline GOF on $\mathrm{F}^{2}$ & 1.044 & 1.100 \\
\hline $\begin{array}{c}\text { Largest peak/ } \\
\text { hole, } \mathrm{e} / \AA^{3}\end{array}$ & $1.29 /-1.74$ & $2.12 /-1.74$ \\
\hline $\begin{array}{c}R_{1} / w R_{2} \\
{[\mathrm{I} \geq 2 \sigma(\mathrm{I})]^{b}}\end{array}$ & $0.0330 / 0.0858$ & $0.0653 / 0.1674$ \\
\hline
\end{tabular}

${ }^{a} \mathrm{Mo}-\mathrm{K}_{\alpha}(\lambda=0.71073 \AA)$ radiation

${ }^{b} R_{1}=\Sigma|| F_{o}|-| \mathrm{F}_{\mathrm{c}}|| / \Sigma\left|F_{o}\right|, w R_{2}=\left\{\Sigma\left[w\left(F_{o}^{2}-F_{c}^{2}\right)^{2}\right] / \Sigma\left[w\left(F_{o 2}\right)_{2}\right]\right\}^{1 / 2}$ 
Table S8. X-ray structure refinement data for Th 6 -BPDC- $10^{a}$ and $\mathrm{Th}_{6}-\mathrm{BPDC}-12 .^{a}$

\begin{tabular}{|c|c|c|}
\hline compound & $\mathrm{Th}_{6}-\mathrm{BPDC}-10$ & $\mathrm{Th}_{6}-\mathrm{BPDC}-12$ \\
\hline formula & $\mathrm{C}_{70} \mathrm{H}_{40} \mathrm{O}_{38} \mathrm{Th}_{6}$ & $\mathrm{C}_{102} \mathrm{H}_{90} \mathrm{~N}_{6} \mathrm{O}_{38} \mathrm{Th}_{6}$ \\
\hline FW & 2881.26 & 3400.03 \\
\hline$T, \mathrm{~K}$ & $100(2)$ & $100(2)$ \\
\hline crystal system & Tetragonal & cubic \\
\hline space group & $\mathrm{P} 4_{2} / m m c$ & $\mathrm{~F} m-3 m$ \\
\hline $\mathrm{Z}$ & 2 & 4 \\
\hline$a, \AA$ & $23.8341(16)$ & $27.8788(10)$ \\
\hline$b, \AA$ & $23.8341(16)$ & $27.8788(10)$ \\
\hline$c, \AA$ & $19.7558(14)$ & $27.8788(10)$ \\
\hline$\alpha,^{\circ}$ & 90 & 90 \\
\hline$\beta,{ }^{\circ}$ & 90 & 90 \\
\hline$\gamma,{ }^{\circ}$ & 90 & 90 \\
\hline$V, \AA^{3}$ & $11222.6(17)$ & $21668(2)$ \\
\hline$\rho_{\text {calc }} \mathrm{g} / \mathrm{cm}^{3}$ & 0.853 & 1.042 \\
\hline$\mu, \mathrm{mm}^{-1}$ & 3.993 & 4.146 \\
\hline$F(000)$ & 2608.0 & 6352.0 \\
\hline crystal size, $\mathrm{mm}^{3}$ & $0.16 \times 0.04 \times 0.04$ & $0.08 \times 0.06 \times 0.04$ \\
\hline theta range & 3.992 to 54.104 & 4.846 to 56.526 \\
\hline index ranges & $\begin{array}{l}-30 \leq \mathrm{h} \leq 30 \\
-30 \leq \mathrm{k} \leq 30 \\
-25 \leq 1 \leq 25\end{array}$ & $\begin{array}{c}-37 \leq \mathrm{h} \leq 37 \\
-37 \leq \mathrm{k} \leq 36 \\
-37 \leq 1 \leq 37\end{array}$ \\
\hline refl. collected & 160135 & 115893 \\
\hline $\begin{array}{c}\text { data/restraints/ } \\
\text { parameters }\end{array}$ & $6633 / 91 / 156$ & $1395 / 51 / 54$ \\
\hline GOF on $\mathrm{F}^{2}$ & 1.050 & 1.166 \\
\hline $\begin{array}{c}\text { Largest peak/ } \\
\text { hole, e } / \AA^{3}\end{array}$ & $0.97 /-1.01$ & $0.53 /-0.78$ \\
\hline $\begin{array}{c}R_{1} / w R_{2} \\
{[\mathrm{I} \geq 2 \sigma(\mathrm{I})]^{b}}\end{array}$ & $0.0290 / 0.0788$ & $0.0226 / 0.0586$ \\
\hline
\end{tabular}

${ }^{a} \mathrm{Mo}^{-\mathrm{K}_{\alpha}}(\lambda=0.71073 \AA)$ radiation

${ }^{b} R_{1}=\Sigma|| F_{o}|-| \mathrm{F}_{c}|/ \Sigma| F_{o} \mid, w R_{2}=\left\{\Sigma\left[w\left(F_{o}^{2}-F_{c}^{2}\right)^{2}\right] / \Sigma\left[w\left(F_{o 2}\right)_{2}\right]\right\}^{1 / 2}$ 


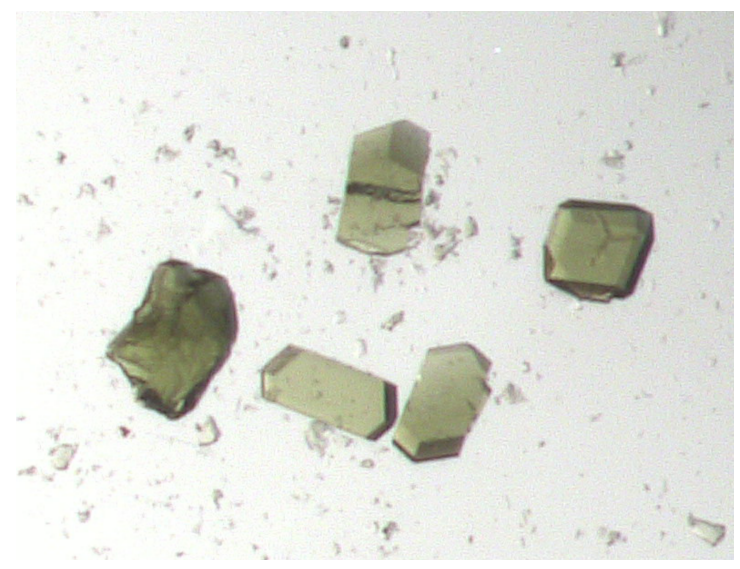

Figure S3. Photograph of the $\mathrm{U}_{6}-\mathrm{Me}_{2} \mathrm{BPDC}-8$ single crystals.
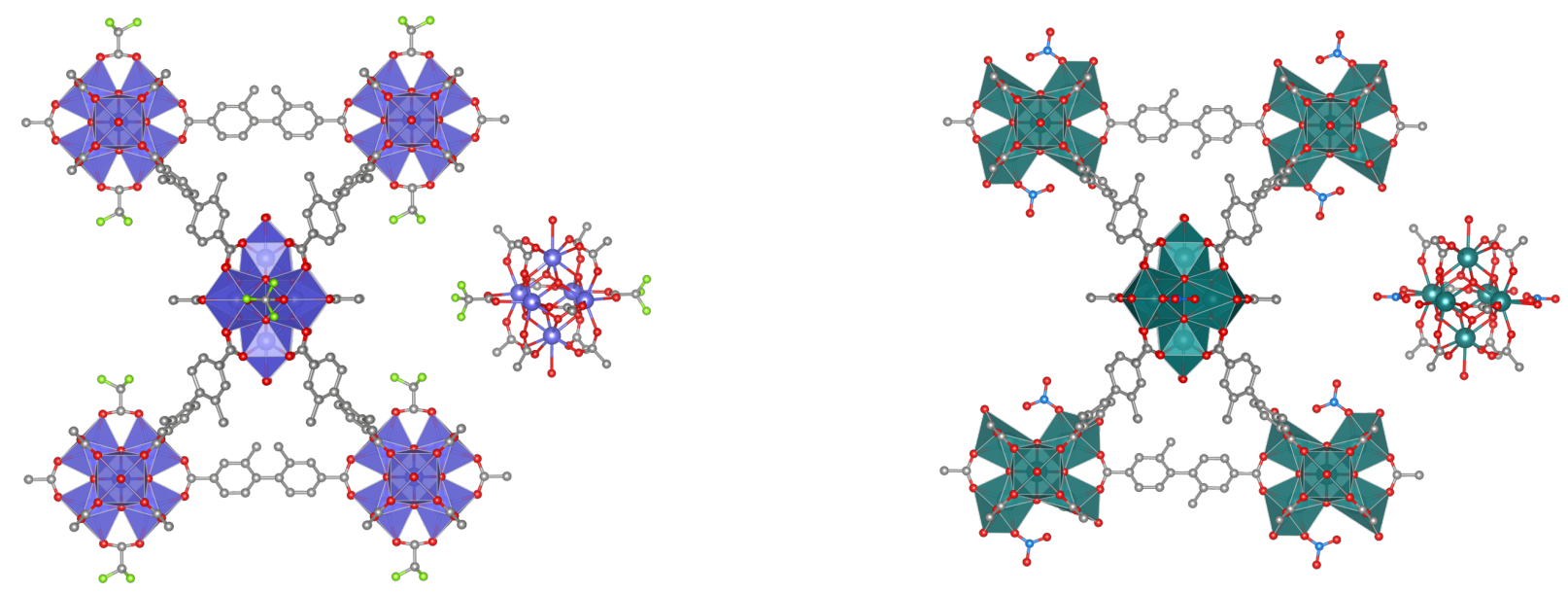

Figure S4. X-ray crystal structures and secondary building units of: (left) $\mathrm{U}_{6}-\mathrm{Me}_{2} \mathrm{BPDC}-\mathrm{TFA}-10$ and (right) $\mathrm{Th}_{6}-\mathrm{Me}_{2} \mathrm{BPDC}-\mathrm{NO}_{3}-10$. The teal, purple, red, gray, blue, and lemon spheres represent Th, U, O, C, N, and F atoms, respectively. Hydrogen atoms and solvents molecules were omitted for clarity. 


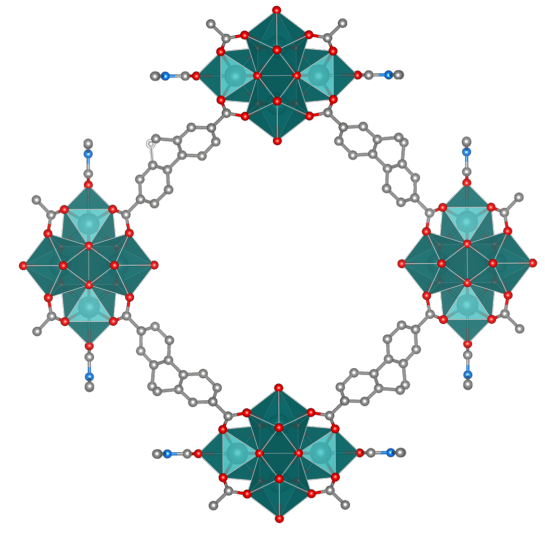

$\mathrm{Th}_{6}-\mathrm{Me}_{2} \mathrm{BPDC}-8 \mathrm{a}$

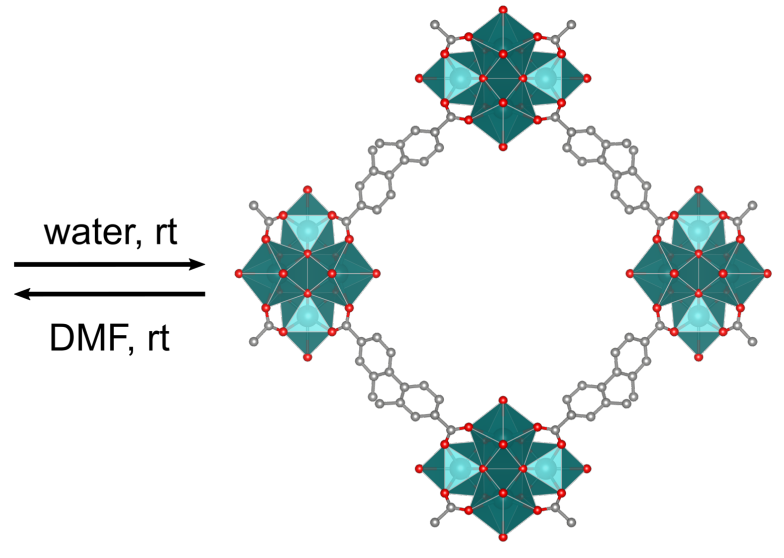

$\mathrm{Th}_{6}-\mathrm{Me}_{2} \mathrm{BPDC}-8 \mathrm{~b}$

Figure S5. Reversible phase transition from $\mathrm{Th}_{6}-\mathrm{Me}_{2} \mathrm{BPDC}-8 \mathrm{a}$ (left) to $\mathrm{Th}_{6}-\mathrm{Me}_{2} \mathrm{BPDC}-8 \mathrm{~b}$ (right) by immersing the former in water and then the latter in DMF at room temperature. The difference between the two phases is that $\mathrm{Th}_{6}-\mathrm{Me}_{2} \mathrm{BPDC}-8 \mathrm{~b}$ crystallizes in the tetragonal $\mathrm{P}_{2} / m m c$ space group $\left(a=b=25.5223(17) \AA\right.$ and $c=14.6275(11) \AA$ ) while $\mathrm{Th}_{6}-\mathrm{Me}_{2} \mathrm{BPDC}-8 \mathrm{a}$ is isostructural to $\mathrm{U}_{6}-\mathrm{Me}_{2} \mathrm{BPDC}-8,{ }^{17}$ which crystallizes in the tetragonal $\mathrm{P} 4_{2} / m m c$ space group $(a=b=24.9768(18)$ $\AA$ and $c=15.9864(12) \AA$ ). The teal, red, gray, and blue spheres represent Th, O, C, and N atoms, respectively. Hydrogen atoms and solvents molecules were omitted for clarity.
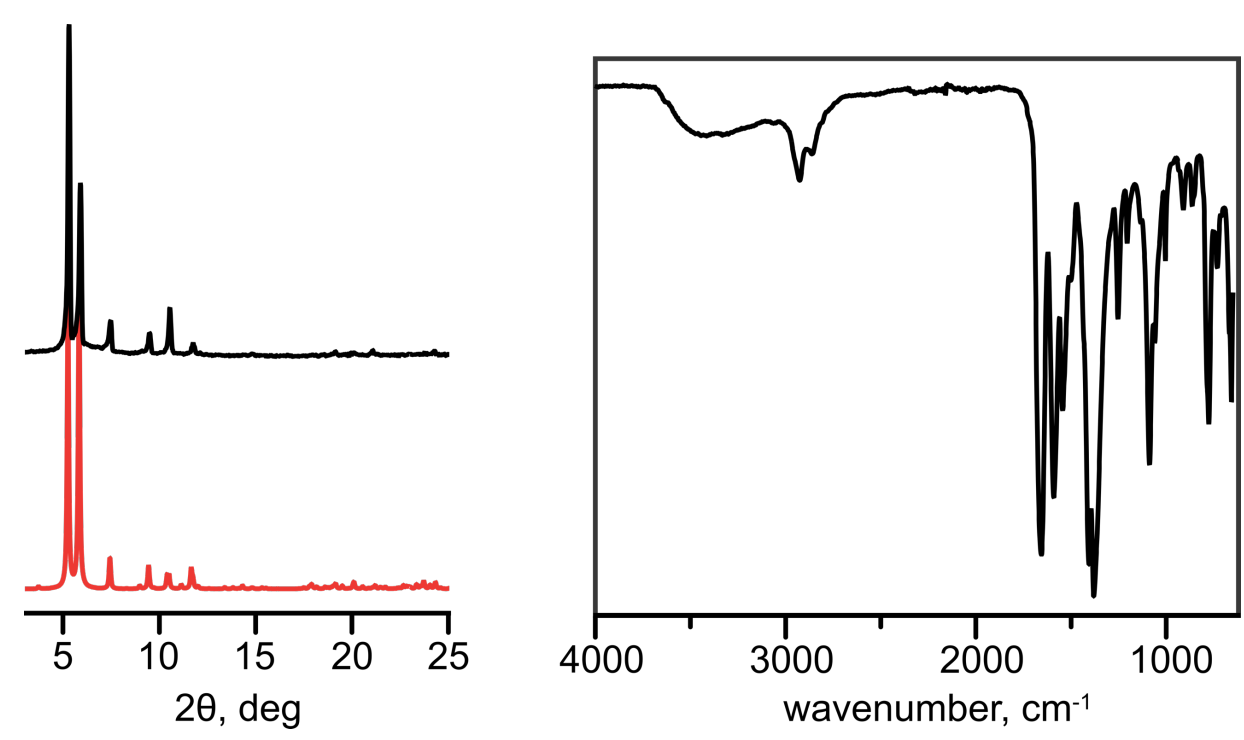

Figure S6. (left) PXRD patterns of $\mathrm{Th}_{6}-\mathrm{Me}_{2} \mathrm{BPDC}-\mathrm{NO}_{3}-10$ : simulated (red) and as-synthesized (black). (right) FTIR spectrum of $\mathrm{Th}_{6}-\mathrm{Me}_{2} \mathrm{BPDC}^{-\mathrm{NO}_{3}-10 .}$ 

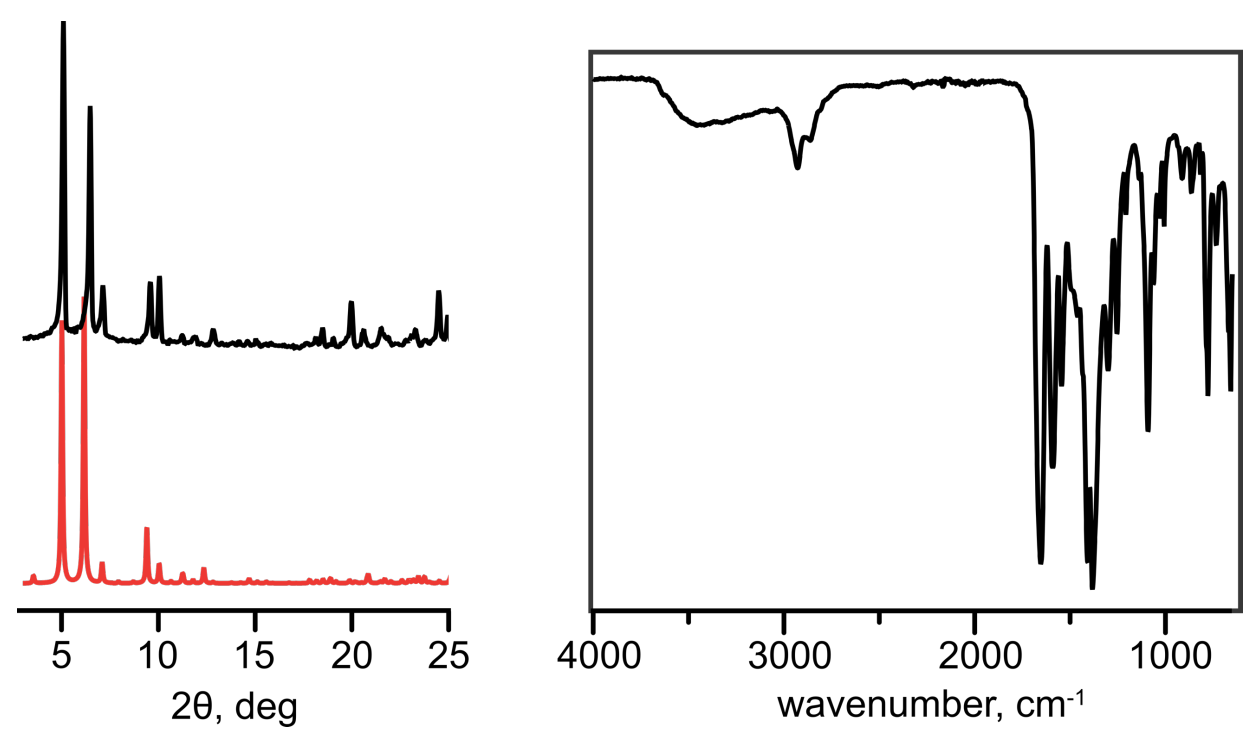

Figure S7. (left) PXRD patterns of $\mathrm{Th}_{6}-\mathrm{Me}_{2} \mathrm{BPDC}-8$ : simulated (red) ${ }^{17}$ and as-synthesized (black). (right) FTIR spectrum of $\mathrm{Th}_{6}-\mathrm{Me}_{2} \mathrm{BPDC}-8$.
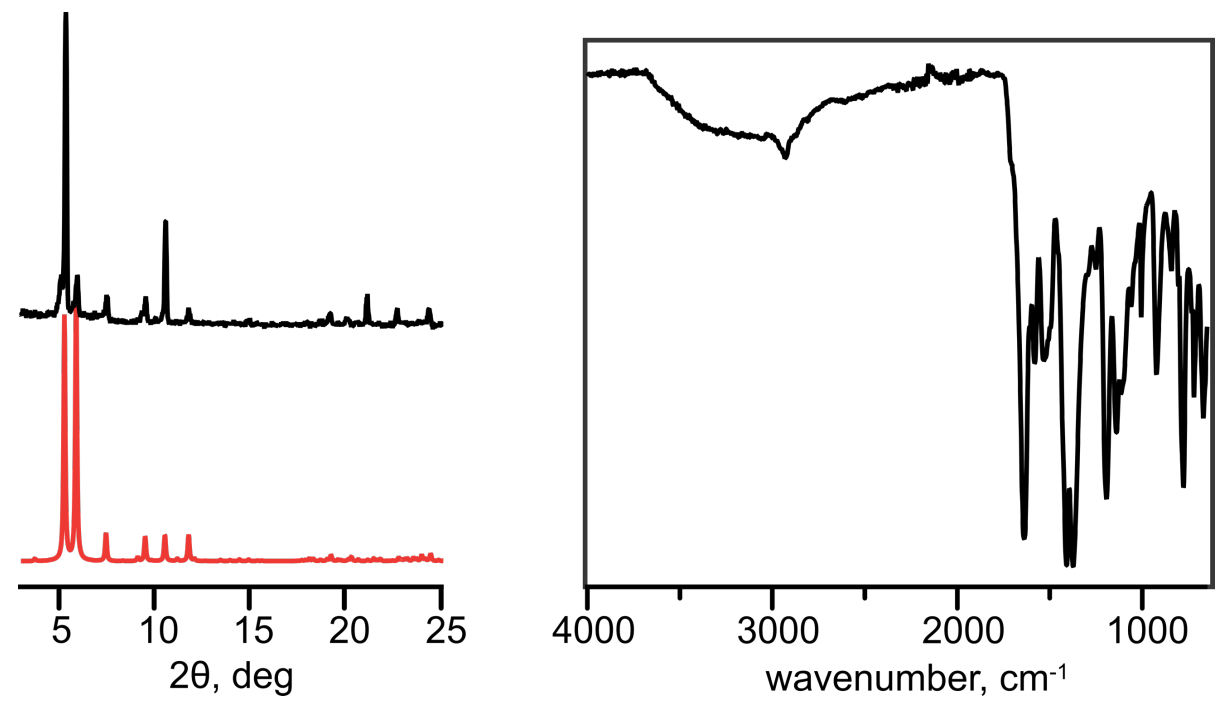

Figure S8. left) PXRD patterns of $\mathrm{U}_{6}-\mathrm{Me}_{2} \mathrm{BPDC}-\mathrm{TFA}-10$ : simulated (red) and as-synthesized (black). (right) FTIR spectrum of $\mathrm{U}_{6}-\mathrm{Me}_{2} \mathrm{BPDC}-\mathrm{TFA}-10$. 

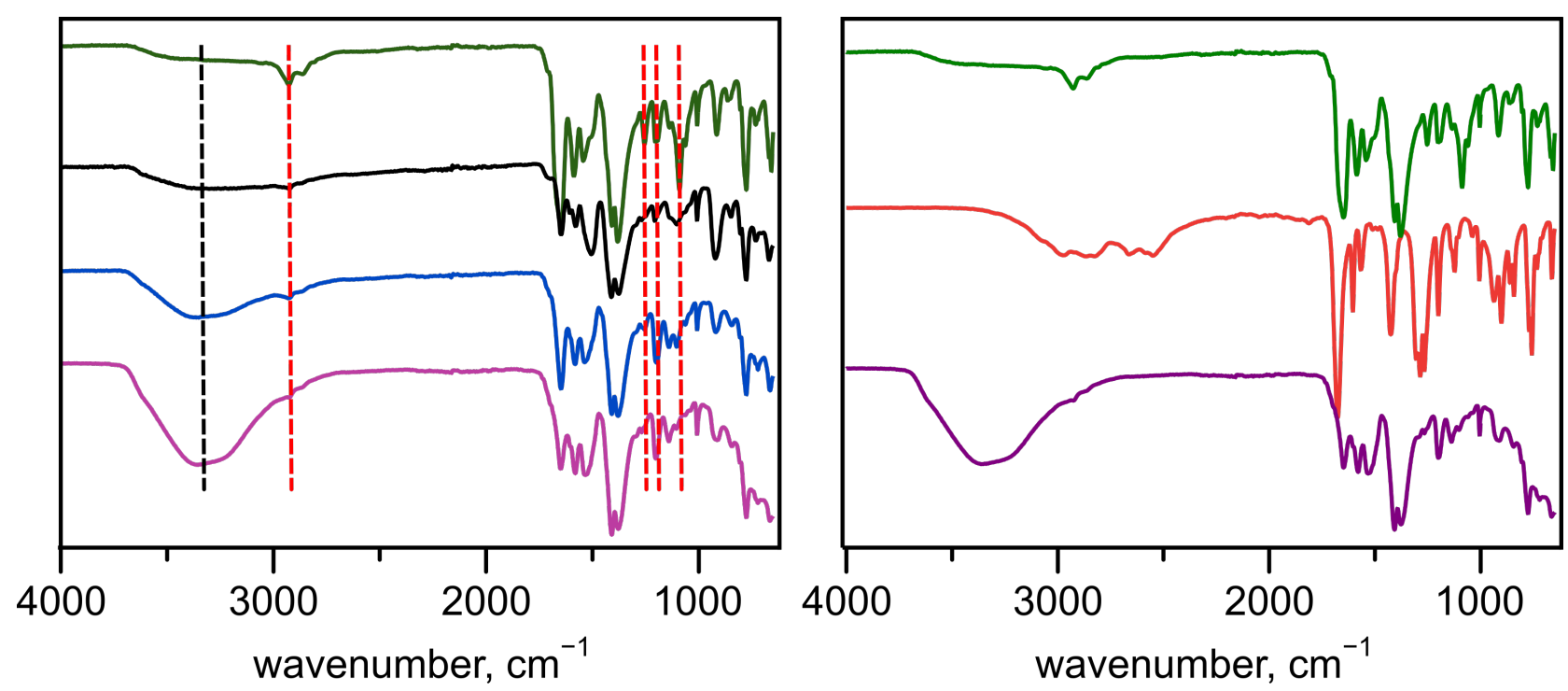

Figure S9. (left) FTIR spectra of $\mathrm{U}_{6}-\mathrm{Me}_{2} \mathrm{BPDC}-8$ after exposure to water for seven days (purple), after exposure to water for four days (blue), after exposure to water for 16 hours (black), and assynthesized (green). The black and red dashed lines show the increasing intensities of the $v(\mathrm{O}-\mathrm{H})$ band at $3400 \mathrm{~cm}^{-1}$ corresponding to water, and the decreasing intensities of bands $2927 \mathrm{~cm}^{-1}, 1254$ $\mathrm{cm}^{-1}, 1137 \mathrm{~cm}^{-1}$, and $1090 \mathrm{~cm}^{-1}$ corresponding to the DMF respectively. (right) FTIR spectra of $\mathrm{U}_{6}-\mathrm{Me}_{2} \mathrm{BPDC}-8$ after exposure to water for seven days (purple), $\mathrm{H}_{2} \mathrm{Me}_{2} \mathrm{BPDC}$ linker (red), and $\mathrm{U}_{6}-\mathrm{Me}_{2} \mathrm{BPDC}-8$ as-synthesized (green).
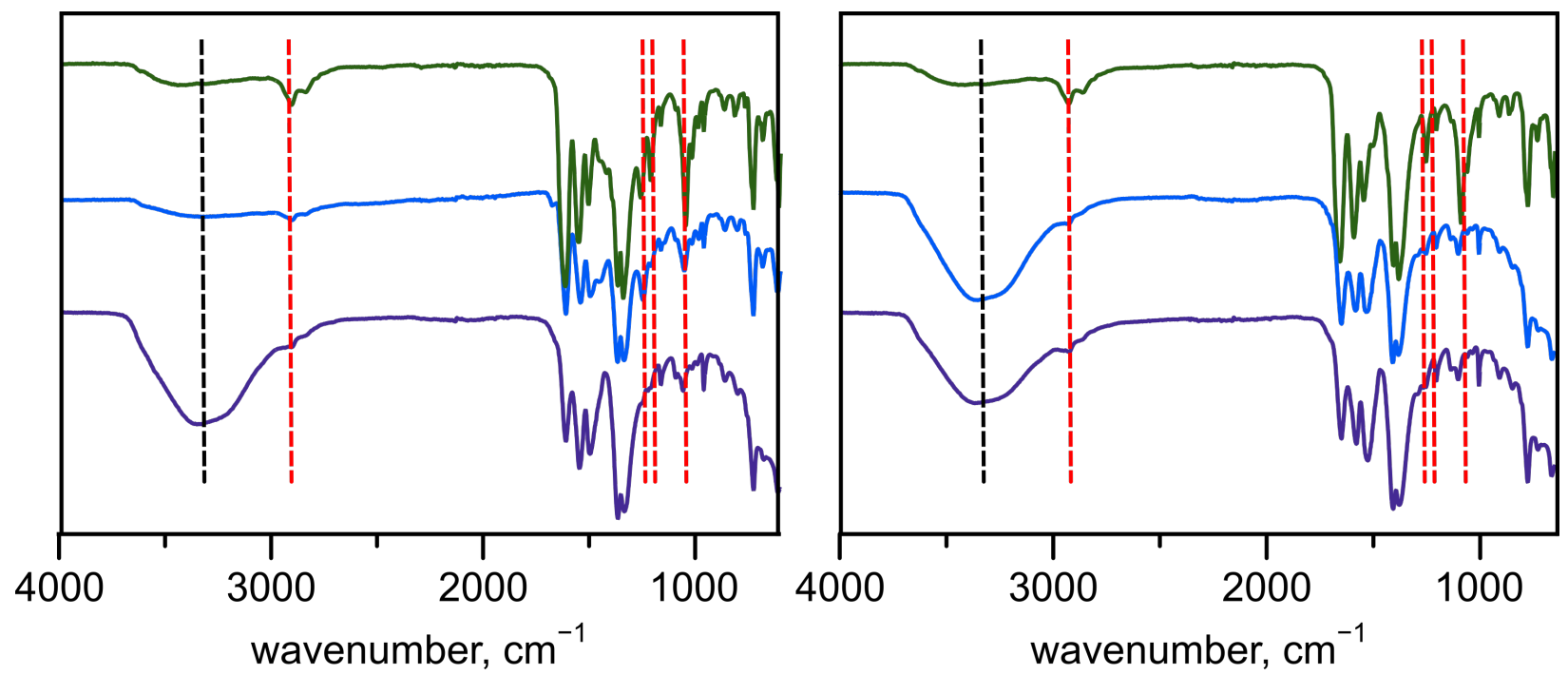

Figure S10. (left) FTIR spectra of $\mathrm{Th}_{6}-\mathrm{Me}_{2} \mathrm{BPDC}-8$ after exposure to water for three months (purple), after exposure to water for one hour (blue), and as-synthesized (green). (right) FTIR spectra of $\mathrm{Th}_{6}-\mathrm{Me}_{2} \mathrm{BPDC}-\mathrm{NO}_{3}-10$ after exposure to water for 11 days (purple), after exposure to water for one day (blue), and as-synthesized (green). The black and red dashed lines show the increasing intensities of the $v(\mathrm{O}-\mathrm{H})$ band at $3400 \mathrm{~cm}^{-1}$ corresponding to water, and the decreasing intensities of bands $2927 \mathrm{~cm}^{-1}, 1254 \mathrm{~cm}^{-1}, 1137 \mathrm{~cm}^{-1}$, and $1090 \mathrm{~cm}^{-1}$ corresponding to the DMF respectively. 

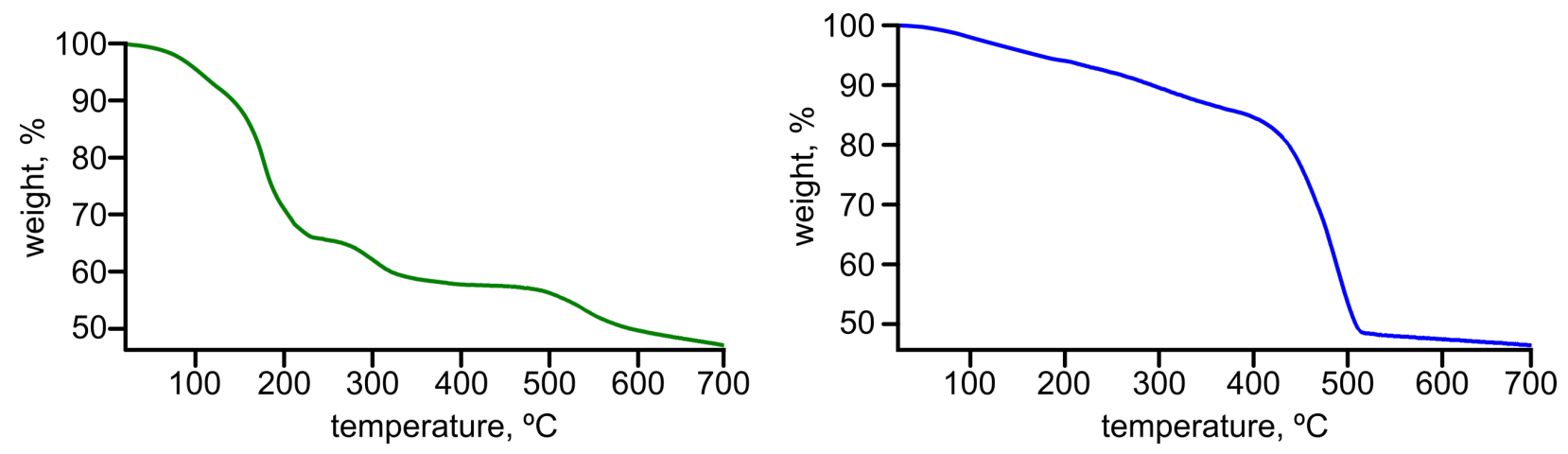

Figure S11. Thermogravimetric analysis plots of (left $) \mathrm{Th}_{6}-\mathrm{Me}_{2} \mathrm{BPDC}-8$ and (right) $\mathrm{Th}_{6}-$ $\mathrm{Me}_{2} \mathrm{BPDC}-8$-water.
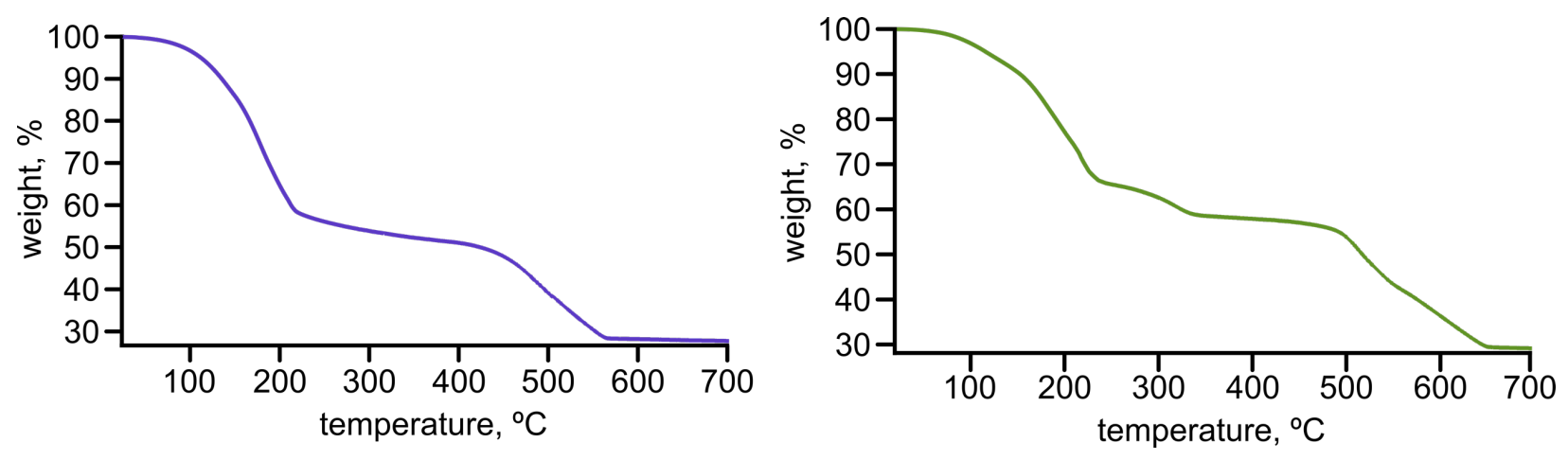

Figure S12. Thermogravimetric analysis plots of $\mathrm{Th}_{6}-\mathrm{Me}_{2} \mathrm{BPDC}-\mathrm{NO}_{3}-10$ (left) and $\mathrm{Th}_{6}-\mathrm{BPDC}-$ 12 (right). 

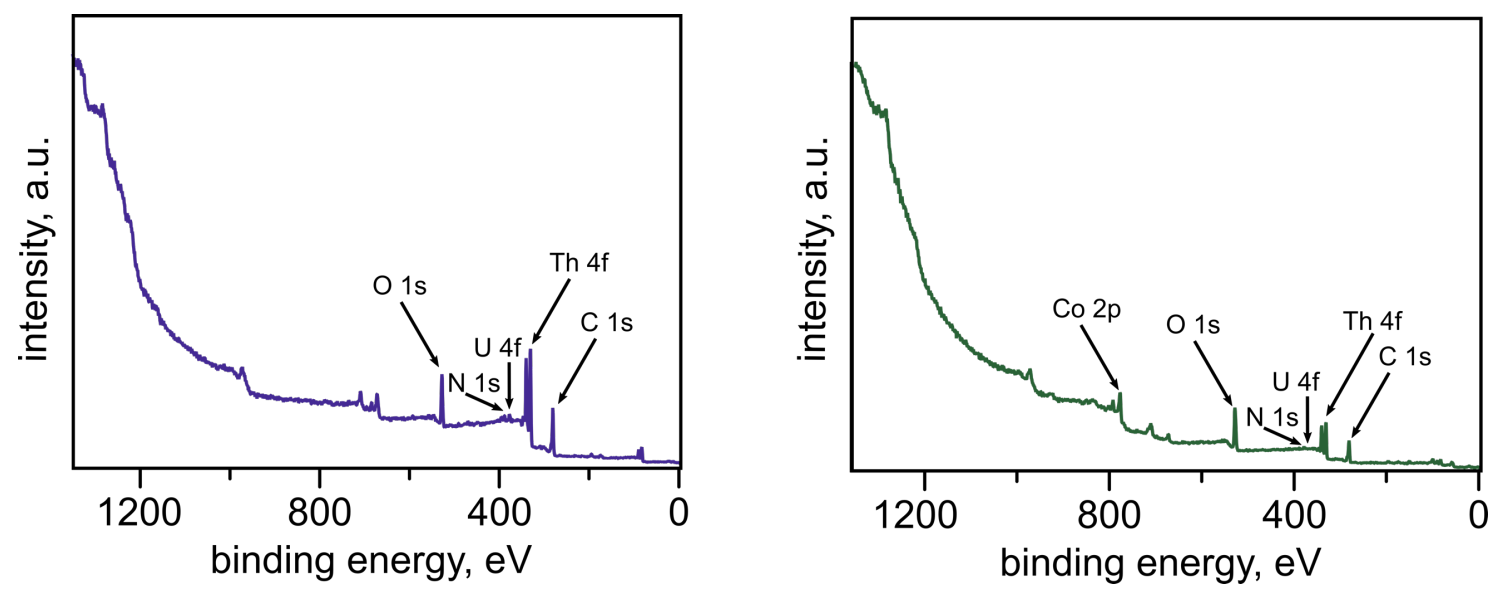

Figure S13. XPS survey scan of (left) $\mathrm{Th}_{4.77} \mathrm{U}_{1.23}-\mathrm{Me}_{2} \mathrm{BPDC}-8$ (U/Th-8) and (right) $\mathrm{Th}_{4.77} \mathrm{U}_{1.23} \mathrm{Co}_{3}-\mathrm{Me}_{2} \mathrm{BPDC}-8$ (U/Th-8-Co).

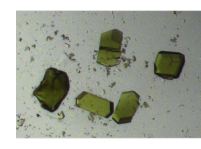

U-8

(a)

)

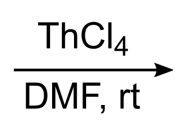

DMF, rt

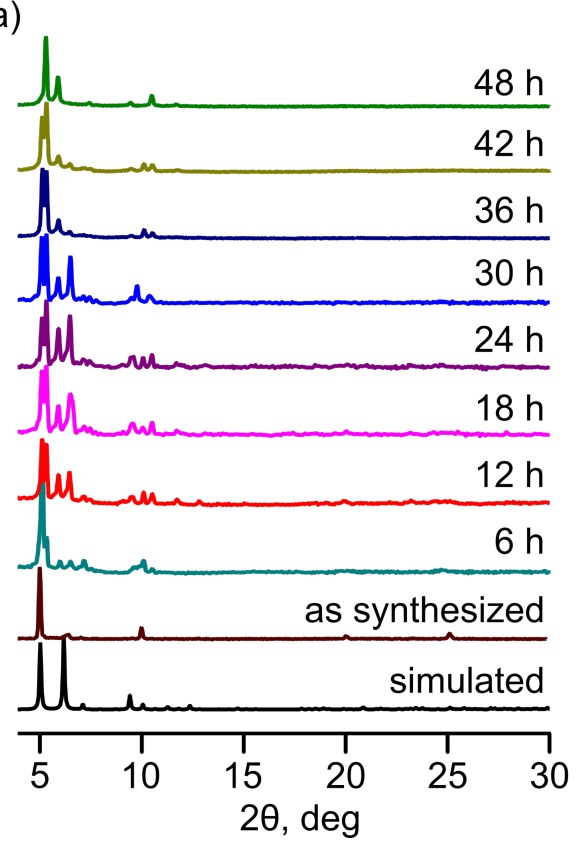

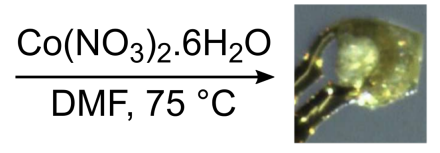

U/Th-Co-8

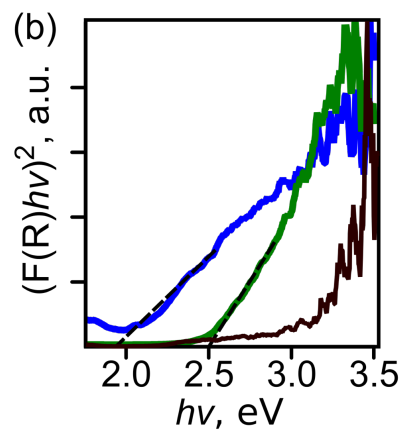

(c)

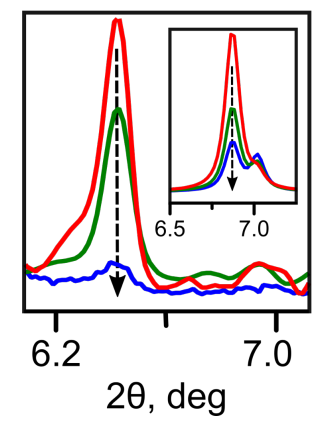

Figure S14. (top) Photographs of single crystals of $\mathrm{U}_{6}-\mathrm{Me}_{2} \mathrm{BPDC}-8, \mathrm{U}_{1.23} \mathrm{Th}_{4.77}-\mathrm{Me}_{2} \mathrm{BPDC}-8$ (U/Th-8), and $\mathrm{U}_{1.23} \mathrm{Th}_{4.77} \mathrm{Co}_{3}-\mathrm{Me}_{2} \mathrm{BPDC}-8$ (U/Th-Co). (a) PXRD patterns demonstrating the

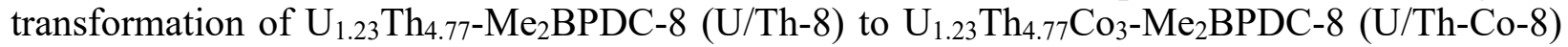
as a function of time. (b) Tauc plots of $\mathrm{Th}_{6}-\mathrm{Me}_{2} \mathrm{BPDC}-8$ (brown), $\mathrm{Th}_{4.77} \mathrm{U}_{1.23}-\mathrm{Me}_{2} \mathrm{BPDC}-8$ (green) and $\mathrm{Th}_{4.77} \mathrm{U}_{1.23} \mathrm{Co}_{3}-\mathrm{Me}_{2} \mathrm{BPDC}-8$ (blue). (c) PXRD patterns of U/Th-8 to U/Th-Co-8 after 24 hours (red), after 30 hours (green) and after 42 hours (blue). Inset shows a part of the calculated PXRD patterns of $\mathrm{Th}_{6}-\mathrm{Me}_{2} \mathrm{BPDC}-8$ ( $0 \%$ cobalt occupancy (red), $25 \%$ cobalt occupancy (green), and $50 \%$ cobalt occupancy SBU (blue)). 

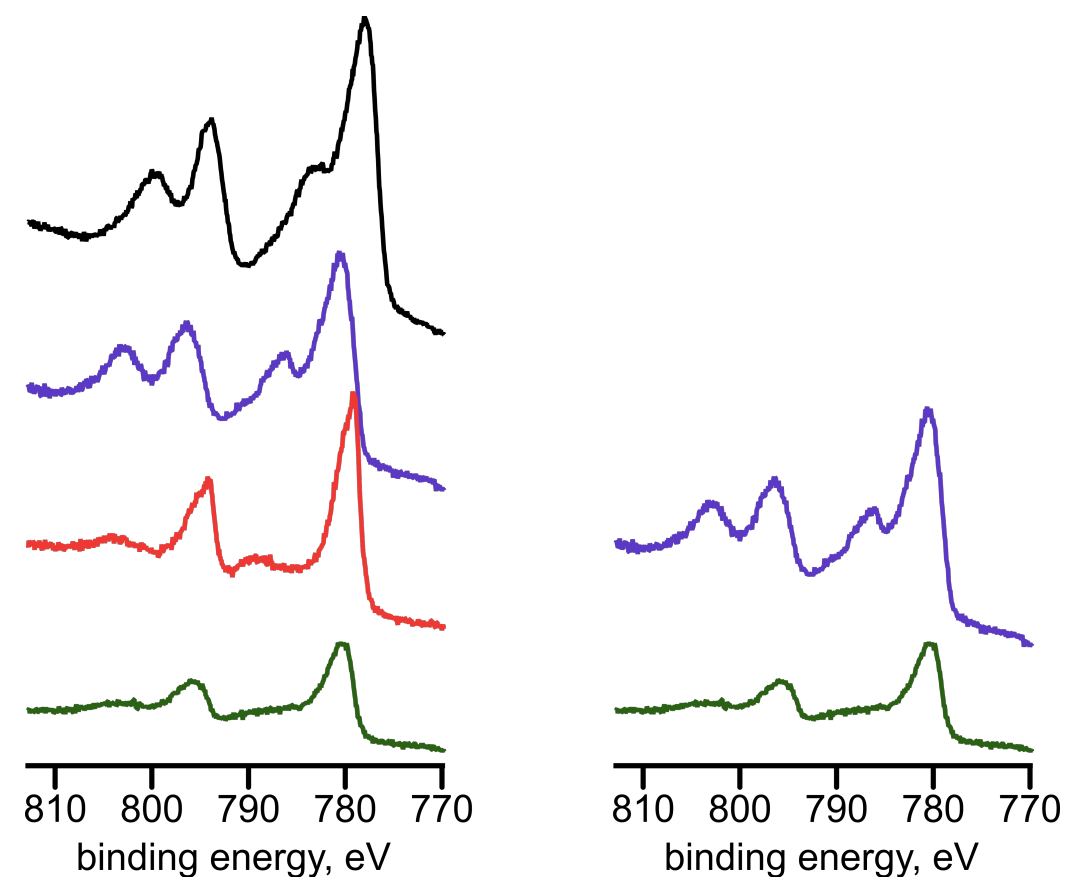

Figure S15. XPS data showing the $\mathrm{Co}(2 \mathrm{p})$ region for $(l e f t) \mathrm{Th}_{4.77} \mathrm{U}_{1.23} \mathrm{Co}_{3}-\mathrm{Me}_{2} \mathrm{BPDC}-8$ (green), $\mathrm{Co}_{3} \mathrm{O}_{4}$ (red), $\mathrm{CoO}$ (purple), and $\mathrm{Co}(\mathrm{OH})_{2}$ (black). (right) The $\mathrm{Co}(2 \mathrm{p})$ region for $\mathrm{Th}_{4.77} \mathrm{U}_{1.23} \mathrm{Co}_{3}-$ $\mathrm{Me}_{2} \mathrm{BPDC}-8$ (green) and $\mathrm{CoO}$ (purple) emphasizing the difference in the XPS spectra of coordinated $\mathrm{Co}^{2+}$ versus cobalt in different oxides and hydroxide.
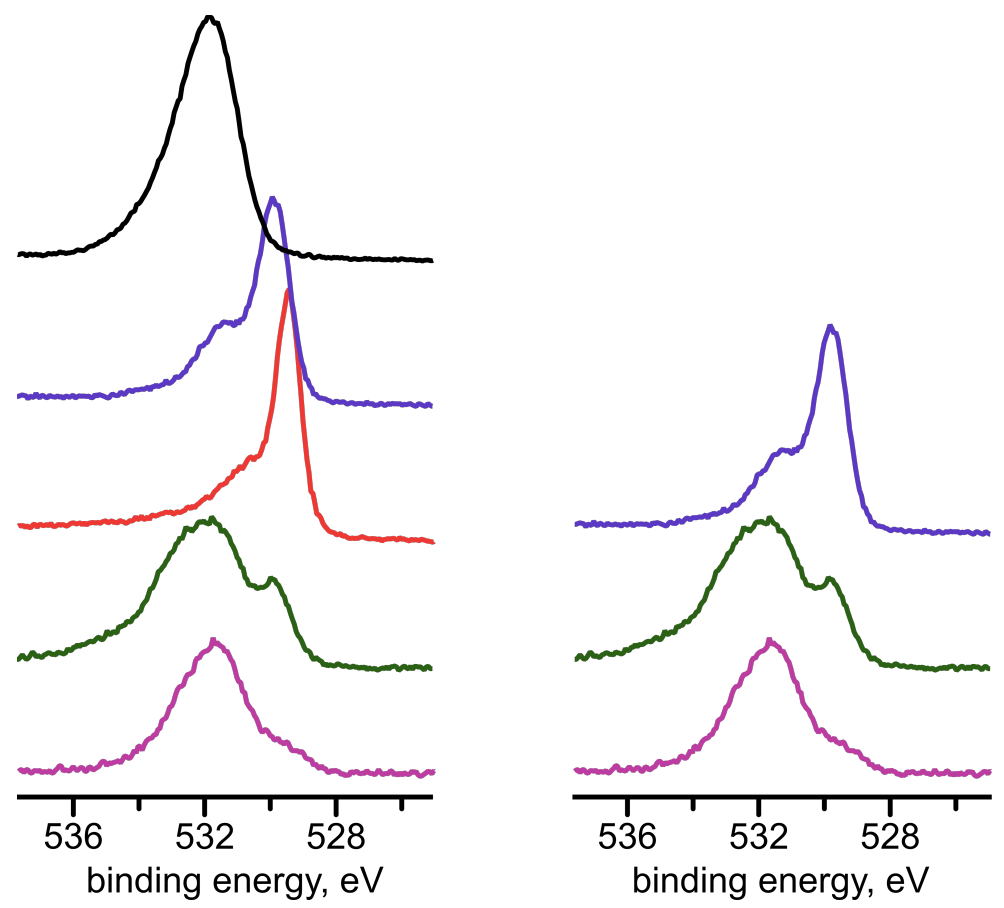

Figure S16. XPS data showing the $\mathrm{O}(1 \mathrm{~s})$ region for $($ left $) \mathrm{Th}_{4.77} \mathrm{U}_{1.23}-\mathrm{Me}_{2} \mathrm{BPDC}-8$ (U/Th-8) (pink), $\mathrm{Th}_{4.77} \mathrm{U}_{1.23} \mathrm{Co}_{3}-\mathrm{Me}_{2} \mathrm{BPDC}-8$ (U/Th-8-Co) (green), $\mathrm{Co}_{3} \mathrm{O}_{4}$ (red), $\mathrm{CoO}$ (purple), and $\mathrm{Co}(\mathrm{OH})_{2}$ (black). (right) The $\mathrm{O}(1 \mathrm{~s})$ region for $\mathrm{U} / \mathrm{Th}-8$ (pink), U/Th-8-Co (green), and $\mathrm{CoO}$ (purple). 

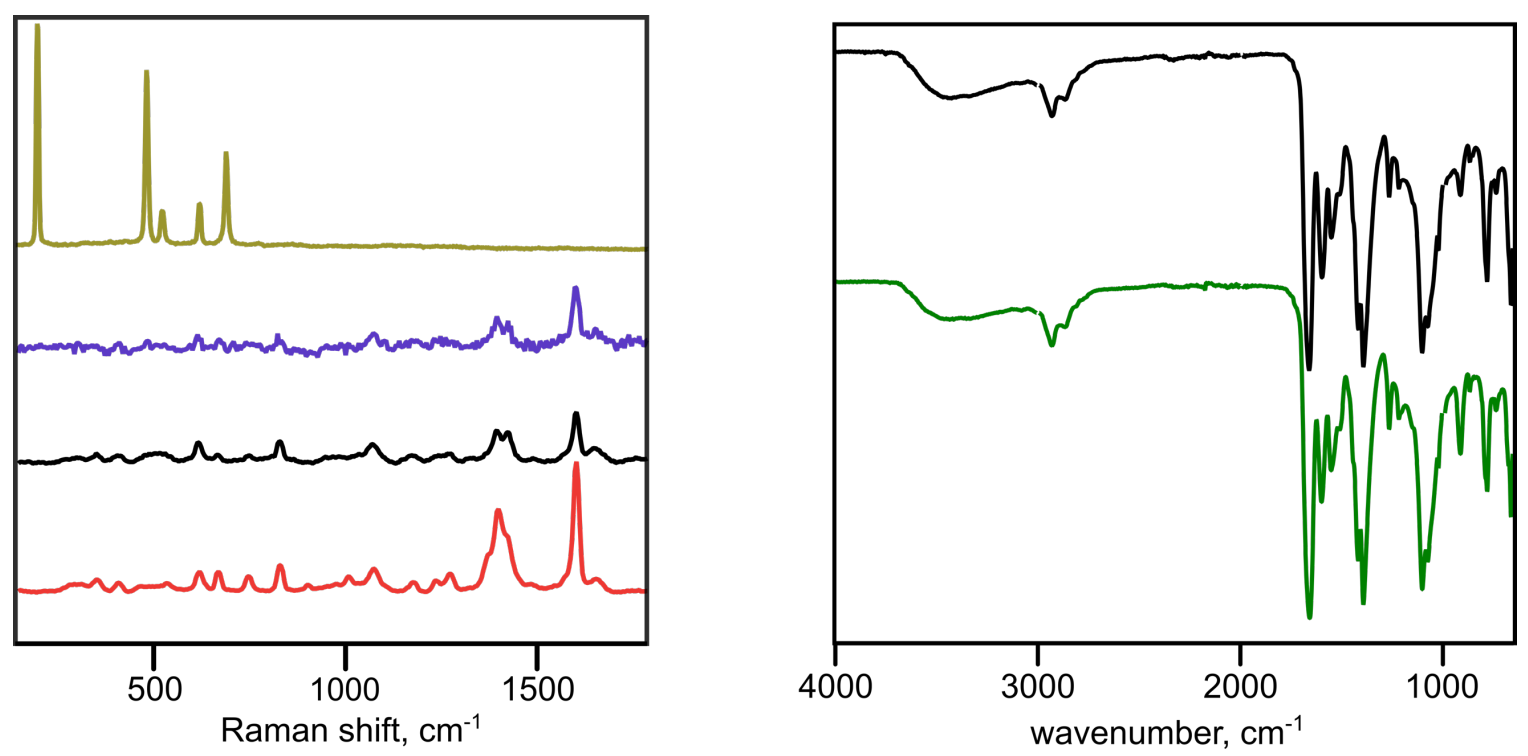

Figure S17. (left) Raman spectra of $\mathrm{Th}_{6}-\mathrm{Me}_{2} \mathrm{BPDC}-8$ (red), $\mathrm{Th}_{4.77} \mathrm{U}_{1.23}-\mathrm{Me}_{2} \mathrm{BPDC}-8$ (black), $\mathrm{Th}_{4.77} \mathrm{U}_{1.23} \mathrm{Co}_{3}-\mathrm{Me}_{2} \mathrm{BPDC}-8$ (purple), and $\mathrm{Co}_{3} \mathrm{O}_{4}$ (dark yellow). (right) FTIR spectra of $\mathrm{Th}_{4.77} \mathrm{U}_{1.23^{-}}$ $\mathrm{Me}_{2} \mathrm{BPDC}-8$ (green) and $\mathrm{Th}_{4.77} \mathrm{U}_{1.23} \mathrm{Co}_{3}-\mathrm{Me}_{2} \mathrm{BPDC}-8$ (black).
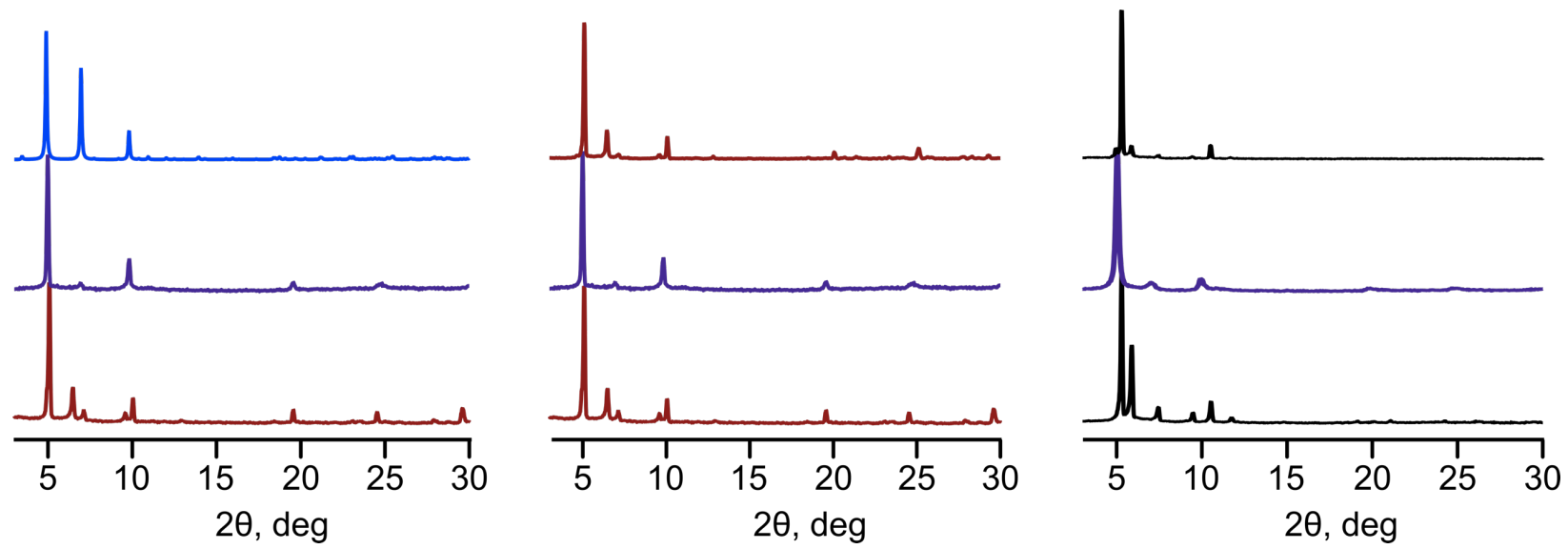

Figure S18 (left) PXRD patterns of $\mathrm{Th}_{6}-\mathrm{Me}_{2} \mathrm{BPDC}-8 \mathrm{a}$ : as-synthesized (brown), after being in water for one week (purple), and simulated $\mathrm{Th}_{6}-\mathrm{Me}_{2} \mathrm{BPDC}-8 \mathrm{~b}$ (blue). (middle) PXRD patterns of $\mathrm{Th}_{6}-\mathrm{Me}_{2} \mathrm{BPDC}-8$ : as-synthesized (brown), after being in water for one week (purple), and after reimmersion in DMF after water treatment (brown). (right) PXRD patterns of $\mathrm{Th}_{6}-\mathrm{Me}_{2} \mathrm{BPDC}-\mathrm{NO}_{3}-$ 10: as-synthesized (black), after being in water for one week (purple), and re-immersed in DMF after water treatment (black). 

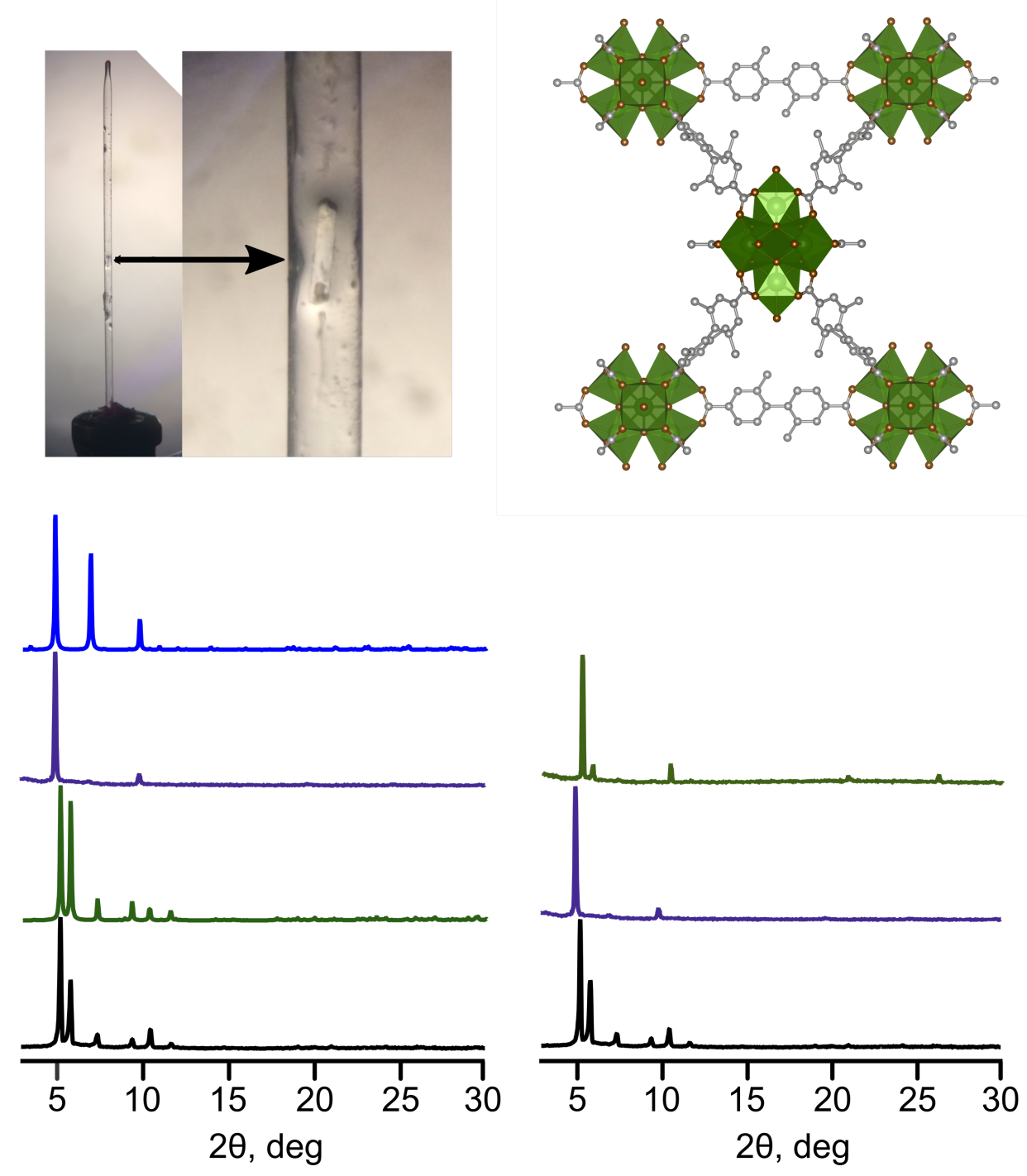

Figure S19. (top, left) Photograph of a $\mathrm{Th}_{6}-\mathrm{Me}_{2} \mathrm{BPDC}-\mathrm{NO}_{3}-10$ crystal in methanol $(\mathrm{MeOH})$ mounted in a capillary tube. (top, right) Single-crystal X-ray structure of Th6-Me $\mathrm{MPPC}_{2} \mathrm{NO}_{3}-10$ in $\mathrm{MeOH}$. The green, brown, and gray spheres represent the $\mathrm{Th}, \mathrm{O}$, and $\mathrm{C}$ atoms, respectively. The hydrogen atoms were omitted for clarity. (bottom, left) PXRD patterns of $\mathrm{Th}_{6}-\mathrm{Me}_{2} \mathrm{BPDC}-\mathrm{NO}_{3}-10$ as-synthesized (black), Th6- $\mathrm{Me}_{2} \mathrm{BPDC}-\mathrm{NO}_{3}-10-\mathrm{MeOH}$ simulated (green), Th6- $\mathrm{Me}_{2} \mathrm{BPDC}-\mathrm{NO}_{3}-$ $10-\mathrm{MeOH}$ as-synthesized (purple), and $\mathrm{Th}_{6}-\mathrm{Me}_{2} \mathrm{BPDC}-8 \mathrm{~b}$ simulated (blue). (bottom, right) PXRD patterns of $\mathrm{Th}_{6}-\mathrm{Me}_{2} \mathrm{BPDC}-\mathrm{NO}_{3}-10$ : as-synthesized (black), after exposure to $\mathrm{MeOH}$ (purple), and after re-immersion in DMF (green). 


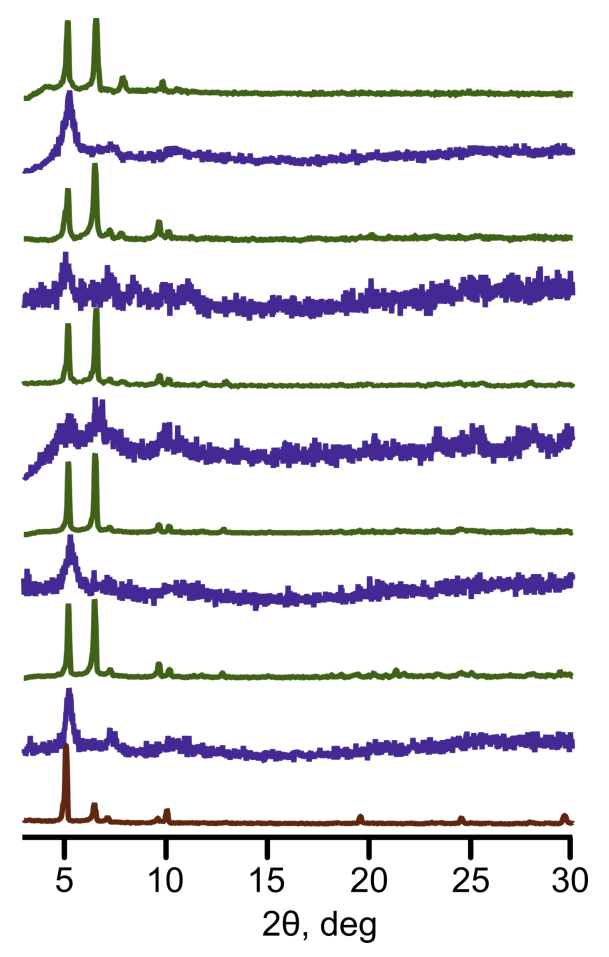

Figure S20. PXRD patterns of $\mathrm{Th}_{6}-\mathrm{Me}_{2} \mathrm{BPDC}-8$ during five structural cycles: as-synthesized (brown), after $72 \mathrm{~h}$ exposure to $\mathrm{MeOH}$ (purple), and after re-immersion in DMF (green).

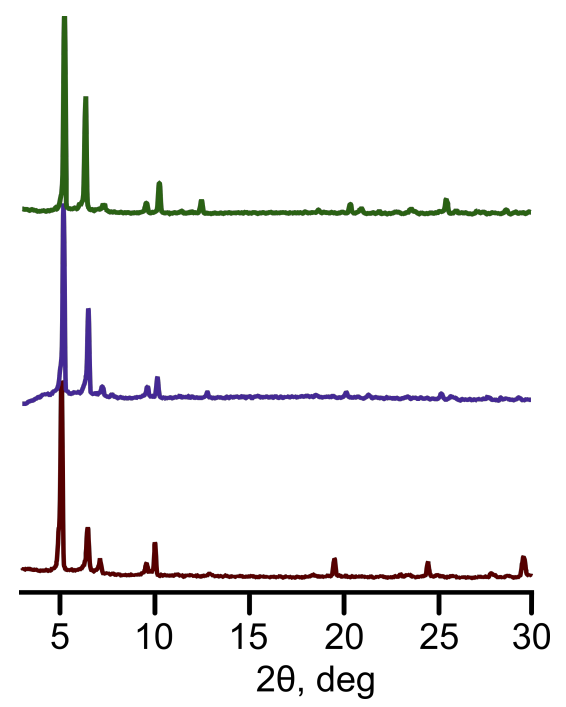

Figure S21. PXRD patterns of: $\mathrm{Th}_{6}-\mathrm{Me}_{2} \mathrm{BPDC}-8$ as-synthesized (brown), $\mathrm{Th}_{6}-\mathrm{Me}_{2} \mathrm{BPDC}-8$ after one-week exposure to dimethylacetamide (DMA) (purple), and after one-week exposure to diethylformamide (DEF) (green). 

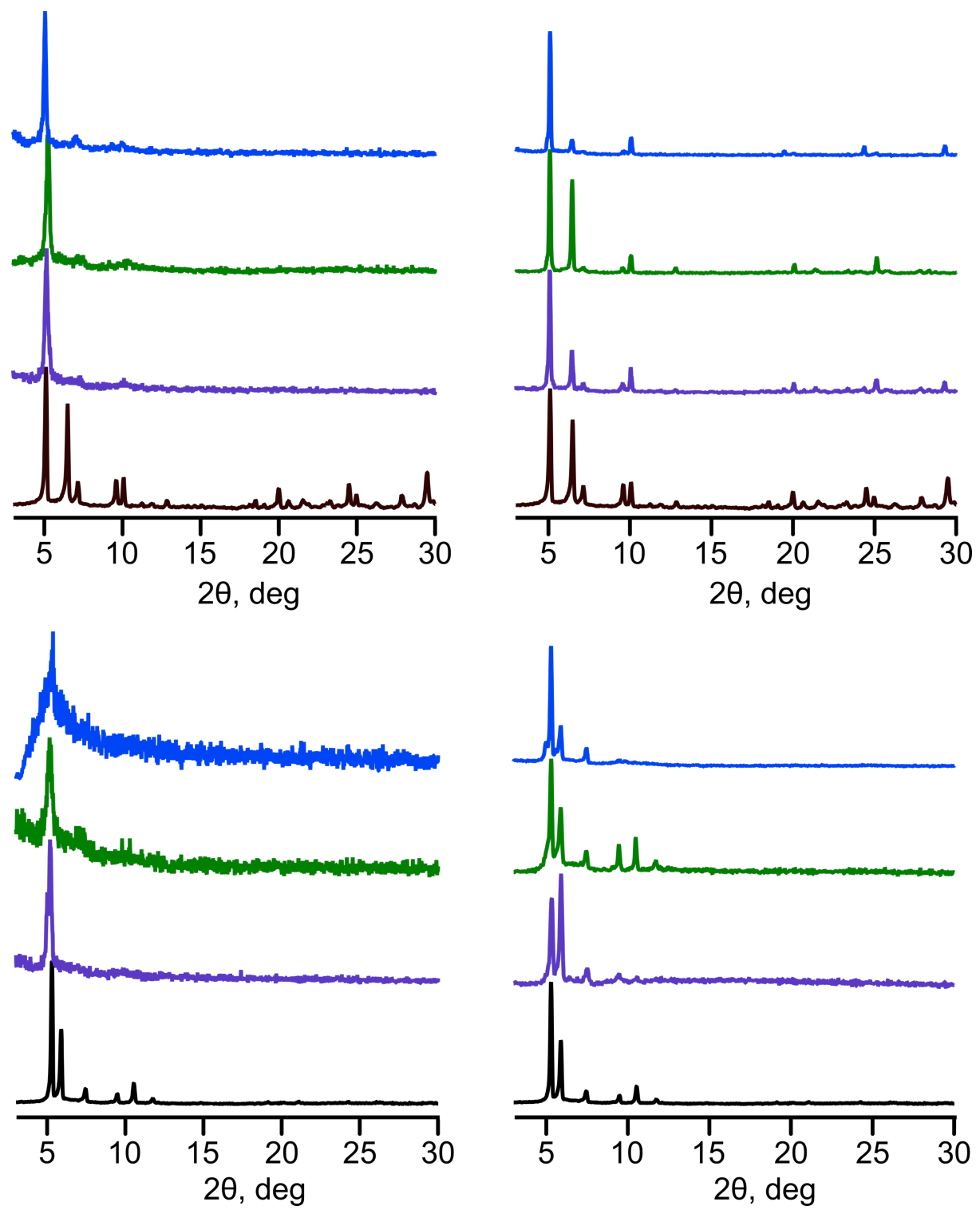

Figure S22. (top, left) PXRD patterns of $\mathrm{Th}_{6}-\mathrm{Me}_{2} \mathrm{BPDC}-8$ : as-synthesized (brown), after dichloromethane for $72 \mathrm{~h}$ (purple), after chloroform for $72 \mathrm{~h}$ (green), and after hexanes for $72 \mathrm{~h}$ (blue). (top, right) PXRD patterns of $\mathrm{Th}_{6}-\mathrm{Me}_{2} \mathrm{BPDC}-8$ : as-synthesized (brown), re-immersed in DMF after $24 \mathrm{~h}$ exposure to dichloromethane (purple), chloroform (green), and hexanes (blue). (bottom, left) PXRD patterns of $\mathrm{Th}_{6}-\mathrm{Me}_{2} \mathrm{BPDC}-\mathrm{NO}_{3}-10$ : as-synthesized (black), after dichloromethane for $72 \mathrm{~h}$ (purple), after chloroform for $72 \mathrm{~h}$ (green), and after hexanes for $72 \mathrm{~h}$ (black). (bottom, right) PXRD patterns of $\mathrm{Th}_{6}-\mathrm{Me}_{2} \mathrm{BPDC}-\mathrm{NO}_{3}-10$ : as-synthesized (black), reimmersed in DMF after $24 \mathrm{~h}$ exposure to dichloromethane (purple), chloroform (green), and hexanes (blue). 

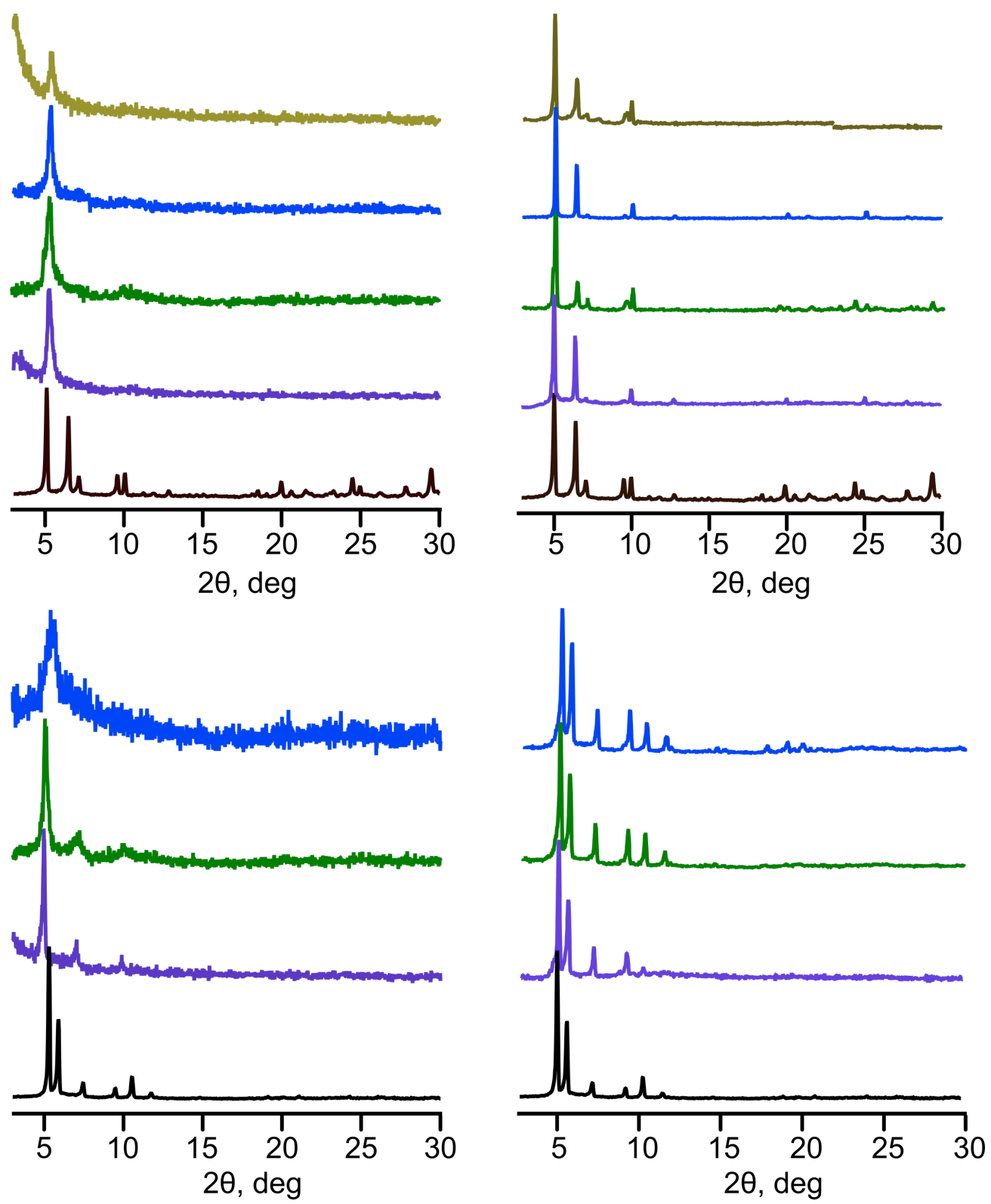

Figure S23. (top, left) PXRD patterns of $\mathrm{Th}_{6}-\mathrm{Me}_{2} \mathrm{BPDC}-8$ : as-synthesized (brown), after exposure to acetonitrile (purple), tetrahydrofuran (green), ethanol (blue), and methanol (deep yellow). The $\mathrm{Th}_{6}-\mathrm{Me}_{2} \mathrm{BPDC}-8 \mathrm{MOF}$ was exposed to solvents for $72 \mathrm{~h}$. (top, right) PXRD patterns of $\mathrm{Th}_{6^{-}}$ $\mathrm{Me}_{2} \mathrm{BPDC}-8$ : as-synthesized (brown), re-immersed in DMF after $24 \mathrm{~h}$ exposure to acetonitrile (purple), after $24 \mathrm{~h}$ exposure to tetrahydrofuran (green), after $24 \mathrm{~h}$ exposure to ethanol (blue), and after $24 \mathrm{~h}$ exposure to methanol (deep yellow). (bottom, left) PXRD patterns of $\mathrm{Th}_{6}-\mathrm{Me}_{2} \mathrm{BPDC}$ $\mathrm{NO}_{3}$-10: as-synthesized (black), after exposure to ethanol (purple), tetrahydrofuran (green), and acetonitrile (blue). The $\mathrm{Th}_{6}-\mathrm{Me}_{2} \mathrm{BPDC}-\mathrm{NO}_{3}-10$ was exposed to solvents for $72 \mathrm{~h}$. (bottom, right) PXRD patterns of $\mathrm{Th}_{6}-\mathrm{Me}_{2} \mathrm{BPDC}-\mathrm{NO}_{3}-10$ : as-synthesized (black), re-immersed in DMF after 24 $\mathrm{h}$ exposure to ethanol (purple), after $24 \mathrm{~h}$ exposure to tetrahydrofuran (green), and after $24 \mathrm{~h}$ exposure to acetonitrile (blue). 

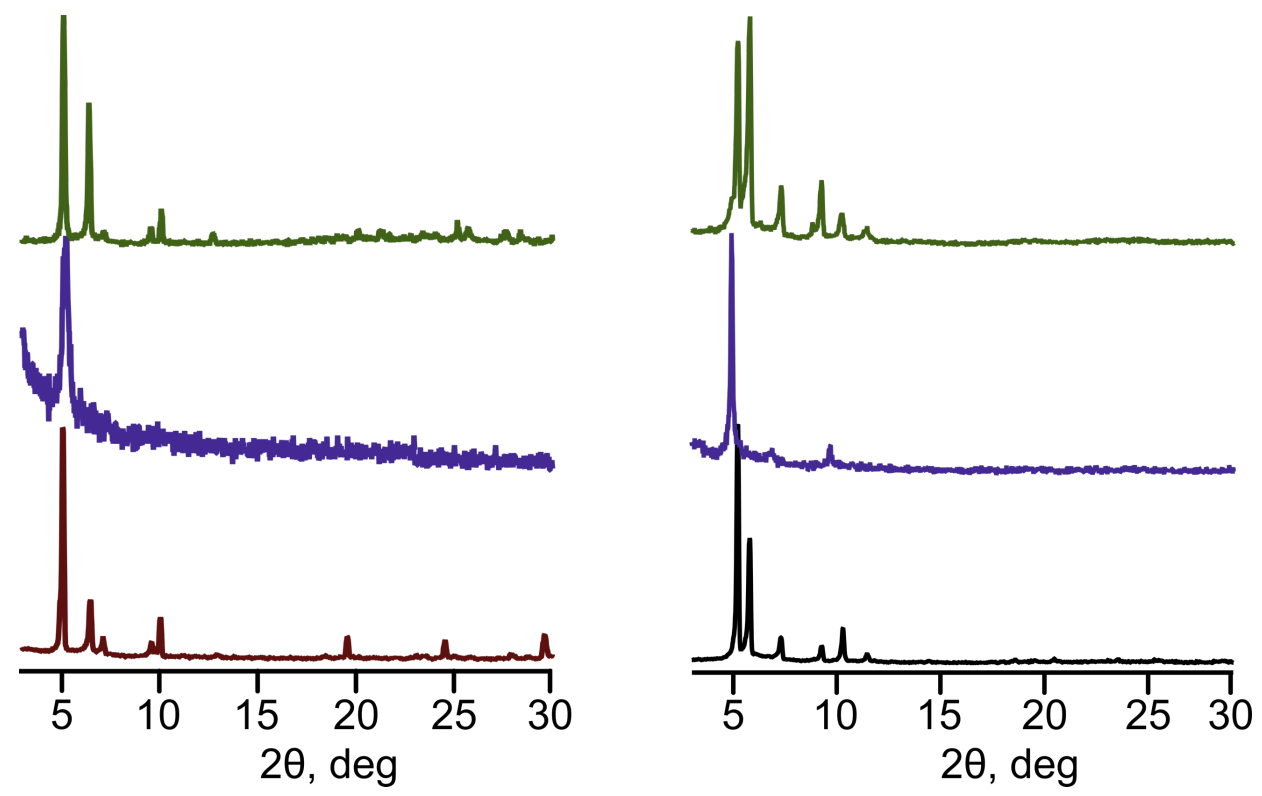

Figure S24. (left) PXRD patterns of Th $6-\mathrm{Me}_{2} \mathrm{BPDC}-8$ : as-synthesized (brown), after $72 \mathrm{~h}$ exposure to acetone (purple), and re-immersed in DMF (green). (right) PXRD patterns of $\mathrm{Th}_{6}-\mathrm{Me}_{2} \mathrm{BPDC}$ $\mathrm{NO}_{3}-10$ : as-synthesized (black), after $72 \mathrm{~h}$ exposure to acetone (purple), and re-immersed in DMF (green).
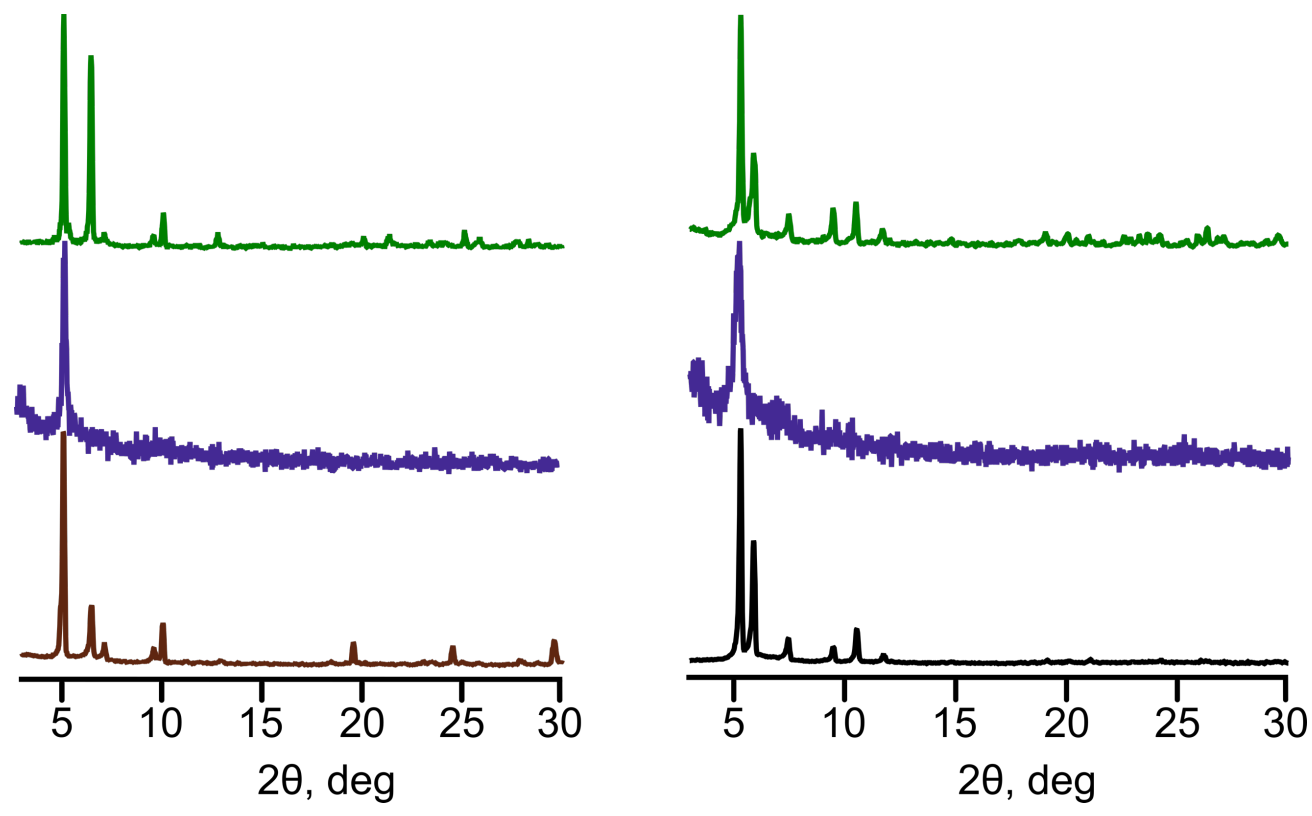

Figure S25. (left) PXRD patterns of $\mathrm{Th}_{6}-\mathrm{Me}_{2} \mathrm{BPDC}-8$ : as-synthesized (brown), after $72 \mathrm{~h}$ exposure to ethyl acetate (purple), and re-immersed in DMF (green). (right) PXRD patterns of Th6$\mathrm{Me}_{2} \mathrm{BPDC}-\mathrm{NO}_{3}-10$ : as-synthesized (black), after $72 \mathrm{~h}$ exposure to ethyl acetate (purple), and reimmersed in DMF (green). 

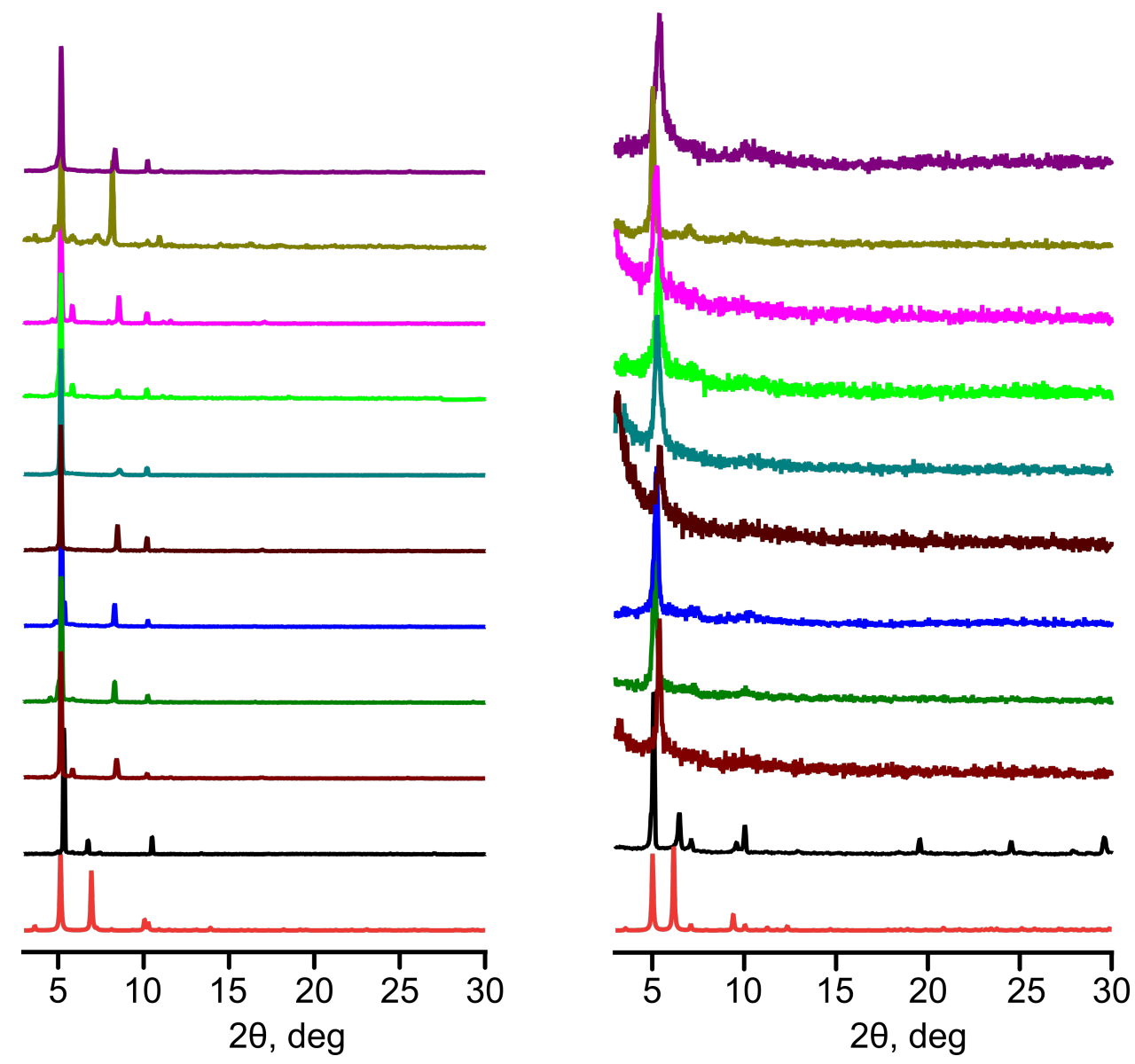

Figure S26. (left) PXRD patterns of $\mathrm{Zr}_{6}-\mathrm{Me}_{2} \mathrm{BPDC}-8:^{18}$ simulated (red), as-synthesized (black), and in solvents including ethyl acetate (dark red), dichloromethane (green), chloroform (blue), methanol (brown), ethanol (teal), acetonitrile (light green), acetone (pink), hexane (dark yellow), and tetrahydrofuran (purple) for $72 \mathrm{~h}$. (right) PXRD patterns of $\mathrm{Th}_{6}-\mathrm{Me}_{2} \mathrm{BPDC}-8$ : simulated (red), as-synthesized (black), and in different solvents including ethyl acetate (dark red), dichloromethane (green), chloroform (blue), methanol (brown), ethanol (teal), acetonitrile (light green), acetone (pink), hexane (dark yellow), and tetrahydrofuran (purple) for $72 \mathrm{~h}$. 


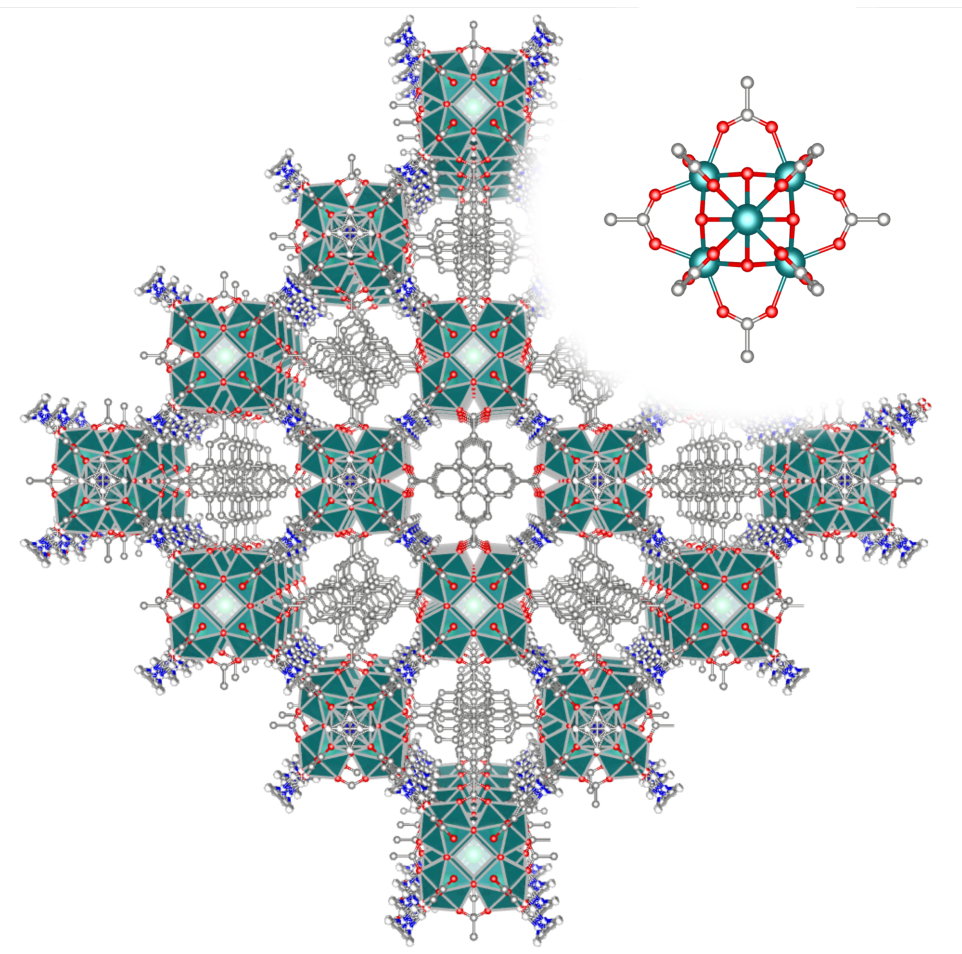

Figure S27. The single-crystal X-ray structure of $\mathrm{Th}_{6}$-BPDC-12. The secondary building unit is shown in the inset. The teal, red, gray, and blue spheres represent the $\mathrm{Th}, \mathrm{O}, \mathrm{C}$, and $\mathrm{N}$ atoms, respectively. Hydrogen atoms and non-coordinated solvent molecules were omitted for clarity.
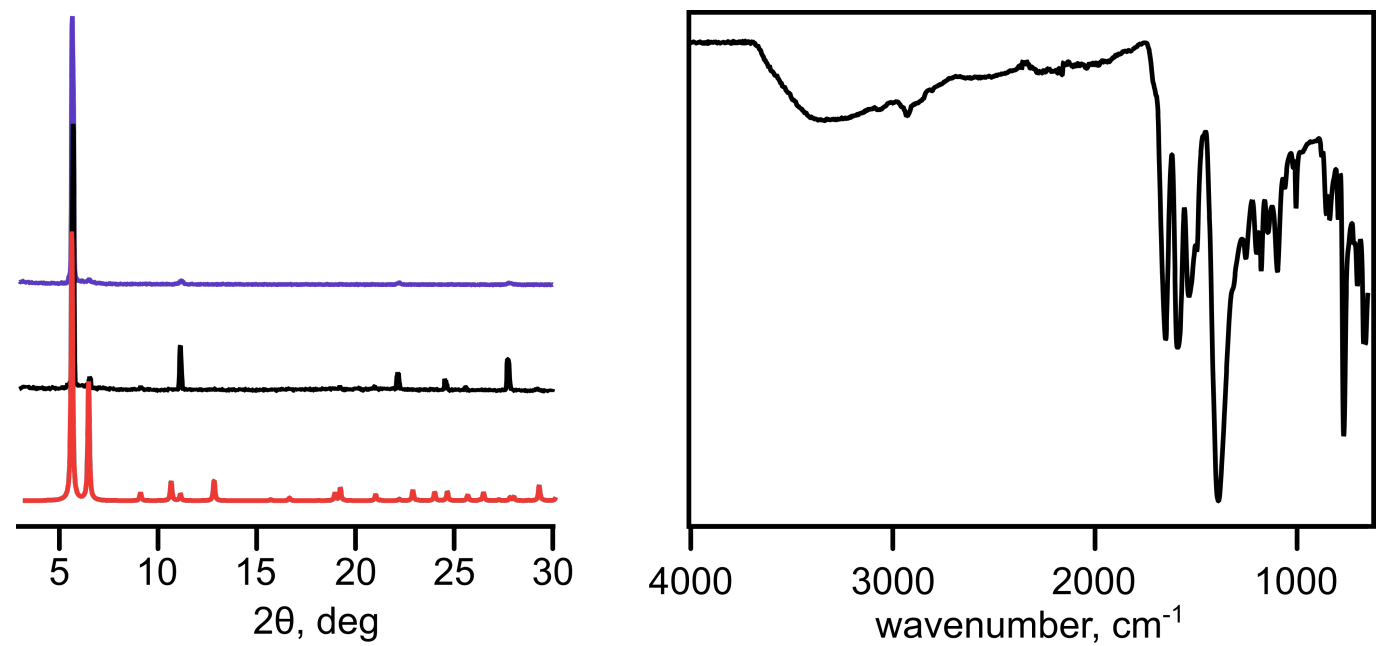

Figure S28. (left) PXRD patterns of $\mathrm{Th}_{6}$-BPDC-12: simulated (red), as-synthesized (black) and after exposed to water for one month (purple). (right) FTIR spectrum of Th6-BPDC-12. 

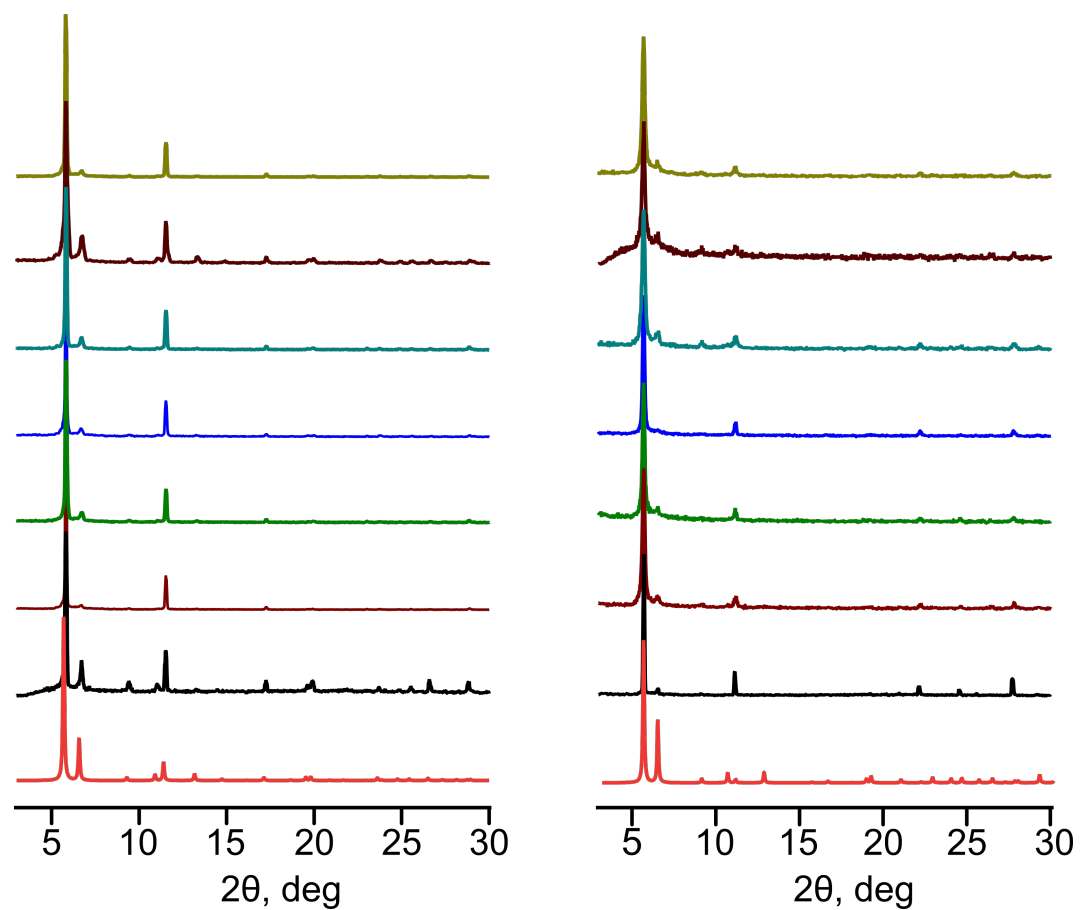

Figure S29. (left) PXRD patterns of $\mathrm{Zr}_{6}-\mathrm{BPDC}-12$ (UiO-67): ${ }^{19}$ simulated (red), as-synthesized (black), and in different solvents including ethyl acetate (dark red), dichloromethane (green), chloroform (blue), ethanol (teal), acetonitrile (brown), and acetone (dark yellow). (right) PXRD patterns of $\mathrm{Th}_{6}$-BPDC-12: simulated (red), as-synthesized (black), and in different solvents including ethyl acetate (dark red), dichloromethane (green), chloroform (blue), ethanol (teal), acetonitrile (brown), and acetone (dark yellow).
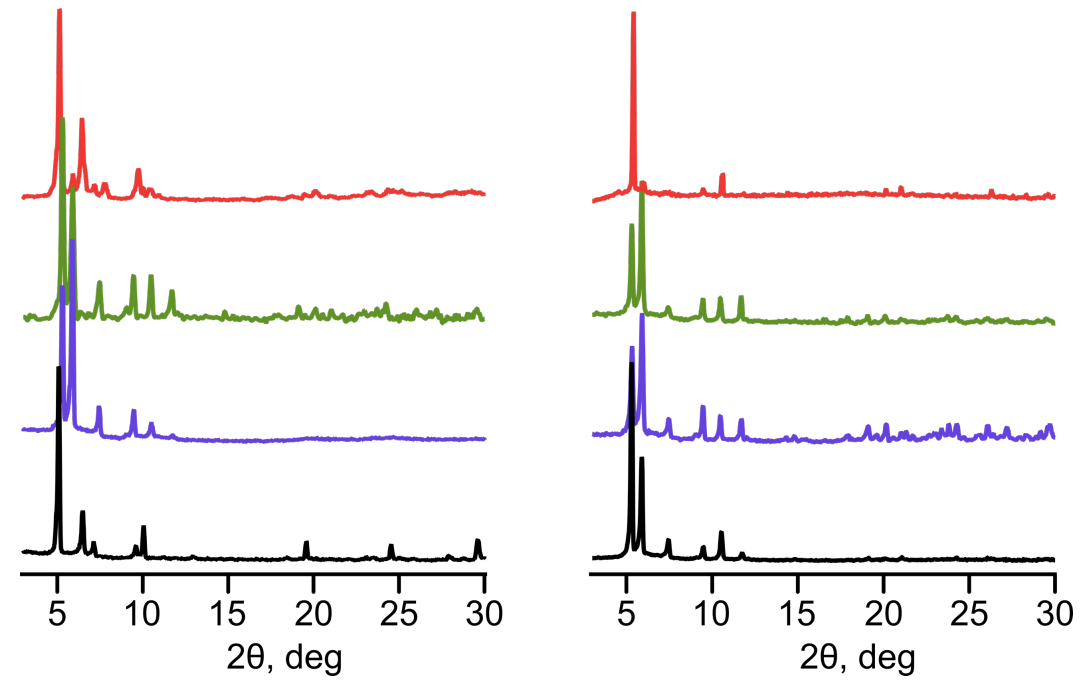

Figure S30. (left) PXRD patterns of as-synthesized Th6 $6 \mathrm{Me}_{2} \mathrm{BPDC}-8$ (black), as-synthesized Th $6^{-}$ $\mathrm{Me}_{2} \mathrm{BPDC}\left(\mathrm{Me}_{2} \mathrm{BPDC}\right.$ )-10 (purple), as-synthesized $\mathrm{Th}_{6}-\mathrm{Me}_{2} \mathrm{BPDC}\left(\mathrm{Me}_{2} \mathrm{TPDC}\right)-10$ (green), and as-synthesized Th ${ }_{6}-\mathrm{Me}_{2} \mathrm{BPDC}$ (“QPDC")-8 (red) [Listed MOFs prepared from $\mathrm{Th}_{6}-\mathrm{Me}_{2} \mathrm{BPDC}-8$ ]. (right) PXRD patterns of as-synthesized $\mathrm{Th}_{6}-\mathrm{Me}_{2} \mathrm{BPDC}-\mathrm{NO}_{3}-10$ (black), as-synthesized $\mathrm{Th}_{6-}$ $\mathrm{Me}_{2} \mathrm{BPDC}$ ("Me 2 BPDC")-10 (purple), as-synthesized $\mathrm{Th}_{6}-\mathrm{Me}_{2} \mathrm{BPDC}\left(\mathrm{Me}_{2} \mathrm{TPDC}\right)-12$ (green), and as-synthesized $\mathrm{Th}_{6}-\mathrm{Me}_{2} \mathrm{BPDC}$ ("QPDC")-10 (red) [Listed MOFs prepared from $\mathrm{Th}_{6}-\mathrm{Me}_{2} \mathrm{BPDC}$ $\left.\mathrm{NO}_{3}-10\right]$. 

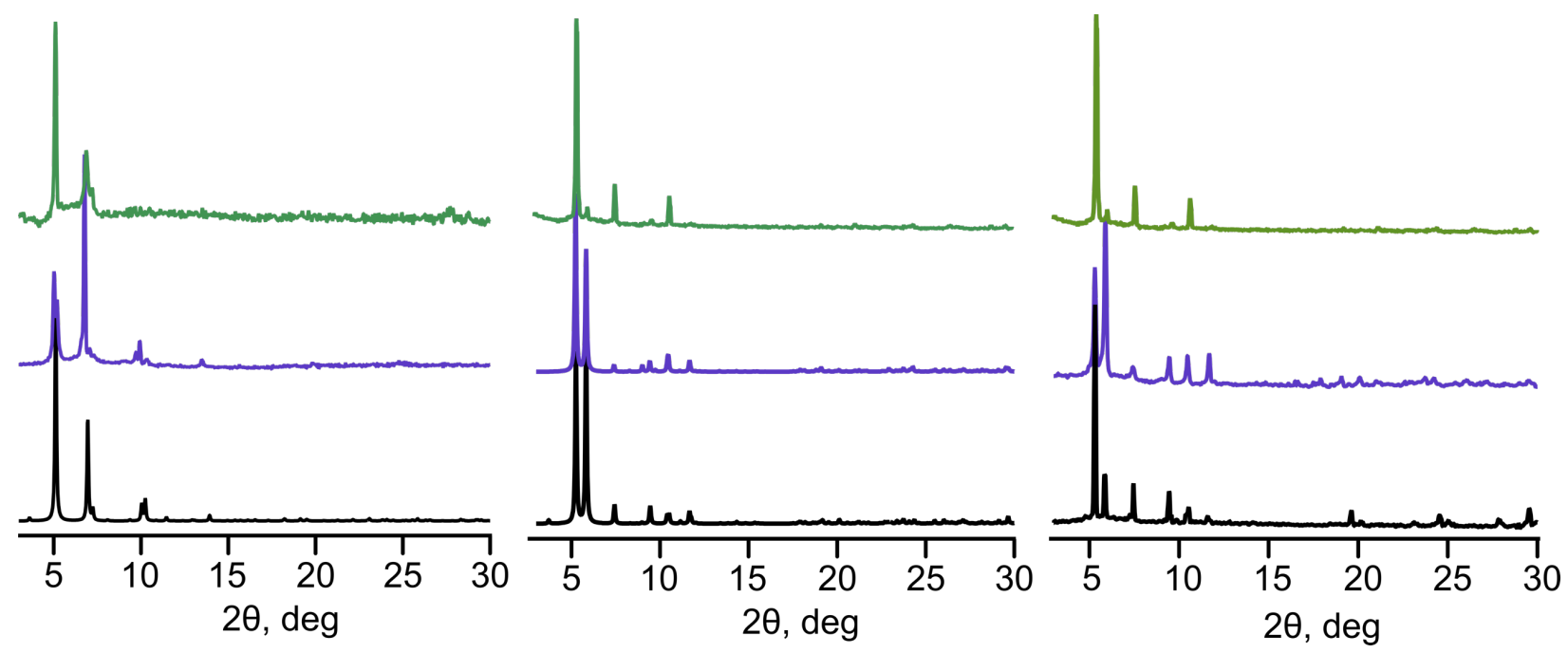

Figure S31. (left) PXRD patterns of $\mathrm{Zr}_{6}-\mathrm{Me}_{2} \mathrm{BPDC}(\mathrm{BDC})-10^{18}$ simulated (black), $\mathrm{Th}_{6}$ $\mathrm{Me}_{2} \mathrm{BPDC}(\mathrm{BDC})-10$ as-synthesized from $\mathrm{Th}_{6}-\mathrm{Me}_{2} \mathrm{BPDC}-8$ (purple), and as-synthesized from $\mathrm{Th}_{6}-$ $\mathrm{Me}_{2} \mathrm{BPDC}-\mathrm{NO}_{3}-10$ parent MOF (green). (middle) $\mathrm{Th}_{6}-\mathrm{Me}_{2} \mathrm{BPDC}-\mathrm{NO}_{3}-10$ simulated (black), $\mathrm{Th}_{6}$ $\mathrm{Me}_{2} \mathrm{BPDC}\left(\mathrm{Me}_{2} \mathrm{TPDC}\right)-12$ simulated (purple), and $\mathrm{Th}_{6}-\mathrm{Me}_{2} \mathrm{BPDC}\left(\mathrm{Me}_{2} \mathrm{TPDC}\right)-12$ as-synthesized (green). (right) $\mathrm{Th}_{6}-\mathrm{Me}_{2} \mathrm{BPDC}-\mathrm{NO}_{3}-10$ as-synthesized (black), $\mathrm{Th}_{6}-\mathrm{Me}_{2} \mathrm{BPDC}-8$ intermediate MOF as-synthesized (purple), and $\mathrm{Th}_{6}-\mathrm{Me}_{2} \mathrm{BPDC}\left(\mathrm{Me}_{2} \mathrm{TPDC}\right)-12$ as-synthesized (green).

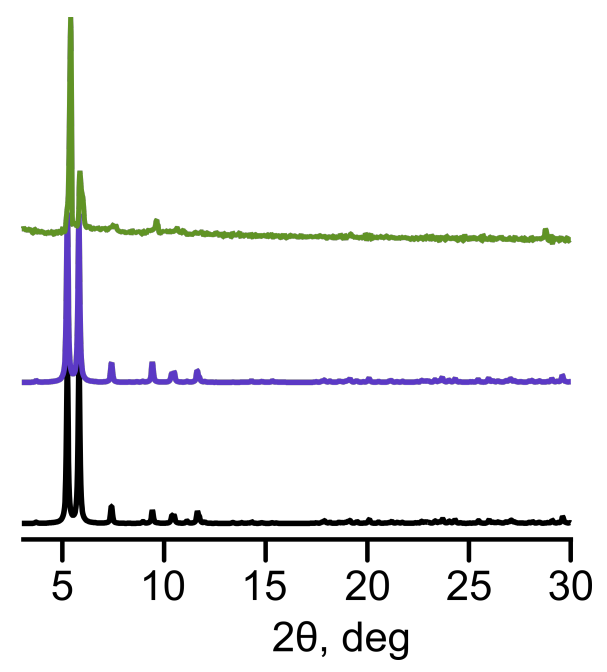

Figure S32. PXRD patterns of simulated $\mathrm{Th}_{6}-\mathrm{Me}_{2} \mathrm{BPDC}-\mathrm{NO}_{3}-10$ (black), simulated $\mathrm{Th}_{6}-\mathrm{BPDC}-$ 10 (purple), and as-synthesized Th6-BPDC-10 (green). 

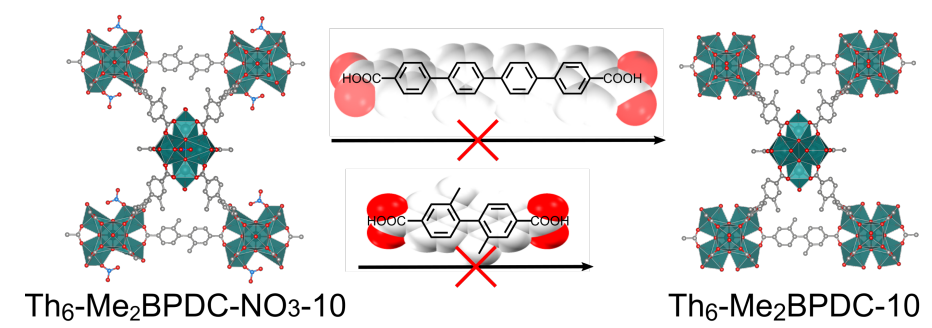

$\mathrm{Th}_{6}-\mathrm{Me}_{2} \mathrm{BPDC}-10$
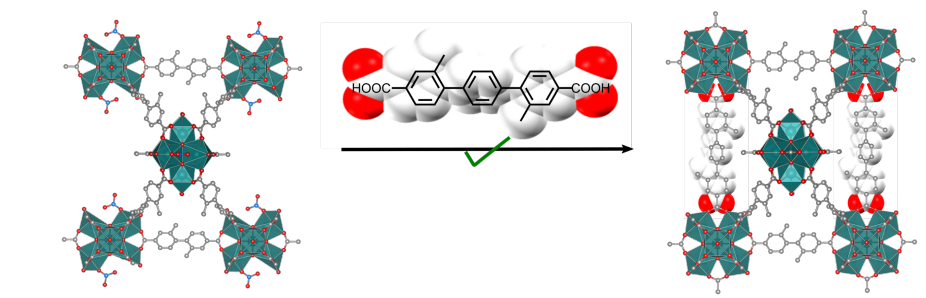

$\mathrm{Th}_{6}-\mathrm{Me}_{2} \mathrm{BPDC}-\mathrm{NO}_{3}-10$

$\mathrm{Th}_{6}-\mathrm{Me}_{2} \mathrm{BPDC}-12$

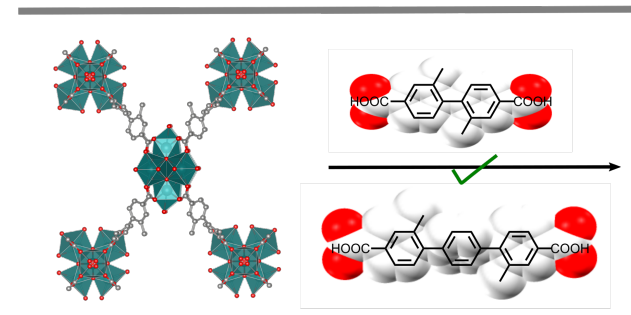

$\mathrm{Th}_{6}-\mathrm{Me}_{2} \mathrm{BPDC}-8$

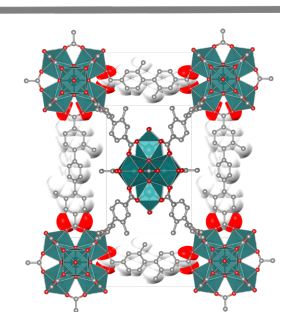

$\mathrm{Th}_{6}-\mathrm{Me}_{2} \mathrm{BPDC}-12$

Figure S33. Schematic representation of the linker installation. The crystal structures were determined using single-crystal X-ray diffraction. The teal, gray, red, and blue spheres represent $\mathrm{Th}, \mathrm{C}, \mathrm{O}$, and $\mathrm{N}$ atoms, respectively. The hydrogen atoms were omitted for clarity. 


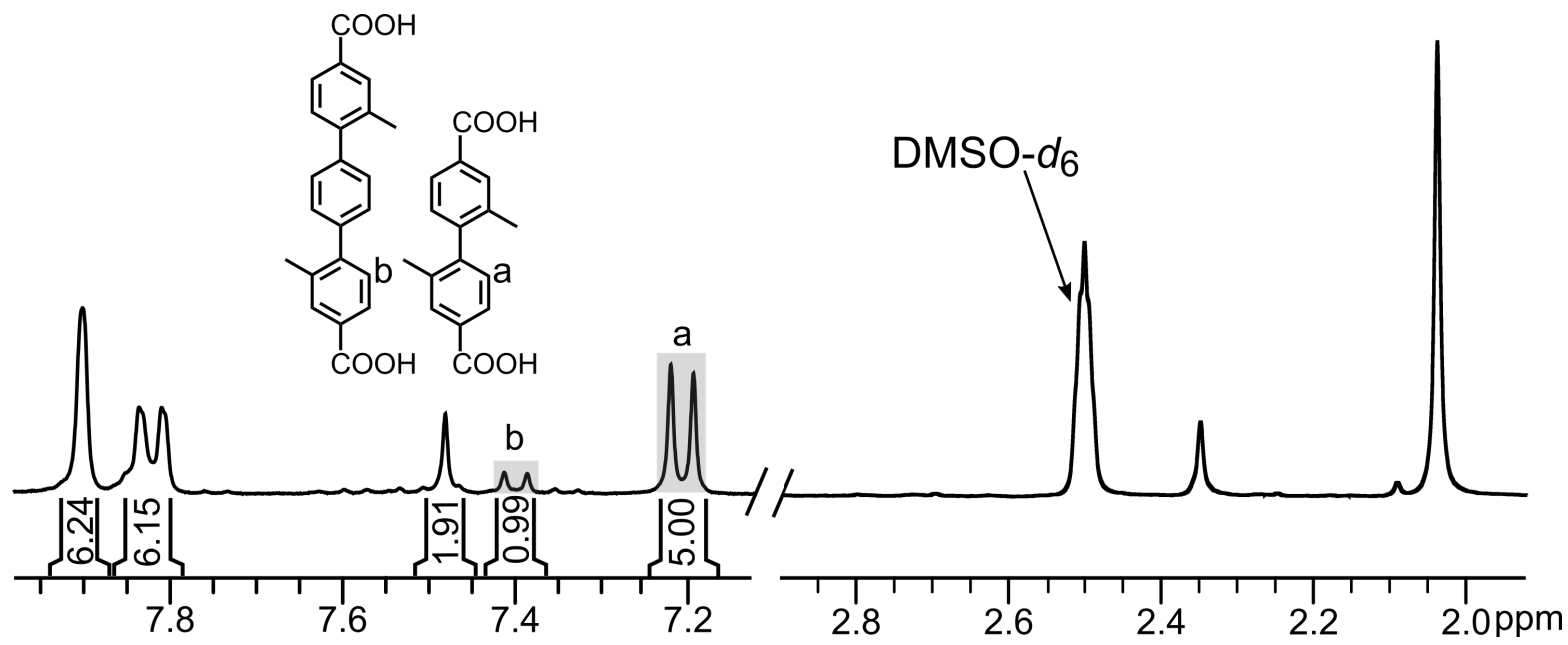

Figure S34. ${ }^{1} \mathrm{H}$ NMR spectrum of digested $\mathrm{Th}_{6}-\mathrm{Me}_{2} \mathrm{BPDC}\left(\mathrm{Me}_{2} \mathrm{TPDC}\right)-12$. Resonances corresponding to $\mathrm{H}_{2} \mathrm{Me}_{2} \mathrm{BPDC}$ and $\mathrm{H}_{2} \mathrm{Me}_{2} \mathrm{TPDC}$, which were chosen for calculations of linker installation, are highlighted in gray.

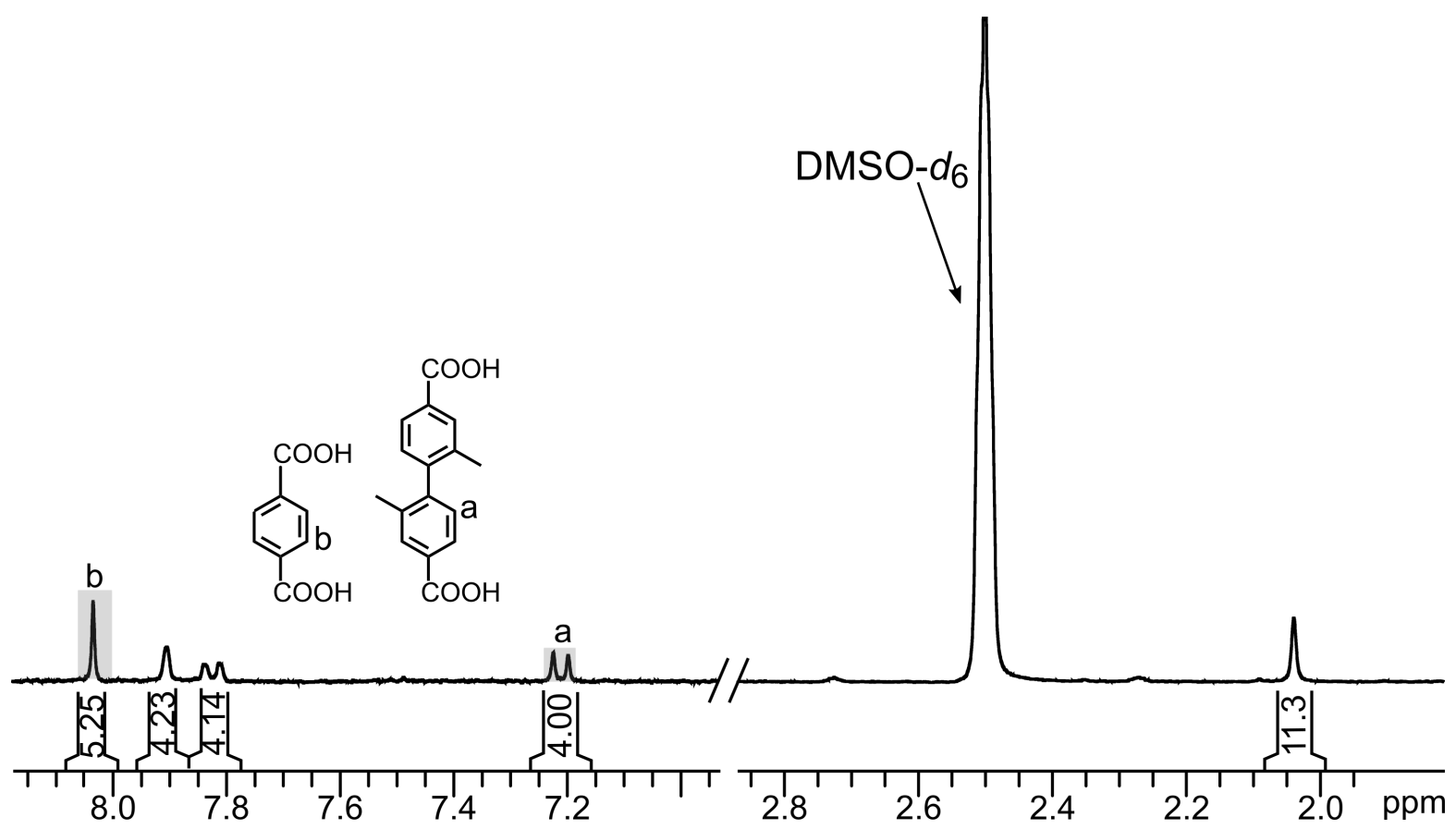

Figure 35. ${ }^{1} \mathrm{H}$ NMR spectrum of digested $\mathrm{Th}_{6}-\mathrm{Me}_{2} \mathrm{BPDC}(\mathrm{BDC})-10$. Resonances corresponding to $\mathrm{H}_{2} \mathrm{Me}_{2} \mathrm{BPDC}$ and $\mathrm{H}_{2} \mathrm{BDC}$, which were chosen for calculations of linker installation, are highlighted in gray. 


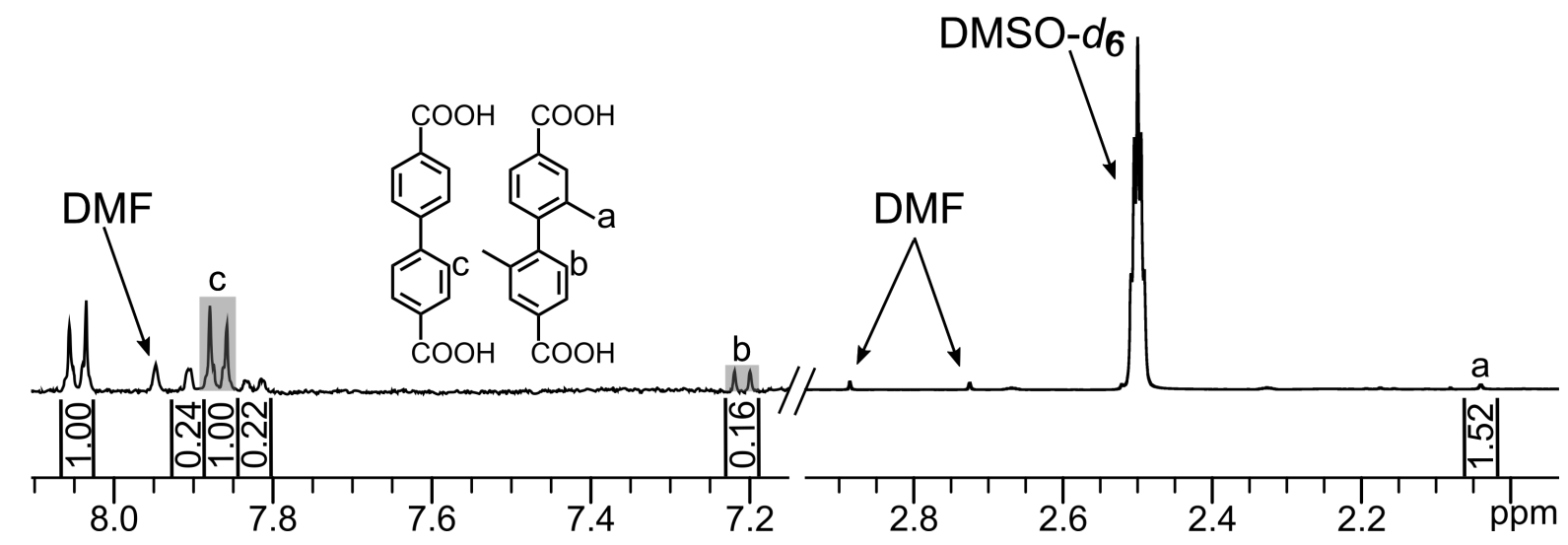

Figure S36. ${ }^{1} \mathrm{H}$ NMR spectrum of digested $\mathrm{Th}_{6}$-BPDC-10. Resonances corresponding to $\mathrm{H}_{2} \mathrm{Me}_{2} \mathrm{BPDC}$ and $\mathrm{H}_{2} \mathrm{BPDC}$, which were chosen for calculations of linker installation, are highlighted in gray.

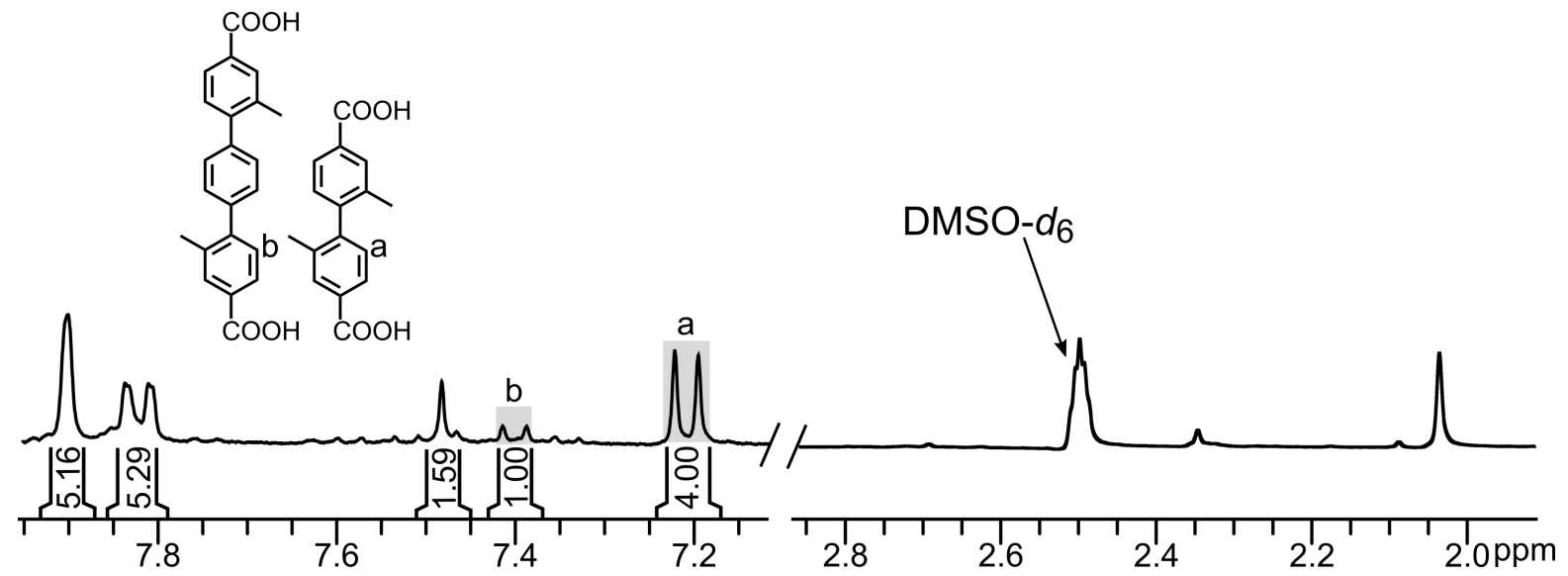

Figure S37. ${ }^{1} \mathrm{H}$ NMR spectrum of digested $\mathrm{Th}_{6}-\mathrm{Me}_{2} \mathrm{BPDC}\left(\mathrm{Me}_{2} \mathrm{TPDC}\right)-10$. Resonances corresponding to $\mathrm{H}_{2} \mathrm{Me}_{2} \mathrm{BPDC}$ and $\mathrm{H}_{2} \mathrm{Me}_{2} \mathrm{TPDC}$, which were chosen for calculations of capping linker installation, are highlighted in gray. 


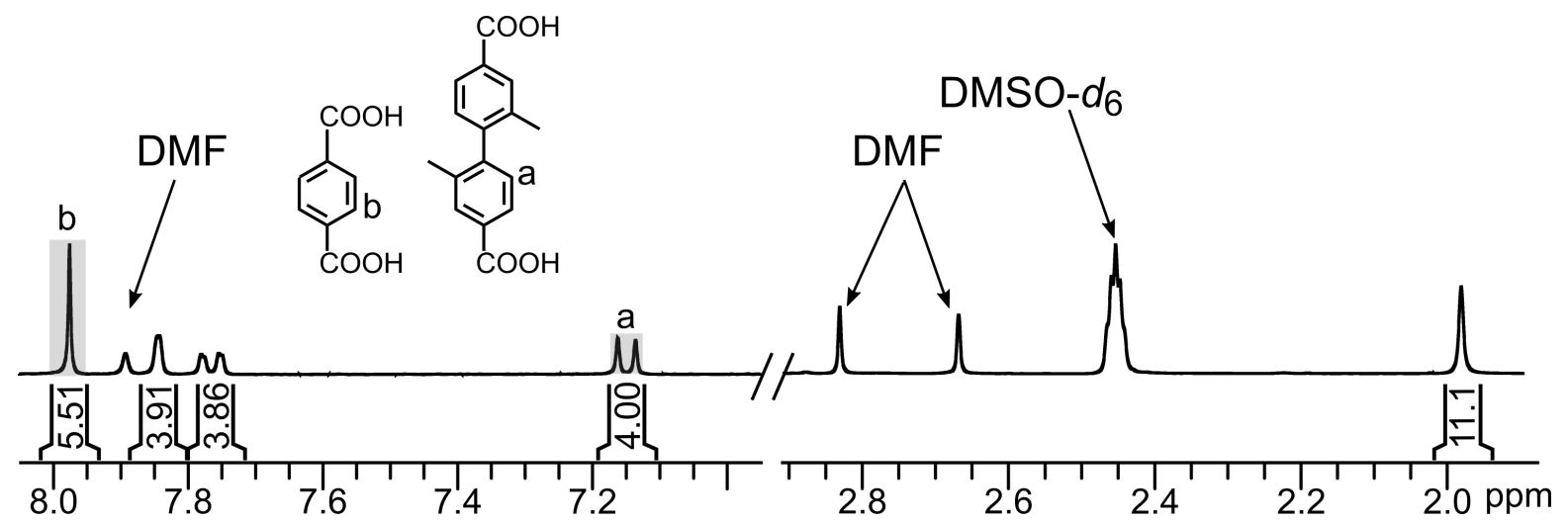

Figure 38. ${ }^{1} \mathrm{H}$ NMR spectrum of digested $\mathrm{Th}_{6}-\mathrm{Me}_{2} \mathrm{BPDC}(\mathrm{BDC})-10$. Resonances corresponding to $\mathrm{H}_{2} \mathrm{Me}_{2} \mathrm{BPDC}$ and $\mathrm{H}_{2} \mathrm{BDC}$, which were chosen for calculations of linker installation, are highlighted in gray.

Table S9. Percentage of linker installations calculated from ${ }^{1} \mathrm{H}$ NMR studies.

\begin{tabular}{lcc}
\multicolumn{1}{c}{ Parent MOF } & $\begin{array}{c}\text { Installed } \\
\text { Linker }\end{array}$ & $\begin{array}{c}\text { Percent } \\
\text { Installation }\end{array}$ \\
\hline $\mathrm{Th}_{6}-\mathrm{Me}_{2} \mathrm{BPDC}-\mathrm{NO}_{3}-10$ & $\mathrm{H}_{2} \mathrm{QPDC}$ & $\mathrm{n} / \mathrm{a}$ \\
\hline $\mathrm{Th}_{6}-\mathrm{Me}_{2} \mathrm{BPDC}-\mathrm{NO}_{3}-10$ & $\mathrm{H}_{2} \mathrm{Me}_{2} \mathrm{TPDC}$ & $* * 99$ \\
$\mathrm{Th}_{6}-\mathrm{Me}_{2} \mathrm{BPDC}-\mathrm{NO}_{3}-10$ & $\mathrm{H}_{2} \mathrm{Me}_{2} \mathrm{BPDC}$ & $\mathrm{n} / \mathrm{a}$ \\
$\mathrm{Th}_{6}-\mathrm{Me}_{2} \mathrm{BPDC}-\mathrm{NO}_{3}-10$ & $\mathrm{H}_{2} \mathrm{BPDC}$ & 84 \\
$\mathrm{Th}_{6}-\mathrm{Me}_{2} \mathrm{BPDC}-\mathrm{NO}_{3}-10$ & $\mathrm{H}_{2} \mathrm{BDC}$ & $* 88$ \\
$\mathrm{Th}_{6}-\mathrm{Me}_{2} \mathrm{BPDC}-8$ & $\mathrm{H}_{2} \mathrm{QPDC}$ & $\mathrm{n} / \mathrm{a}$ \\
$\mathrm{Th}_{6}-\mathrm{Me}_{2} \mathrm{BPDC}-8$ & $\mathrm{H}_{2} \mathrm{Me}_{2} \mathrm{TPDC}$ & 100 \\
$\mathrm{Th}_{6}-\mathrm{Me}_{2} \mathrm{BPDC}-8$ & $\mathrm{H}_{2} \mathrm{BDC}$ & $* 92$ \\
\hline
\end{tabular}

*Installation percentage considering all possible available sites.

**The structure was determined by single-crystal X-ray diffraction. 


\section{References:}

(1) OECD/NEA. Chemical Thermodynamics of Thorium, Chemical Thermodynamics, OECD; 2008.

(2) Hughes, J. T.; Navrotsky, A. MOF-5: Enthalpy of Formation and Energy Landscape of Porous Materials. J. Am. Chem. Soc. 2011, 133, 9184-9187.

(3) Morss, L. R.; Edelstein, N. M.; Fuger, J.; Katz, J. J. The Chemistry of the Actinide and Transactinide Elements.; Springer, 2006.

(4) Moon, H. Equilbrium Ultrafiltration of Hydrolyzed Thorium(IV) Solutions. Bull. Korean Chem. Soc. 1989, 10, 270-272.

(5) Robie, R. A.; Hemingway, B. S. Thermodynamic Properties of Minerals and Related Substances at $298.15 \mathrm{~K}$ and 1 Bar (105 Pascals) Pressure and at Higher Temperatures; Washington, 1995.

(6) Joback, K. G.; Reid, R. C. Estimation of Pure-Component Properties from GroupContributions. Chem. Eng. Commun. 1987, 57, 233-243.

(7) Vasil'eva, T. F.; Zhil'tsova, E. N.; Vvedenskii, A. A. Enthalpies of Combustion of NNDimethylformamide and NN-Dimethylacetamide. Russ. J. Phys. Chem. (Engl. Transl.) 1972, 46, 315 .

(8) Bhunia, M. K.; Hughes, J. T.; Fettinger, J. C.; Navrotsky, A. Thermochemistry of Paddle Wheel MOFs: Cu-HKUST-1 and Zn-HKUST-1. Langmuir 2013, 29, 8140-8145.

(9) APEX III Version 2016.5 - 0 and SAINT+ Version 8.37A. 2016, Bruker AXS, Inc., Madison, Wisconsin, USA.

(10) Krause, L.; Herbst-Irmer, R.; Sheldrick, G. M.; Stalke, D. Comparison of Silver and Molybdenum Microfocus X-Ray Sources for Single-Crystal Structure Determination. J. Appl. Crystallogr. 2015, 48, 3-10.

(11) Sheldrick, G. M. SHELXT - Integrated Space-Group and Crystal-Structure Determination. Acta Crystallogr. Sect. A Found. Adv. 2015, 71, 3-8.

(12) Sheldrick, G. M. A Short History of SHELX. Acta Crystallogr. Sect. A Found. Crystallogr. 2008, 64, 112-122.

(13) Dolomanov, O. V.; Bourhis, L. J.; Gildea, R. J.; Howard, J. A. K.; Puschmann, H. OLEX2: A Complete Structure Solution, Refinement and Analysis Program. J. Appl. Crystallogr. 2009, 42, 339-341.

(14) Van Der Sluis, P.; Spek, A. L. BYPASS: An Effective Method for the Refinement of Crystal Structures Containing Disordered Solvent Regions. Acta Crystallogr. Sect. A 1990, 46, 194-201.

(15) Spek, A. L. PLATON SQUEEZE: A Tool for the Calculation of the Disordered Solvent Contribution to the Calculated Structure Factors. Acta Crystallogr. Sect. C Struct. Chem. 2015, 71, 9-18.

(16) Sheldrick, G. M. Crystal Structure Refinement with SHELXL. Acta Crystallogr. Sect. C, Struct. Chem. 2015, 71, 3-8.

(17) Dolgopolova, E. A.; Ejegbavwo, O. A.; Martin, C. R.; Smith, M. D.; Setyawan, W.; Karakalos, S. G.; Henager, C. H.; zur Loye, H. C.; Shustova, N. B. Multifaceted Modularity: A Key for Stepwise Building of Hierarchical Complexity in Actinide Metal- 
Organic Frameworks. J. Am. Chem. Soc. 2017, 139, 16852-16861.

(18) Yuan, S.; Lu, W.; Chen, Y.-P.; Zhang, Q.; Liu, T.-F.; Feng, D.; Wang, X.; Qin, J.-S.; Zhou, H.-C. Sequential Linker Installation: Precise Placement of Functional Groups in Multivariate Metal-Organic Frameworks. J. Am. Chem. Soc. 2015, 137, 3177-3180.

(19) Cavka, J. H.; Jakobsen, S.; Olsbye, U.; Guillou, N.; Lamberti, C.; Bordiga, S.; Lillerud, K. P. A New Zirconium Inorganic Building Brick Forming Metal Organic Frameworks with Exceptional Stability. J. Am. Chem. Soc. 2008, 130, 13850-13851. 